\title{
Next level tibial nerve stimulation in the treatment of overactive bladder syndrome
}

Citation for published version (APA):

te Dorsthorst, M. J. (2022). Next level tibial nerve stimulation in the treatment of overactive bladder syndrome. [Doctoral Thesis, Maastricht University]. Proefschrift-AIO. https://doi.org/10.26481/dis.20220217md

Document status and date:

Published: 01/01/2022

DOI:

10.26481/dis.20220217md

Document Version:

Publisher's PDF, also known as Version of record

\section{Please check the document version of this publication:}

- A submitted manuscript is the version of the article upon submission and before peer-review. There can be important differences between the submitted version and the official published version of record.

People interested in the research are advised to contact the author for the final version of the publication, or visit the DOI to the publisher's website.

- The final author version and the galley proof are versions of the publication after peer review.

- The final published version features the final layout of the paper including the volume, issue and page numbers.

Link to publication

\footnotetext{
General rights rights.

- You may freely distribute the URL identifying the publication in the public portal. please follow below link for the End User Agreement:

www.umlib.nl/taverne-license

Take down policy

If you believe that this document breaches copyright please contact us at:

repository@maastrichtuniversity.nl

providing details and we will investigate your claim.
}

Copyright and moral rights for the publications made accessible in the public portal are retained by the authors and/or other copyright owners and it is a condition of accessing publications that users recognise and abide by the legal requirements associated with these

- Users may download and print one copy of any publication from the public portal for the purpose of private study or research.

- You may not further distribute the material or use it for any profit-making activity or commercial gain

If the publication is distributed under the terms of Article $25 \mathrm{fa}$ of the Dutch Copyright Act, indicated by the "Taverne" license above, 


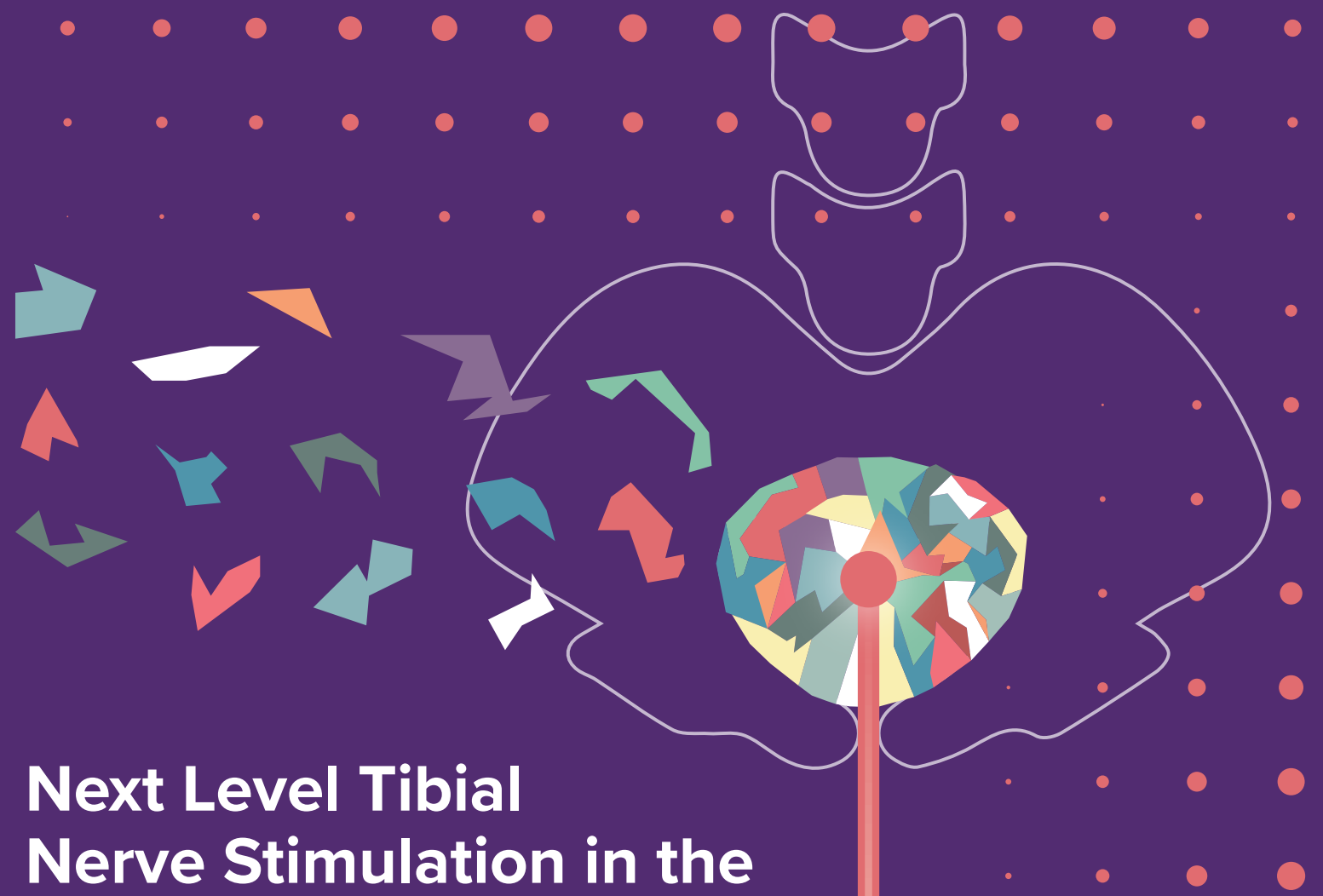
Treatment of Overactive Bladder Syndrome

Manon J. te Dorsthorst 



\section{Next Level Tibial Nerve Stimulation in the Treatment of Overactive Bladder Syndrome}

Manon Joyce te Dorsthorst 


\section{Colophon}

Lay-out by: Little \& More Design - Lisanne ter Wiel - Buter

Printed by: Proefschrift All in One (AIO)

Cover: Little \& More Design - Lisanne ter Wiel - Buter

Maastricht University, 2022

ISBN: 978-94-93270-32-9

(c) Manon te Dorsthorst, 2022 All rights reserved.

No part of the material protected by this copyright notice may be reproduced or utilized in any form or by any electronic, mechanical, or other means, now know or hereafter invented, including photocopying and recording, or in any information storage and retrieval system without prior written permission of the author. Publication of this dissertation was supported by the Maastricht University, Goodlife BV, Hoogland Medical, Tramedico BV, Bluewind Medical. 


\title{
Next Level Tibial Nerve Stimulation in the Treatment of Overactive Bladder Syndrome
}

\author{
Academisch proefschrift \\ ter verkrijging van de graad van doctor aan de Universiteit Maastricht, \\ op gezag van de Rector Magnificus, Prof. dr. Pamela Habibovic \\ volgens het besluit van het College van Decanen, \\ in het openbaar te verdedigen \\ op donderdag 17 februari 2022 om 16.00 uur \\ door \\ Manon Joyce te Dorsthorst \\ geboren op 19 december 1990 \\ te Didam
}


Promotor:

Prof. dr. J.P.F.A. Heesakkers

Copromotoren:

Dr. M.R. van Balken (Rijnstate Ziekenhuis, Arnhem) Dr. F.M.J Martens (RadboudUMC, Nijmegen)

Beoordelingscommissie:

Prof. dr. W.F. Buhre (voorzitter)

Prof. dr. R.R. Dmochowski (Vanderbilt University, Nashville, Tennessee) Prof. dr. G A. van Koeveringe Prof. dr. L M.O de Kort (UMC Utrecht)

Paranimfen Marianne Kersjes - Blom Iris Brummelhuis 


\title{
Next Level Tibial Nerve Stimulation in the Treatment of Overactive Bladder Syndrome
}

\author{
Doctoral thesis
}

to obtain the degree of Doctor at the Maastricht University, on the authority of the Rector Magnificus, Prof. dr. Pamela Habibovic in accordance with the decision of the Board of Deans, to be defended in public

on Thursday, February 172022 at 16.00 hours

by

\section{Manon Joyce te Dorsthorst}

born on December 19, 1990

in Didam, the Netherlands 
Supervisor:

Prof. dr. J.P.F.A. Heesakkers

Co-supervisors:

Dr. M.R. van Balken (Rijnstate Hospital, Arnhem) Dr. F.M.J Martens (RadboudUMC, Nijmegen)

Doctoral thesis committee:

Prof. dr. W.F. Buhre (chair)

Prof. dr. R.R. Dmochowski (Vanderbilt University, Nashville, Tennessee) Prof. dr. G A. van Koeveringe Prof. dr. L M.O de Kort (UMC Utrecht)

Paranymphs Marianne Kersjes - Blom Iris Brummelhuis 
Kees,

Want ik mis je zo graag

' $T$ is oke als je gaat

Want wanneer ik je mis

Weet ik weer hoe goed het is 



\section{TABLE OF CONTENTS}

$\begin{array}{lll}\text { Chapter } 1 \quad \text { General introduction of this thesis } & 11\end{array}$

Chapter 2 Long-term real life adherence of percutaneous 33 tibial nerve stimulation in over 400 patients.

Chapter 3 Real life Patient Experiences of TTNS in the 47 Treatment of Overactive Bladder Syndrome.

Chapter 4 What is the fate of patients and implanted neuromodulation devices who embarked for translational research?

Chapter 5 Tibial nerve stimulation in the treatment of overactive bladder syndrome: technical features of latest applications.

Chapter 6 3-Year Follow up of a New Implantable Tibial Nerve 87 Stimulator for the Treatment of Overactive Bladder Syndrome.

Chapter 7 Patient Tailored Healthcare and Tibial Nerve 103 Neuromodulation in the Treatment of Patients with Overactive Bladder Symptoms.

Chapter 8 Summary, general discussion and future perspectives

Chapter 9 Nederlandse Samenvatting 133

Appendices Appendices 139

Bibliography 141

List of abbreviations 142

Curriculum Vitae 143

Dankwoord (Acknowledgements) 
4

$\nabla<$

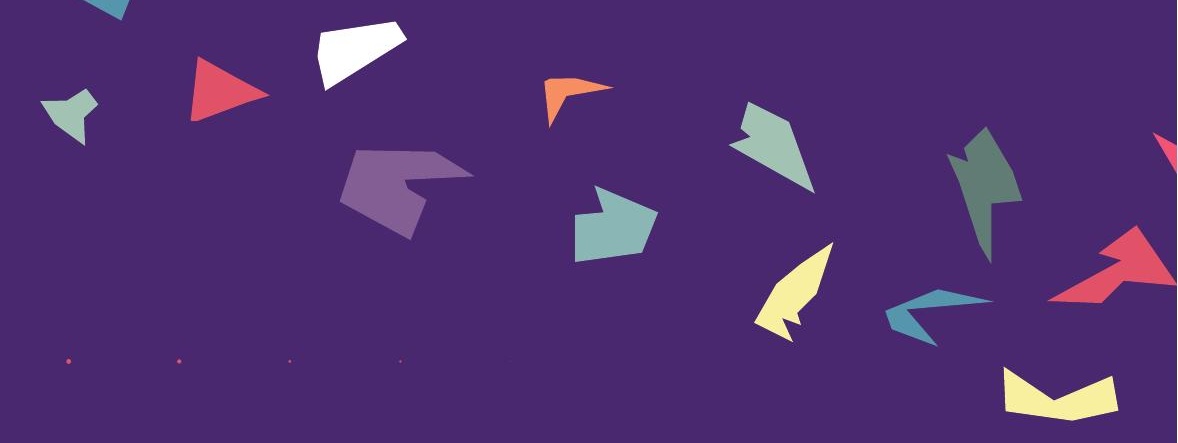

$\begin{array}{llllllllllllll}0 & 0 & 0 & 0 & 0 & 0 & 0 & 0 & 0 & 0 & 0 & 0 & 0 & 0\end{array}$

$\begin{array}{llllllllllllll}0 & 0 & 0 & 0 & 0 & 0 & 0 & 0 & 0 & 0 & 0 & 0 & 0 & 0\end{array}$

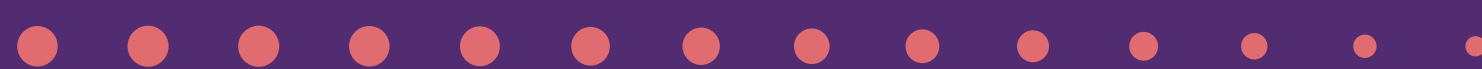

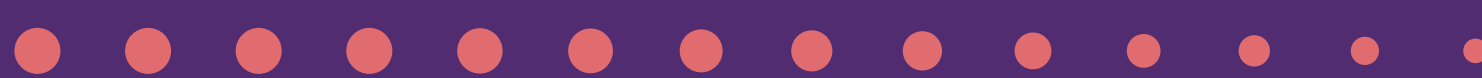

0000000000000000

000000000000000

00000000000000

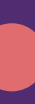

$\cdot \bullet$

00000000000000
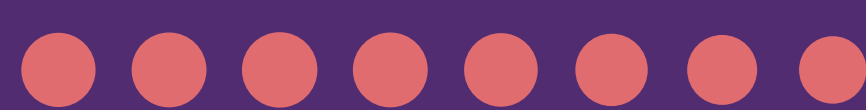

O

0

0

000
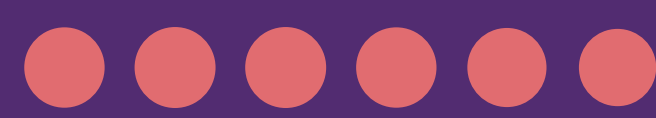

0

0

0

O

O

0

0
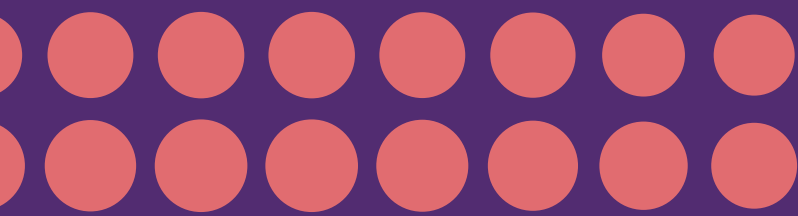

1000000000000

1000000000000

1000000000000

1000000000000 

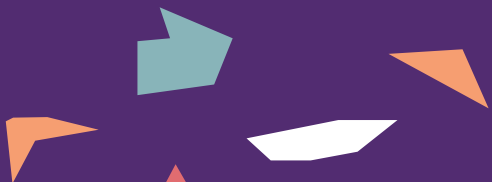

$A$ is

4
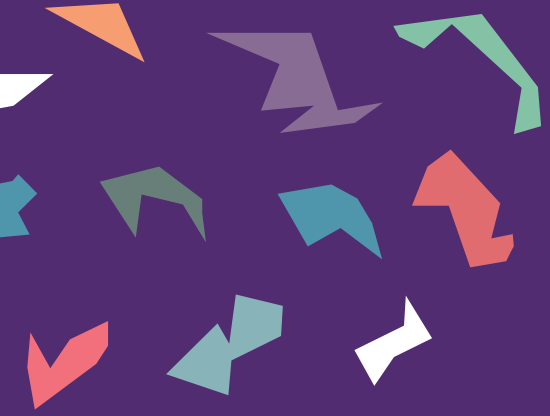

General introduction of this thesis

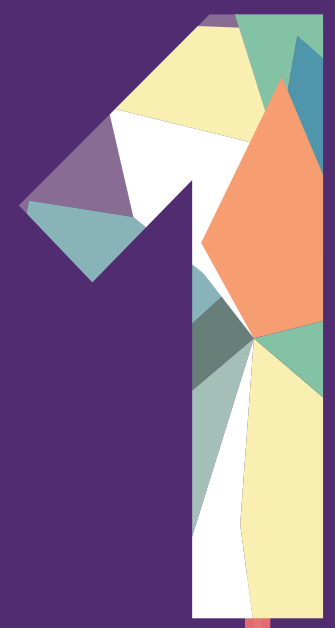

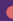




\section{ORIGIN OF OVERACTIVE BLADDER}

Overactive bladder (OAB) is a chronic condition where patients have urinary urgency, usually accompanied by frequency and nocturia, with or without urgency incontinence, in the absence of urinary tract infection or other obvious pathology according to the ICS terminology. [1] Abrams specified this definition further: "the complaint of a sudden compelling desire to pass urine, which is difficult to defer." [1] The prevalence of OAB for women over 30 years varies between $7 \%-30 \%$ and is increasing with age. $[2,3]$

Symptoms which are described above do have a significant impact on the quality of life in patients with OAB. OAB is a large social burden and comes with large financial costs for patients and our healthcare system. [4, 5] Quality of life is impaired due to the fact $O A B$ disturbs daily activities, patients have interrupted sleeping patterns, decreased self-esteem and do have more anxiety symptoms. Lai et al. reported a positive correlations between the severity of anxiety and OAB or incontinence symptoms. [6] It is suggested, the total costs of OAB in the United States, including direct and indirect costs, was $\$ 65.9$ billion in 2007 with a projected increase to $\$ 82.6$ billion in 2020. [7]

The etiology and pathophysiology of OAB is still unclear. Over the years several new theories have emerged. However, still there is no clear understanding about the etiology and pathophysiology of OAB. The only concluding message what could be given is: pathophysiology of $O A B$ is multi-factorial. Research is focused on sensory nerve (afferent) activity, motor control and reflexes of the lower urinary tract (LUT) in order to find those answers. [8] There are three theories which might explain the increased afferent activity in association with the onset of OAB and detrusor overactivity in terms of increased involuntary muscle contractions during the storage phase of micturition.

1. Urothelium-based hypothesis: Increased release of various neurotransmitters (i.e. bradykinin, acetylcholine, norepinephrine) can release signaling molecules which can alter the actions on the afferent nerves including, urothelial nerve growth factor, prostaglandin subtype E2. $[9,10]$ This all togethers may influence afferent nerve activity and could facilitate a cascade of reactions produced by bladder fullness ending in changed contractions of the bladder/ urinary urgency and activation of the micturition reflex. [8] The precise mechanism of action of these processes is not known yet. 
2. Myogenic hypothesis: It suggest that overactive detrusor contractions result from a combination of an increased likelihood of spontaneous excitation within the smooth muscle of the bladder and enhanced propagation of this activity to affect an excessive proportion of the bladder. [11] There is a upregulation of surface membrane receptor which alters the membrane potential of the bladder smooth muscle cell. This could lead to spontaneous contractions in the myocytes and lead to a spread of spontaneous contractions. [12] Furthermore, the myogenic hypothesis suggests that a range of triggers can generate localized detrusor contractions (micromotions), which can spread in the bladder wall through various routes of propagation. [13]

3. Neurogenic hypothesis: Bladder overactivity could be caused by various changes in central peripheral and neural pathways. A reduction in peripheral or central inhibition, enhancement of excitatory transmission in the micturition reflex pathway, increased primary afferent input from the bladder or bladder reflexes which are resistant to central inhibition could be one of the reasons for the emergence of primitive voiding reflexes which could be an onset for bladder overactivity. [14]

However, in a more recent publication from Peyronnet et al. the way of how we look at $O A B$ (etiology and treatment) nowadays is changing. In their paper they conclude that there is not one form of OAB syndrome but rather several OAB phenotypes based on the underlying mechanisms (i.e. myogenic theory, urothelium-based hypothesis) and pathophysiological cofactors (i.e. metabolic syndrome, affective disorders, urinary microbiota). [15] Due to this change of view, treatment of OAB syndrome in the future could be tailored to each individual patient. Figure $1 \mathrm{~A}$ shows the newly introduced "prism" approach in the etiology of OAB syndrome and Figure $1 \mathrm{~B}$ combines this new approach with a possible treatment algorithm for the future. Michel stated about next generation OAB treatment: "It is unlikely that a single drug target is promising to make the vast majority of patient with $\mathrm{OAB}$ symptom-free." [16] In the future we should identify subsets of OAB patients based on specific pathophysiology. Almost all research in the past focused on successful treating $O A B$ if all key symptoms were improving. Which means all patients had to show improvement on urinary frequency, urgency, UUI and nocturia. However, not all patients do suffer from all those key symptoms and still suffer from OAB. Michel in his article advocates for a different approach, focus on one symptom rather than the overall symptomatology of OAB and focus on a subgroup of OAB patients. In case off nocturia this new approach is already done by identifying 
the results of desmopressin in reducing nocturia. [17] So according to Michel, key priorities for future $O A B$ research should focus on identify subsets of $O A B$ patients, development of translational animal model for these subsets and identify biomarkers allowing selective inclusion of subsets into clinical studies. [16]

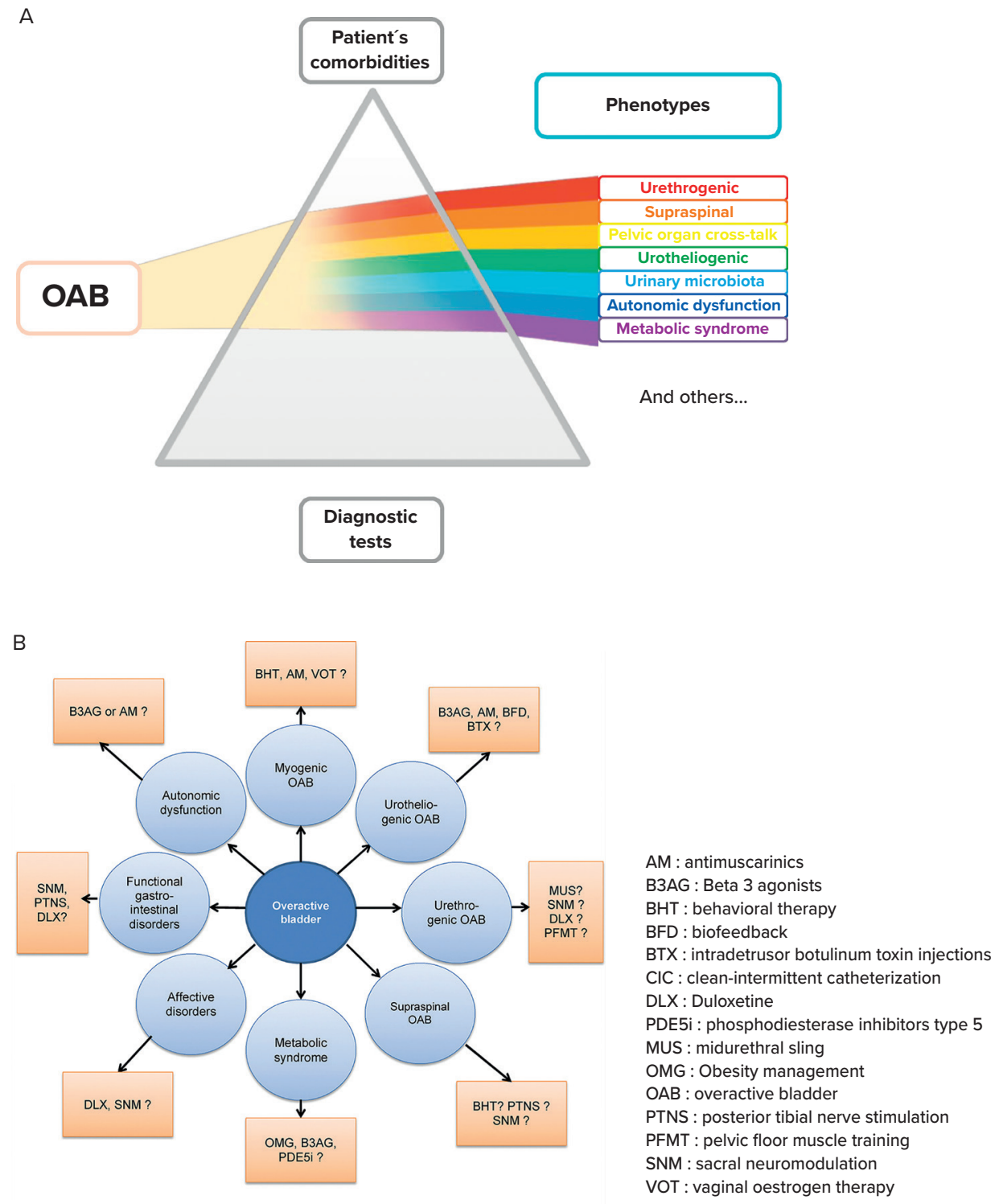

Figure $1 A$. Recent view on $O A B$, "prism" approach of $O A B$ phenotypes. Figure 1B. Possible future patient tailored treatment algorithm in patient suffering from OAB. [18] 


\section{TREATMENT OPTIONS OVERACTIVE BLADDER SYNDROME}

Management and treatment of OAB starts with behavioral therapies/conservative management, like pelvic floor muscle training (PFMT), according to the recent EAU guidelines. [18] Behavioral therapy consists of pelvic floor muscle training and lifestyle interventions. Lifestyle factors which are associated with OAB are obesity, level of physical activity and diet. [18] Patients are advised to reduce their caffeine intake and encouraged to reduce overweight if this is the case. Other than that, fluid intake is reviewed by their physician. The evidence to support these recommendations is low. Tomlinson et al. published a randomized clinical trial, in this trial 41 of 94 older women reduced their daily incontinence rate with $34 \%$ by dietary interventions. [19] However, a more recent meta-analysis from Sun et al. found no evidence for an association between coffee/caffeine consumption and the risk of Ul. Though, as mentioned in their conclusion results must be drawn with caution, and more well-designed studies with large sample sizes should be conducted for further validation. [20] Overall after behavioral therapy, reduction in frequency of incontinence range from $60-80 \%$. A cure rate of $31 \%$ for UUI episodes in women receiving behavioral training has been reported. [21] PFMT might reduce OAB symptoms, however, due to many limitations of published studies it is not possible to clearly determine the effect PFMT on OAB symptoms. [22]

If behavioral therapy is failing the next step is medication as a second line of treatment. Success rates of medication differ, based on all different kind of medications but as well based on all different kind of definitions of success nowadays. However, Sussman et al. described in their large $(n=1147)$ prospective, open-label trial, for tolterodine success rates based on 3-day voiding dairies and percentages of improvement from baseline. Their results show a 50\% or more success rate in UUI was found in $75 \%$ of the patients. Though, a $100 \%$ success rate 12 weeks after starting treatment was only found in $51 \%$ of the patients with UUI. In addition, only $37 \%$ of the patients reported a normal micturition frequency $(<8 /$ day) after 12 weeks. [23]

When medication is unsuccessful in the treatment of OAB the next line of treatment is minimal invasive therapy like neuromodulation in terms of percutaneous tibial nerve stimulation (PTNS) or botulinum toxin type A (BTA) followed by sacral nerve stimulation (SNS). Success rates of PTNS was described by Peters et al. in the first sham-controlled trial for PTNS. They described $43 \%$ improvement of urinary 
urgency, $48 \%$ improvement of urinary frequency, 38\% improvement of UUI and an overall improvement of 55\% based on GRA-scale (global response assessment) after 13 weeks of treatment. [24] However, in the 24 month follow up study the median UUI episodes among those patients with urge incontinence at baseline is still 0.3 (3.7 at baseline). [25] The Rosetta trial from Amundsen et al, comparing BTA versus SNS, showed significant changes in urinary incontinence rates in both interventions. After 6 months of follow up $67 \%$ in BTA group versus $52 \%$ of the patients showed $>50 \%$ reduction. However only $20 \%$ in the BTA intervention group reported complete resolution versus $2 \%$ in the SNS intervention group. [26] Last option for patients who are still suffering from $O A B$ is substantial reconstructive surgical intervention which means bladder augmentation or urinary diversion. [18] Patients with bladder augmentation do have a segment of the bowel patched to the bisected bladder. Outcomes in terms of continence rates for this surgery in patients with idiopathic OAB were described by Ivil et al. They describe an 83\% (15 patients out of 18) continence rate after a mean follow up of 11 months. Two other patients still had post-operative incontinence and one patient had severe irritative symptoms that were considered unacceptable and therefore as well considered as failure.

\section{MEDICATION IN OAB}

The second step in the treatment of OAB is medication, i.e. antimuscarinics or $\beta 3$ agonists. Normal human bladder contraction is mediated mainly through stimulation of muscarinic receptors in the detrusor muscle. The muscarinic receptors in the human detrusor are the $M_{2}$ and $M_{3}$ subtypes. $M_{3}$ receptors are less in number comparing to $\mathrm{M}_{2}$ receptors, but they are mainly responsible for the normal micturition contraction. [27-30] The effect of antimuscarinics is more or less selectively, inhibition of the parasympathetic innervation (cholinergic). Which results during storage phase in increase of compliance, reducing the intra-vesical pressure and detrusor contractions. [30] In Figure 2 a simplified pathway of the mechanism of action of antimuscarinics is shown. [31] In this figure both $M_{2}$ and $M_{3}$ receptors are coupled to $G$ proteins $(G)$ and can contribute to bladder contraction, but different signal transduction pathways are involved. Although a functional role for the $M_{2}$ receptor has not been definitively identified, it has been suggested that stimulation of this receptor opposes sympathetically ( $\beta$ adrenoceptor) mediated smooth muscle relaxation by inhibition of adenylate cyclase), which leads to a decreased intracellular concentration of cyclic AMP (cAMP). cAMP mediates bladder relaxation. [32] Stimulation of $M_{3}$ receptors activates phospholipase $C$ 
(PLC) to generate inositol triphosphate (IP3). IP3 can release calcium ions (Ca2+) from the sarcoplasmic reticulum and these activate the contractile machinery within the cell with resulting bladder contraction. [31]

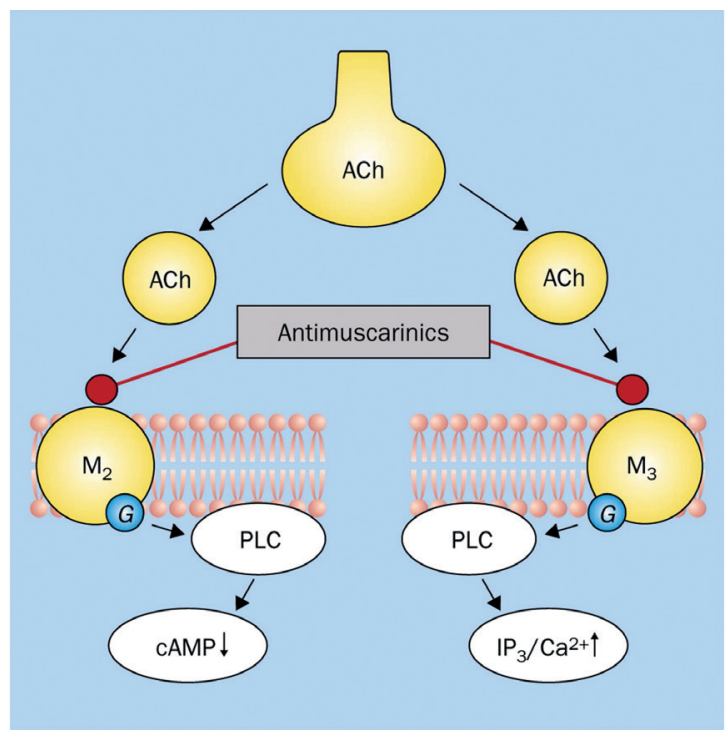

Figure 2. Mechanism of action of antimuscarinic drugs by blocking the $M_{2}$ and $M_{3}$ - receptors selectively on the detrusor muscle which is stimulated by acetylcholine (ACh) released from the parasympathetic nerves. [31]

Clinically used antimuscarinics are competitive antagonists, so the massive release of acetylcholine from neurons initiating the micturition contraction overcomes most of the effects of the drugs, which are present only in low concentrations with recommended doses. At high doses, the antimuscarinics influence the voiding contraction, eventually leading to urinary retention. [33] However, urgency is a definition based on sensory pathways and detrusor overactivity (DO) is a urodynamic observation, characterized by involuntary detrusor contractions during the filling phase which may be spontaneous or provoked. [1] The traditional view is that in $\mathrm{OAB}$ and $\mathrm{DO}$, the drugs act by blocking the muscarinic receptors on the detrusor muscle, which are stimulated by ACh. Thereby they decrease the ability of the bladder to contract. However, antimuscarinic drugs act mainly during the storage phase, decreasing urgency and increasing bladder capacity, and during this phase, there is normally no parasympathetic input to the LUT. [8, 31] So, the exact beneficial effect of antimuscarinics has not yet been established. However, during the storage phase, $\mathrm{ACh}$ may be released from both neuronal and non- 
neuronal sources (e.g. the urothelium and suburothelium) and directly or indirectly excite afferent nerve in the suburothelium and within the detrusor. The data in the study of De Laet et al. show that antimuscarinics given systemically, reduces afferent spike rate and afferent sensitivity in both $A \delta$ and $C$ fibers. The reduced afferent input to the central nervous system may explain the observed sensory effects seen in clinical practice after administration of antimuscarinic agents. [34]

The mode of action of $\beta 3$ agonist is slightly different in comparing to antimuscarinics. During the filling phase of the bladder, $\beta 3$ agonist causes relaxation of detrusor in terms of basal tone. [35] This is due to activation of receptors which are located in the detrusor and urothelium of the bladder. The normal micturition reflex is activated by bladder distension, which initiates activity in in-series coupled, low threshold mechanoreceptive (Aס) afferents. [36] So, if this response to distention is decreased by the detrusor muscle being relaxed and more compliant, the afferent activity needed to initiate micturition will be delayed and bladder capacity will be increased. This effect could be reached because of stimulating the $\beta 3$ adrenoreceptor agonist. [37] $\beta 3$ adrenoreceptor are found in the detrusor muscle, urothelium, interstitial cells and afferent nerves. [37-40] This could, if stimulated, induce the effect of $\beta 3$ adrenoreceptor agonists. Currently, only mirabegron is available as a $\beta 3$ adrenoreceptor agonist. There are some other $\beta 3$ adrenoreceptor agonist on their way (i.e. solabegron, ritobegron) however these drugs are still in their research phase.

Over the past years oral medication has proven his efficacy in the treatment of OAB. [41, 42] Although medication is the mainstay for OAB treatment, over $70 \%$ of all patients quit medication within one year because of intolerability, side effects or ineffectiveness. [43-45] One of the most common side effects/ adverse effects is dry mouth. [46] Another problem in the treatment of OAB with medication is the time until muscarinic medication show their maximum benefit in $O A B$ treatment. It could take up to a few weeks until the maximum effect of the treatment has been reached. [47] Taken this together, many patients quit their treatment due to an imbalance of effect of the treatment (effectiveness) versus the side effects of the treatment. [48] 


\section{PTNS AS A TREATMENT FOR OAB}

As a third line of treatment, minimal invasive therapy like PTNS could been done. In 1983 McGuire was the first person who performed tibial nerve stimulation in humans. This was performed due transcutaneous stimulation of the tibial nerve in 15 patients with different neural lesions and detrusor overactivity. [49] However, the idea of electrical stimulation and neuromodulation in medicine has been happening since the year 46 AD. Scribonius Largus described already by then the use of the torpedo fish, the ray and the eel in the treatment of headaches and gout. This was stated in his Compositiones medicae. Patients were asked to place their painful extremities into a pool of water with torpedo fish or direct application of a torpedo fish. This resulted in a numbness of the painful due to the electrical shocks. Torpedo fishes can generate up to $200 \mathrm{~V}$, the average which is described is around 10-50 V. [50] However, after the discovery of how to produce electrostatic electricity in the seventeenth century, there was no need for living organisms anymore.

Christian Kratzenstein, professor of medicine at Halle was the first person in Europe who used electricity for medical purposes. A woman was suffering from contraction of the little finger and he treated her with electrification for 15 minutes. The permanent effect on the finger is not described in his Abhandlung van die kraft der Electricitat der Arzneiwissenscahft - 1744. After the discovery of the first sort of battery by Alessandro Volta several researchers started to working with electricity as a therapeutic agent. [50] Jean-Baptiste Salrandière, a French physician demonstrated in 1825 for the first time the use of electroacupuncture. He stated: "In my opinion electro-acupuncture is the most proper method of treating rheumatism, nervous afflictions and attack of gout. Introducing a shock into the very place I wish modifies pain, motion or capillary circulation. As I have said, even the lightest discharges upon the needle introduced into our tissue will cause a feeling of vibration all through the suffering part. If this part is a muscle, one can feel, and even see the contraction through the skin. Heavy discharges result in a sort of convulsion and by its being suddenly shaken in this way, the nervous functions of a suffering part are modified and pain is relieved." [51] During the 19th century the use of electricity in medicine was widely spread. It was used in the treatment of several dental, neurological, psychiatric and gynecological diseases. 
Since the second half of the $20^{\text {th }}$ century electrotherapy became field of interest in treating (chronical) pain. This was mainly because of the introduction of the gate control theory by Wall and Melzack in 1965. They provided a potential treatment for chronic pain by stimulating the spinal cord and the peripheral nerves. [52] Based on this theory Shealy and Long were the first who implanted spinal cord and peripheral nerve stimulators in the treatment of chronic pain. $[53,54]$

During the 1970's and 1980's indications for the use of electrotherapy were widened. Since then treatment of OAB was also a field of interest for many researchers starting with McGuire as described above. Based on the earlier mentioned promising results from McGuire, Stoller et al. started with percutaneous stimulation of the tibial nerve. After obtaining promising results in his pig-tailed monkey study PTNS was introduced as a new line of treatment in OAB.[55] Peters et al. published in 2009 the first randomized controlled trial (SUmiT), which is still one of the most important publications in the field of tibial nerve stimulation. This study compares effectiveness of PTNS versus Sham in a multicenter, double-blind, randomized, controlled trial. [24]

The way PTNS is performed nowadays has not changed over the last 20 years. (Figure 3) Patients are in the supine position with the soles of the feet together, and knees abducted and flexed ("frog-position"). A 34-gauge stainless steel needle is inserted approximately $3-4 \mathrm{~cm}$ about 3 fingerbreadths cephalad to the medial malleolus, between the posterior margin of the tibia and soleus muscle. A stick on electrode is placed on the same leg near the arch of the foot. The needle and electrode are connected to a low voltage (9 volts) stimulator with an adjustable pulse intensity of 0-10 mA, a fixed pulse width of 200 microseconds and a frequency of $20 \mathrm{~Hz}$. The amplitude is slowly increased until the large toe starts to curl or toes start to fan. If the large toe does not curl or pain occurs near the insertion site the stimulation device is switched off and the procedure is repeated. If necessary, the amplitude can be increased during the session. [56] Most of the patients will start with 12 weekly sessions of 30 minutes. After these first 12 sessions patients will discuss the benefit of the treatment and can continue to chronic treatment. Chronic treatment sessions differ in intensity mostly depending on time of beneficial effect and possibility to undergo chronic treatment sessions in the hospital. 

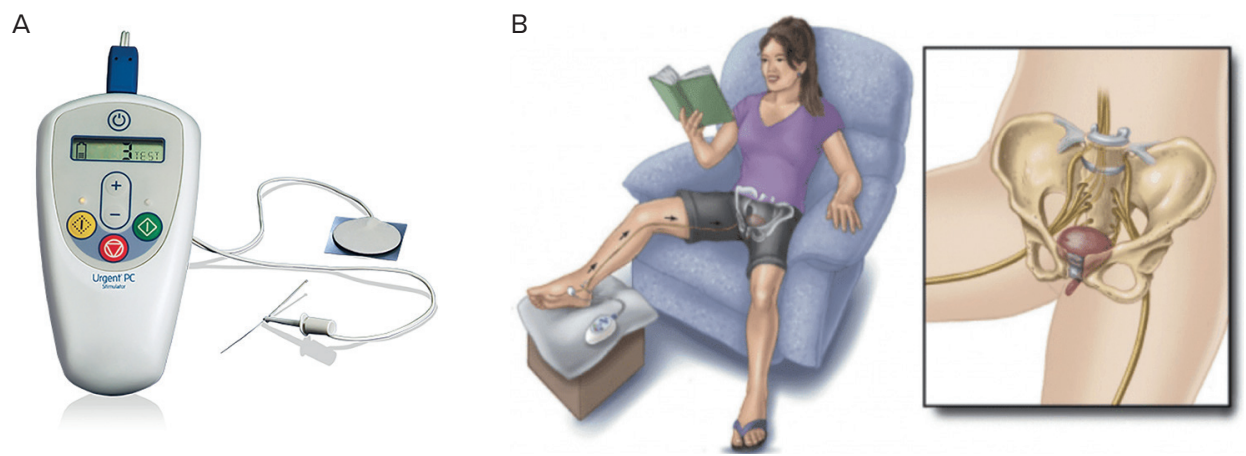

Figure 3a. Urgent-PC system in the treatment of OAB. Figure 3b. Positioning of the patient while undergoing PTNS.

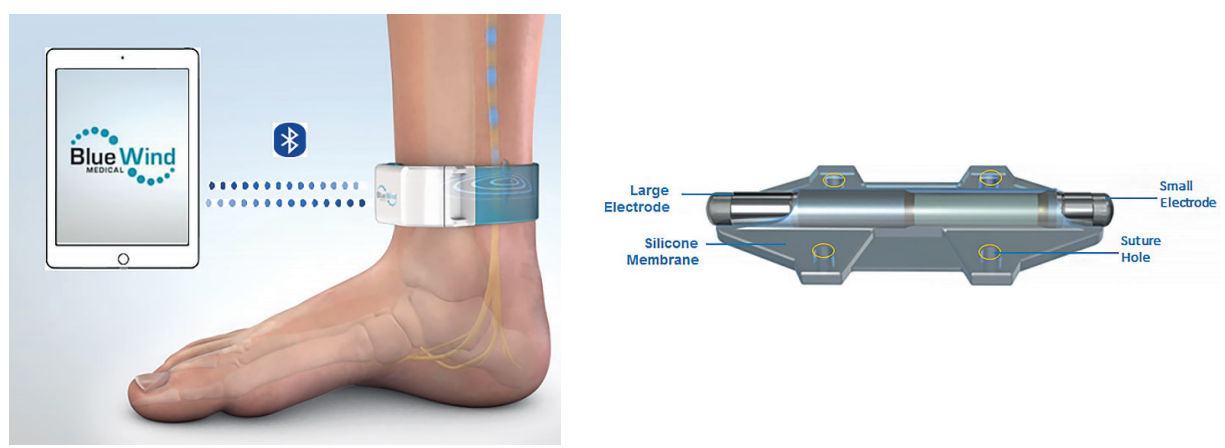

Figure 4. Bluewind Renova-system $\odot$ containing the clinician programmer (CP), external control unit (ECU) and the implant containing two smart electrodes.

However as briefly mentioned above, one of the main disadvantages of PTNS is the fact that patients every time have to come over to the hospital for their treatment. Once PTNS treatment is quitted the effect of the treatment will fade away. This problem could be solved by using an implant and perform homebased treatments. Van der Pal was in 2006 the first who described the use of an implantable tibial nerve stimulator. [57] In this study she reported satisfying results 1 year after implantation. Five patients (5/8) showed significant improvement in their voiding diary outcome and four of them showed as well significant improvement in quality-of-life parameters. Few year later Janssen et al. published the 9 year follow up of this Urgent-SQ. [58] In his study he focused on the safety and efficacy in an open label follow up study. Six of the seven patients still had sensory and loco-motor responses on stimulation at 9-year follow-up. The implants are intact with no migration and/or displacement. Three out of seven patients who had still the Urgent SQ implant were still using their device. 
One of the new main players in the field of implantable tibial nerve stimulators in the treatment of OAB is the Bluewind Renova-system (C) (Figure 4). This wireless battery-free tibial nerve stimulation system consists of three components: implant with two smart electrodes, external control unit (ECU) and clinician programmer (CP). Patients are provided with the stimulator, a $25 \mathrm{~mm}$ implant with small fixating wings to prevent migration of the implant (Figure 4). The implant is fixated near the tibial nerve, in an open surgical procedure under local anesthesia. Patient specific treatment set-up can be selected by the clinician based on motor and/or sensory response to optimize therapeutic outcome. [59, 60] During follow up visits treatment set-up can be changed based on patient specific outcomes. Patients wear the ECU only during treatment sessions, which is set 30 minutes twice a day. The ECU provides the implant with the energy needed for treatment (closed-loop system). In a first pilot study 36 patients ( $86 \%$ female) were implanted with the system. During the 6 months follow up a response rate of $71 \%$ was described. The clinical success rate was also supported by subjective Quality of life outcomes measured by OAB-q questionnaire that includes HRQL-health related QoL questions and symptoms severity scores. There was a significant increase in the subjects' QoL and significant decrease in symptom severity at each follow-up. The positive change in QoL was larger than the Minimally Important Difference (MID).

The potential of other options in the treatment of OAB such as botulinum toxin type A (BTA) followed by sacral nerve stimulation (SNS) and last option substantial reconstructive surgical intervention will not be discussed here. This thesis does not comprise these treatment modalities for OAB. 


\section{OUTLINE OF THIS THESIS}

The overall aim of this thesis is to improve our understanding of $O A B$ and in specific the treatment of $O A B$ by tibial nerve stimulation. Studies included in this thesis are focused on where we are now in the treatment of $O A B$ and new treatment modalities in the field of tibial nerve stimulation and OAB. The outline and corresponding research objectives are as follows:

Chapter 2 concerns the real life data on the long-term follow up of PTNS in a single center retrospective study. PTNS has been introduced for some time in guidelines as a next line of treatment in OAB syndrome. One of the main disadvantages of PTNS is the fact that patients do have to come over to the hospital for each single treatment. In chapter $\mathbf{2}$ we focus on the reason for discontinuation of PTNS. In this chapter we confirmed our hypothesis for reasons of quitting PTNS. More than $40 \%$ of the patients quitted during maintenance treatment due to nonmedical reasons. In other words, the treatment is beneficial however the practical limitations of the treatment are the reason for discontinuation. In chapter $\mathbf{3}$ we focus on the treatment of transcutaneous tibial nerve stimulation. We evaluated all patients who continued transcutaneous tibial nerve stimulation in their home situation after 12 weeks of percutaneous stimulation. Almost all of these patients quitted their therapy due to various reasons. One of the main reasons is loss off effect over time and preference for other types of neuromodulation. This problem could hopefully be solved by using an implant and perform home-based treatments. Van der Pal was in $\mathbf{2 0 0 6}$ the first who described the use of an implantable tibial nerve stimulator, the Urgent-SQ system. [57] Chapter 4 concerns the long-term follow up of the Urgent-SQ system over the past 18 years. In this chapter we describe the safety and efficacy outcomes of the Urgent-SQ system based on patient interviews. Besides we discuss the long-term technical support by manufacturers who introduce implantable devices.

The increase of technical possibilities over the past few years ensured the emergence of many smart, rechargeable and implantable peripheral nerve stimulators. In chapter $\mathbf{5}$ we will have a closer look on all new implants for the treatment of $O A B$ by tibial nerve stimulation. In this chapter we review the technical aspects of recent developed implants and techniques of tibial nerve stimulation in a transcutaneous, percutaneous and minimal invasive way. 
One of the newly innovated implants in the treatment of OAB syndrome by tibial nerve stimulation and discussed in chapter $\mathbf{5}$ is the Bluewind Renova-system (C) Heesakkers and van Breda were the first to describe the efficacy and safety results of the pilot study in their 3 and 6 months follow up study. $[59,60]$ Chapter 6 outlines the 3-year follow up results of the Bluewind Renova-system $\subset$. All patients who were previously implanted with the Bluewind Renova-system (C) and completed 6 months pilot study were offered continued participation into this 3-year follow-up study. In this long-term follow up study of the previously published prospective, self-controlled, interventional study, efficacy and quality of life was measured during 3 years post activation.

In chapter 7 we will focus on personalized healthcare and tibial nerve stimulation with in specific treatment with the Bluewind Renova-system ( $)$. The aim of this study is to show the positive features of patient tailored $O A B$ treatment in tibial nerve stimulation based on patient prediction factors and technical prediction factors during treatment by using a tibial nerve implant. The study objectives are: do patients use the ability to change their treatment level? Do patients change their treatment regime after a strict study protocol? Is parameter check and adjusting during all follow up moments necessary in patient tailored treatment? Are there any prediction factors for being a responder based on the technical features or patient features in the treatment of OAB with a tibial nerve implant?

Last, chapter $\mathbf{8}$ contains the summary of the main findings of this thesis and our future perspectives. Besides, it serves as a general discussion of this thesis, providing a critical appraisal contrasted to recent literature in the field of OAB and tibial nerve stimulation. 



\section{REFERENCES}

1. Abrams, P., et al., The standardisation of terminology of lower urinary tract function: report from the Standardisation Sub-committee of the International Continence Society. Neurourol Urodyn, 2002. 21(2): p. 167-78.

2. Milsom, I., et al., Global Prevalence and Economic Burden of Urgency Urinary Incontinence: A Systematic Review. European Urology, 2014. 65(1): p. 79-95.

3. Grinstein, E., et al., Update on non-invasive treatment for female overactive bladder. J Gynecol Obstet Hum Reprod, 2020. 49(3): p. 101683.

4. Irwin, D.E., et al., Population-based survey of urinary incontinence, overactive bladder, and other lower urinary tract symptoms in five countries: results of the EPIC study. Eur Urol, 2006. 50(6): p. 1306-14; discussion 1314-5.

5. Stewart, W.F., et al., Prevalence and burden of overactive bladder in the United States. World J Urol, 2003. 20(6): p. 327-36.

6. Lai, H.H., et al., The Relationship Between Anxiety and Overactive Bladder or Urinary Incontinence Symptoms in the Clinical Population. Urology, 2016. 98: p. 50-57.

7. Ganz, M.L., et al., Economic costs of overactive bladder in the United States. Urology, 2010. 75(3): p. 526-32, 532.e1-18.

8. W. Stuart Reynolds, J.A.C., Campbell-Walsh-Wein Urology. Overactive Bladder. Vol. 12. 2021, Philadelphia: Elsevier. 2637-2649.

9. Yoshimura, N., Lower urinary tract symptoms (LUTS) and bladder afferent activity. Neurourol Urodyn, 2007. 26(6 Suppl): p. 908-13.

10. Keay, S.K., L.A. Birder, and T.C. Chai, Evidence for bladder urothelial pathophysiology in functional bladder disorders. Biomed Res Int, 2014. 2014: p. 865463.

11. Brading, A.F., A myogenic basis for the overactive bladder. Urology, 1997. 50(6A Suppl): p. 57-67; discussion 68-73. 
12. Elbadawi, A., Functional pathology of urinary bladder muscularis: the new frontier in diagnostic uropathology. Semin Diagn Pathol, 1993. 10(4): p. 314-54.

13. Coolsaet, B.L., et al., New concepts in relation to urge and detrusor activity. Neurourol Urodyn, 1993. 12(5): p. 463-71.

14. de Groat, W.C., A neurologic basis for the overactive bladder. Urology, 1997. 50(6A Suppl): p. 36-52; discussion 53-6.

15. Peyronnet, B., et al., A Comprehensive Review of Overactive Bladder Pathophysiology: On the Way to Tailored Treatment. Eur Urol, 2019. 75(6): p. 988-1000.

16. Michel, M.C., Where will the next generation of medical treatments for overactive bladder syndrome come from? Int J Urol, 2020. 27(4): p. 289-294.

17. Han, J., et al., Desmopressin for treating nocturia in men. The Cochrane database of systematic reviews, 2017. 10(10): p. CD012059-CD012059.

18. F.C. Burkhard (Chair), J.L.H.R.B., F. Cruz, G.E. Lemack,, et al., EAU-Guidelineson-Urinary-Incontinence-2020. 2020.

19. Tomlinson, B.U., et al., Dietary caffeine, fluid intake and urinary incontinence in older rural women. Int Urogynecol J Pelvic Floor Dysfunct, 1999. 10(1): p. 22-8.

20. Sun, S., D. Liu, and Z. Jiao, Coffee and caffeine intake and risk of urinary incontinence: a meta-analysis of observational studies. BMC Urol, 2016. 16(1): p. 61.

21. Van Kerrebroeck, P.E., Does conservative management really benefit patients with OAB? Curr Urol Rep, 2012. 13(5): p. 348-55.

22. Bo, K., et al., Is pelvic floor muscle training effective for symptoms of overactive bladder in women? A systematic review. Physiotherapy, 2020. 106: p. 65-76.

23. Sussman, D.O., et al., Onset of efficacy of tolterodine extended release in patients with overactive bladder. Curr Med Res Opin, 2007. 23(4): p. 777-81. 
24. Peters, K.M., et al., Randomized trial of percutaneous tibial nerve stimulation versus Sham efficacy in the treatment of overactive bladder syndrome: results from the SUmiT trial. J Urol, 2010. 183(4): p. 1438-43.

25. Peters, K.M., et al., Sustained therapeutic effects of percutaneous tibial nerve stimulation: 24-month results of the STEP study. Neurourology and Urodynamics, 2013. 32(1): p. 24-29.

26. Amundsen, C.L., et al., OnabotulinumtoxinA vs Sacral Neuromodulation on Refractory Urgency Urinary Incontinence in Women: A Randomized Clinical Trial. JAMA, 2016. 316(13): p. 1366-1374.

27. Hegde, S.S. and R.M. Eglen, Muscarinic receptor subtypes modulating smooth muscle contractility in the urinary bladder. Life Sci, 1999. 64(6-7): p. 419-28.

28. Chess-Williams, R., et al., The minor population of M3-receptors mediate contraction of human detrusor muscle in vitro. J Auton Pharmacol, 2001. 21(56): p. 243-8.

29. Yamanishi, T., C.R. Chapple, and R. Chess-Williams, Which muscarinic receptor is important in the bladder? World J Urol, 2001. 19(5): p. 299-306.

30. Andersson, K.E. and M. Yoshida, Antimuscarinics and the overactive detrusor-which is the main mechanism of action? Eur Urol, 2003. 43(1): p. 1-5.

31. Andersson, K.E., Antimuscarinics for treatment of overactive bladder. Lancet Neurol, 2004. 3(1): p. 46-53.

32. Abrams, P. and K.-E. Andersson, Muscarinic receptor antagonists for overactive bladder. BJU International, 2007. 100(5): p. 987-1006.

33. Andersson, K.E., Antimuscarinic mechanisms and the overactive detrusor: an update. Eur Urol, 2011. 59(3): p. 377-86.

34. De Laet, K., S. De Wachter, and J.J. Wyndaele, Systemic oxybutynin decreases afferent activity of the pelvic nerve of the rat: new insights into the working mechanism of antimuscarinics. Neurourol Urodyn, 2006. 25(2): p. 156-61. 
35. Michel, M.C., et al., beta-adrenoceptor agonist effects in experimental models of bladder dysfunction. Pharmacol Ther, 2011. 131(1): p. 40-9.

36. Iggo, A., Tension receptors in the stomach and the urinary bladder. J Physiol, 1955. 128(3): p. 593-607.

37. Andersson, K.E., N. Martin, and V. Nitti, Selective beta(3)-adrenoceptor agonists for the treatment of overactive bladder. J Urol, 2013. 190(4): p. 1173-80.

38. Limberg, B.J., et al., beta-Adrenergic receptor subtype expression in myocyte and non-myocyte cells in human female bladder. Cell Tissue Res, 2010. 342(2): p. 295-306.

39. Otsuka, A., et al., Expression and functional role of beta-adrenoceptors in the human urinary bladder urothelium. Naunyn Schmiedebergs Arch Pharmacol, 2008. 377(4-6): p. 473-81.

40. Murakami, S., et al., The role of the urothelium in mediating bladder responses to isoprenaline. BJU Int, 2007. 99(3): p. 669-73.

41. Hsu, F.C., et al., Updating the evidence on drugs to treat overactive bladder: a systematic review. Int Urogynecol J, 2019. 30(10): p. 1603-1617.

42. Cui, Y., et al., The efficacy and safety of mirabegron in treating OAB: a systematic review and meta-analysis of phase III trials. Int Urol Nephrol, 2014. 46(1): p. 275-84.

43. Kelleher, C.J., et al., A medium-term analysis of the subjective efficacy of treatment for women with detrusor instability and low bladder compliance. $\mathrm{Br}$ J Obstet Gynaecol, 1997. 104(9): p. 988-93.

44. Lawrence, M., et al., Immediate-release oxybutynin versus tolterodine in detrusor overactivity: a population analysis. Pharmacotherapy, 2000. 20(4): p. 470-5.

45. Hampel, C., Long-Term Management of Overactive Bladder with Antimuscarinic Agents. European Urology Supplements, 2007. 6(5): p. 432-437. 
46. Chapple, C.R., Muscarinic receptor antagonists in the treatment of overactive bladder. Urology, 2000. 55(5A Suppl): p. 33-46; discussion 50.

47. Rudy, D., et al., Time to onset of improvement in symptoms of overactive bladder using antimuscarinic treatment. BJU Int, 2006. 97(3): p. 540-6.

48. Wagg, A., et al., Persistence with prescribed antimuscarinic therapy for overactive bladder: a UK experience. BJU Int, 2012. 110(11): p. 1767-74.

49. McGuire, E.J., et al., Treatment of motor and sensory detrusor instability by electrical stimulation. J Urol, 1983. 129(1): p. 78-9.

50. Martellucci, J., Electrical Stimulation for Pelvic Floor Disorders. 2015, Switzerland: Springer, Cham.

51. JB, S., Mémoires sur l'électro-puncture, considérée comme moyen nouveau de traiter effi cacement la goutte, les rhumatismes et les aff ections nerveuses, et sur l'emploi du moxa japonais en France; suivis d'un traité de l'acupuncture et du moxa: principaux moyens curatifs chez les peuples de la Chine, de la Corée et du Japon: ornés de fi gures japonaises. . 1825, Paris: Delaunay.

52. Melzack, R. and P.D. Wall, Pain mechanisms: a new theory. Science, 1965. 150(3699): p. 971-9.

53. Long, D.M., et al., Electrical stimulation of the spinal cord and peripheral nerves for pain control. A 10-year experience. Appl Neurophysiol, 1981. 44(4): p. 207-17.

54. Shealy, C.N., J.T. Mortimer, and J.B. Reswick, Electrical inhibition of pain by stimulation of the dorsal columns: preliminary clinical report. Anesth Analg, 1967. 46(4): p. 489-91.

55. Stoller, M.L., et al., The Efficacy of Acupuncture in Reversing the Unstable Bladder in Pig-Tailed Monkeys. Journal of Urology, 1987. 137(6): p. 104A-104A.

56. van Balken, M.R., et al., Posterior tibial nerve stimulation as neuromodulative treatment of lower urinary tract dysfunction. J Urol, 2001. 166(3): p. 914-8. 
57. van der Pal, F., et al., Implant-Driven Tibial Nerve Stimulation in the Treatment of Refractory Overactive Bladder Syndrome: 12-Month Follow-up. Neuromodulation, 2006. 9(2): p. 163-71.

58. Janssen, D.A., F. Farag, and J.P. Heesakkers, Urgent-SQ implant in treatment of overactive bladder syndrome: 9-year follow-up study. Neurourol Urodyn, 2013. 32(5): p. 472-5.

59. Heesakkers, J., et al., A novel leadless, miniature implantable Tibial Nerve Neuromodulation System for the management of overactive bladder complaints. Neurourol Urodyn, 2018. 37(3): p. 1060-1067.

60. van Breda, H.M.K., et al., A New Implanted Posterior Tibial Nerve Stimulator for the Treatment of Overactive Bladder Syndrome: 3-Month Results of a Novel Therapy at a Single Center. J Urol, 2017. 198(1): p. 205-210. 
47

$\nabla \Delta$

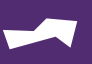
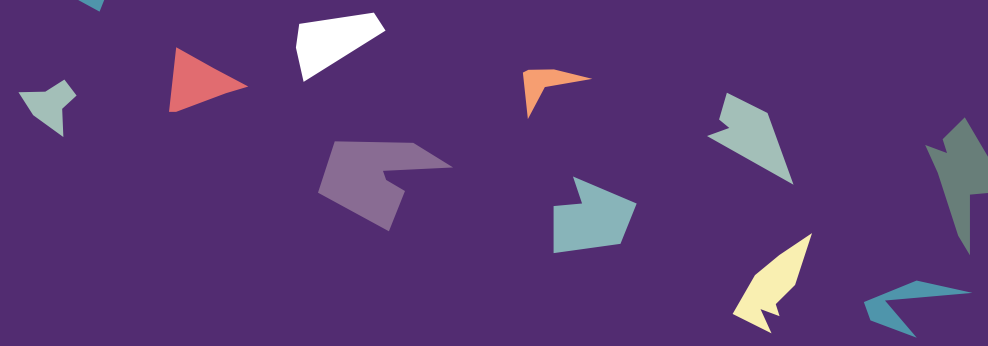

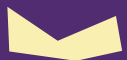

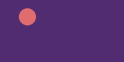

$\circ$

:

0

(

$\circ \circ$

$\circ$

$\circ$

$\circ$

$\circ \circ$

$\circ \circ \circ$

$\circ 0$

$\begin{array}{lllllll}0 & 0 & 0 & 0 & 0 & 0\end{array}$

$\circ 0$

00

0

0

○。

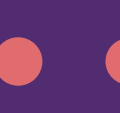

0

0

0

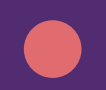

0

0

0

0

0

0

O
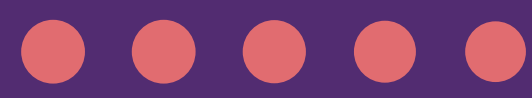

0

0

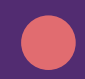

0
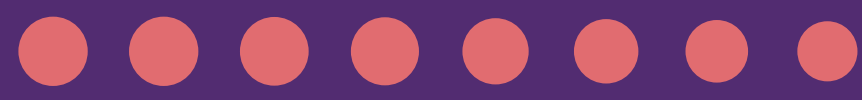

\section{Auteurs:}

Te Dorsthorst MJ, Heesakkers JPFA, van Balken MR.

\section{Tijdschrift:}

Neurourol Urodyn. 2020 Feb;39(2):702-706. 


\section{ABSTRACT}

Percutaneous tibial nerve stimulation (PTNS) is used as a treatment to reduce the complaints of overactive bladder (OAB). Although it is a rewarding therapy patients need maintenance treatment in order to preserve the beneficial effect. This real life retrospective study was performed to assess the feasibility of PTNS adherence.

All patients who underwent PTNS were retrospectively included. We analyzed the following: indication, kind of treatments (pharmacologic and third line therapy) before and after PTNS treatment, time and reason for quitting therapy. Statistical analysis was done by performing competitive-risk analysis and Kaplan-Meier curves. Patients were categorized into four groups. Group 1: all patients. Group 2: all patients on maintenance PTNS therapy (continuing after 12 weeks). Group 3: patients on maintenance PTNS therapy excluding the following: (a) patients with initial good response who seized treatment due to death, (b) patient who successfully switched to transcutaneous stimulation, (c) patients who were cured of their OAB symptoms or (d) patients who relocated. Group 4: group 3 but excluding those who stopped treatment because of non-medical reasons (physical strain, inconveniencies associated with visiting the hospital).

402 Patients (70\% female) with median age 70 years underwent PTNS. Underlying treatment indications were: OAB-wet (54\%) and OAB- dry (29\%). The median follow up (FU) of group 1 was 4 months. Fifty seven percent $(\mathrm{N}=228)$ of the patients received maintenance PTNS therapy. Median FU in group 4 was 46 months (range 3-111 months). Over 40\% of the maintenance patients stopped PTNS because of logistic reasons and physical strain during a FU time of 6 years.

The real-world data described herewith is in line with earlier published work in terms of success rate of OAB treatment. However over $40 \%$ quit their therapy due to non-medical reasons. 


\section{INTRODUCTION}

In the treatment of overactive bladder (OAB), percutaneous tibial nerve stimulation (PTNS) is used to reduce complaints of patients. OAB is a feature of storage LUTS characterized by urinary urgency with or without urinary incontinence (UI), usually with frequency and nocturia. [1] In Europe the overall prevalence of OAB reported by women is $13 \%$ and $12 \%$ in men. Nearly half of the women who report symptoms of OAB also suffer from UI. [2] Behavioral therapy and pharmacologic therapy such as antimuscarinics or beta3 agonists are first lines of treatment in OAB. Although medication is the mainstay for OAB treatment, over $70 \%$ of all patients quit medication within one year because of intolerability or ineffectiveness. [3-5]

McGuire et al. were the first to report the use of transcutaneous tibial nerve stimulation for urologic conditions. [6] Stoller modified the above therapy to a percutaneous technique by using a 34-gauge needle. This resulted in reduction of complaints regarding urgency, frequency, urge incontinence and pelvic pain. [7] The mechanism by which PTNS inhibits OAB complaints is not yet clearly defined. PTNS has clinical success rates ranging from $55 \%$ to $80 \%$. [8-14] Although PTNS has gained its place in the treatment of $O A B$, real life data on a substantial group of patients followed for a long time are scarce. Almost all published studies are clinical trials with a strict study-protocol. Real life data presenting clinical rates of success or reasons for quitting this therapy is rare. If published, it is mainly a small number of patients or a short period of follow up. We hereby report the results during long-term (median 4 months, maximum 111 months) follow up of over 400 patients who underwent PTNS in our single center (Rijnstate hospital, Arnhem).

\section{MATERIALS AND METHODS}

All patients who underwent PTNS (Urgent PC system) in our single center hospital from January 2008 until July 2018 were retrospectively included. During the first 12 weeks patients were treated weekly with PTNS, while during maintenance treatment, PTNS was performed based on clinical symptoms indicated by the patient. PTNS technique applied was previously described by van Balken et al. [15] Baseline characteristics, indication for PTNS, time and/ or reason for treatment discontinuation and other treatments before and after PTNS were extracted from patients' files. Treatment success was determined based subjective parameters. Together with the urologist, patients evaluated the beneficial effect after 12 weeks of treatment. Positive treatment outcome warranted continuation to maintenance therapy. 
Patients were grouped into four categories based on response rate and reason for discontinuing treatment, in order to be able to analyze causes for treatment cessation. Group 1: all patients who ever had a PTNS treatment in our hospital (Intention To Treat population, ITT). Group 2: all patients during maintenance PTNS. These patients continued to maintenance therapy after 12 weeks initial treatment and after concluding a positive therapy outcome with their urologist. Group 3: group 2 excluding those with a good response that did not continue due to relocation, death, switching to transcutaneous nerve stimulation or free of OAB complaints. Group 4: group 3 excluding patients who stopped treatment due to physical strain (painful ankle during maintenance PTNS) or practical problems to come to the hospital during the maintenance PTNS. Group 4 is, the most pure group of successful PTNS treatment, in order to evaluate the long term effect with correction for the initial good responders who stopped treatment due to reasons that are not related to treatment effect. This group represents the Per Protocol treated population.

We used SPSS 22.0 (SPSS, Chicago, IL) for statistical analysis. To evaluate the survival of the treatment Kaplan-Meier curves were used. Discontinuing PTNS was used as the survival event. We investigated the risk of quitting the therapy because of logistic reasons and physical strain by using competitive-risk analysis. Death and quitting the therapy was used as a competitive risk. The hospital's local ethical committee approved the study.

\section{RESULTS}

From January 2008 until July 2018, 402 patients were included with median age of 70 years, ranging from $19-80$ (group 1). Seventy percent $(70 \%)$ of the patients were female. The mean distance patients had to drive for their treatment was 13,8 kilometers (ranging from 1.5 to 110 kilometers). Indications for the treatment were: OAB-wet (54\%), OAB-dry (29\%), neurogenic bladder (defined as patients with multiple sclerosis, post-CVA, Parkinson's disease, dementia, myelopathy, spinal disc herniation, cerebellar ataxia, cauda equine syndrome, congenital diseases and isolated neurogenic bladder; 15\%), others (2\%). Most patients had had 2 different types of pharmacologic treatment previous to starting PTNS (range: 0-5). Some patients did not go through the initial OAB medication trial prior to PTNS due to patients' prior beliefs and/or preferences based on side-effects or fear because of hypersensitivity/allergies. The median follow up (FU) of group 1 $(\mathrm{N}=402$ ) was 4 months (ranging from 1-111 months). In group 2, 57\% of the patients 
$(\mathrm{N}=228)$ went into maintenance treatment after 12 weeks of initial PTNS treatment and after concluding on a positive outcome with their urologist with a median FU of 14 months (range 3-111 months). Group $3(\mathrm{~N}=183)$ and $4(\mathrm{~N}=131)$ had a median FU of 18 months (ranging 3-111 months) and 46 months (range 3-111 months) (Figure 1).

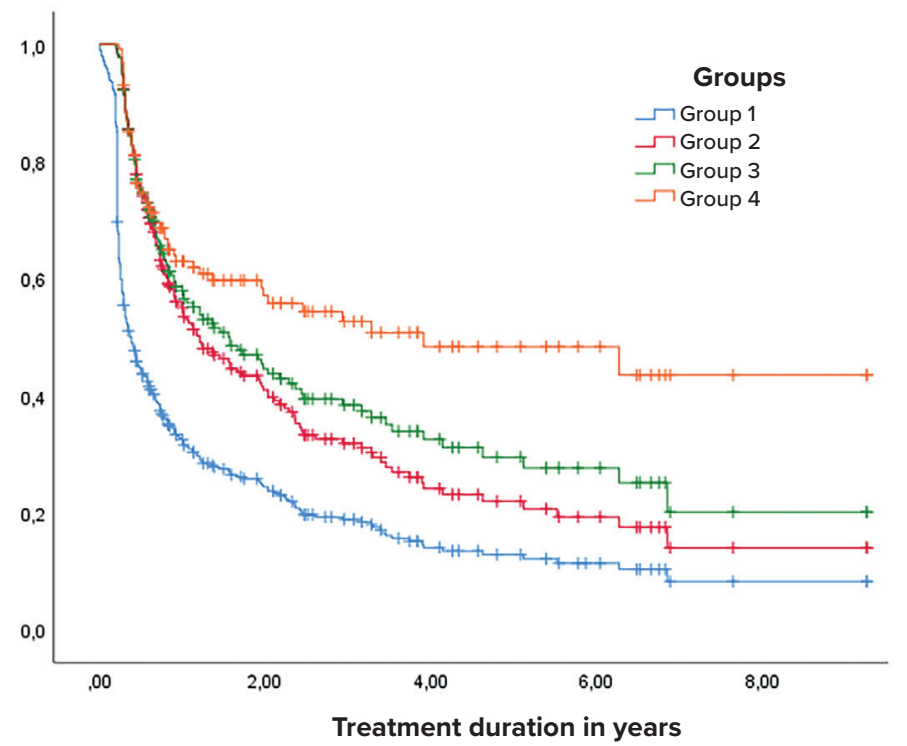

Figure 1. Treatment duration of PTNS in months according to different groups.

Forty five (45) patients in group 2 stopped their treatment because of non-medical reasons ( 2 patients died, 3 patients relocated, 20 patients switched to TENS therapy and 20 patients were free of complaints), leaving 183 patients in group 3. Switching to TENS therapy was mainly done due to patient's preference. Only 2 patients were already treating themselves with TENS because of chronic pain whereby transcutaneous treatment for OAB was more convenient. In 4 patients the reason for switching to transcutaneous treatment was not reported.

In group $4(\mathrm{~N}=131), 57 \%$ of the patients still continues maintenance treatment nowadays. Fifty two (52) patients quitted their therapy because of physical strain (painful ankle) or logistic reasons (problems visiting the hospital). Figure 2 shows an estimation of the risk of quitting the therapy because of logistic reasons and physical strain. This is demonstrated that the risk of quitting therapy due to logistic reasons and physical strain, is over $40 \%$ at 6 years of FU for all patients during maintenance treatment. 
Baseline criteria for the groups as described above are listed in table 1. If patients did not continue their PTNS treatment, they mostly selected no treatment (57\%) followed by botulinum toxin (14\%), several different types of anticholinergics (13\%), Mirabegron (10\%), alternative medicine (4\%) or pelvic floor treatment (2\%).

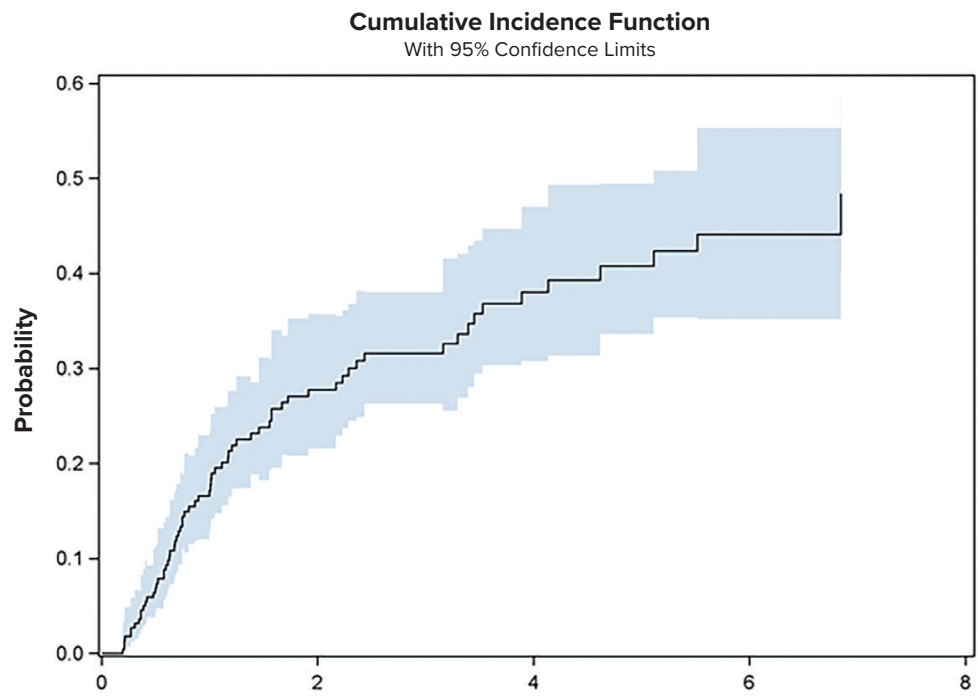

Figure 2. Risk analysis for quitting the treatment because of nonmedical reasons by using competitive risk-factor analysis.

\begin{tabular}{|c|c|c|c|c|}
\hline & All/ Group 1 & Group 2 & Group 3 & Group 4 \\
\hline $\begin{array}{l}\text { Number of } \\
\text { patients (n) }\end{array}$ & 402 & 228 & 183 & 131 \\
\hline Men/women (n) & $122 / 280$ & $67 / 161$ & $52 / 131$ & $37 / 94$ \\
\hline $\begin{array}{l}\text { Median age } \\
\text { (years) }\end{array}$ & $\begin{array}{c}70 \\
\text { (range 19-80) }\end{array}$ & $\begin{array}{c}71 \\
\text { (range 23-76) }\end{array}$ & $\begin{array}{c}73 \\
\text { (range 23-76) }\end{array}$ & $\begin{array}{c}71 \\
\text { (range 26-76) }\end{array}$ \\
\hline $\begin{array}{l}\text { Median number } \\
\text { of previous } \\
\text { drug treatments }\end{array}$ & $\begin{array}{c}2 \\
\text { (range 0-5) }\end{array}$ & $\begin{array}{c}2 \\
\text { (range 0-4) }\end{array}$ & $\begin{array}{c}2 \\
\text { (range 0-4) }\end{array}$ & $\begin{array}{c}2 \\
\text { (range 0-4) }\end{array}$ \\
\hline $\begin{array}{l}\text { Median follow- } \\
\text { up (months) }\end{array}$ & 4 & 14 & 18 & 46 \\
\hline $\begin{array}{l}\text { Maximum } \\
\text { follow-up } \\
\text { (months) }\end{array}$ & 111 & 111 & 111 & 111 \\
\hline
\end{tabular}

Table 1. Baseline criteria for the groups. 


\section{DISCUSSION}

In this real life data study we report that $57 \%$ of our patients continues PTNS treatment after 12 weekly treatment sessions based on the decision made together with their urologist that the treatment was successful and the willingness to continue. This is in line with former studies that report success rates, defined as continuing treatment to maintenance therapy after 12 weeks of treatment, between $54.5 \%-79.5 \%$. [8-14, 16]

Peters et al. described in the STEP study that over $75 \%$ of the study population with an initial good response after 12 weeks of treatment still benefit from the PTNS after 3 years of treatment. The average number of maintenance treatments in that study population was once a month. [17] In our analysis from daily practice it can be shown that only $32 \%$ of all the patients who continued PTNS treatment after a good response to 12 weekly PTNS treatment (group 2), continues for a longer period with a maximum follow up of 111 months. In this group the median number of treatments during our follow up period was 32 (range 14-261). Various reasons can account for this discrepancy between our findings and the STEP study. One could be the inclusion criteria for the STEP study in which patients from the therapy arm of the SUmiT trial were allowed to participate if they reported bladder symptoms as moderately or markedly improved on the 7-point global response assessment (GRA). [17, 18] If we compare this to our group 4, 53\% still continue their treatment after 3 years in a non-study population. (Figure 1) The difference between the outcome in the STEP study and our results could be explained by the fact that our patients were not chosen based on specific eligibility criteria and the FU in a real life cohort is not as strict as in a study-cohort. Recently Sirls et al. published their real-world experience in over 100 patients. They showed that $55 \%$ of the patients continued after 3 months of maintenance treatment which is more in line with our real life data. [16]

PTNS is a minimal invasive and cheap treatment modality without serious side effects compared to other surgical and drug therapies for OAB. [10, 17] As described above, $57 \%$ of the patients continues after a good response for a longterm treatment. In comparison to PTNS, OAB pharmacologic therapies have a higher rate of discontinuation within 1 year (mean 70\%). [3-5] When comparing the long-term treatment outcomes of sacral nerve stimulation, van Kerrebroeck et al. showed $70 \%$ of the patients still experiencing a benefit after 5 years. In our real life data, after 5 years $44 \%$ of patient in group 4 still benefited from the PTNS 
treatment. Nonetheless, due to the limited battery life of SNS systems the average time for re-operations/explanations is 5-7 years. [19, 20] In addition, although SNS therapy has demonstrated higher patient satisfaction at 5 year time-point, the procedure is more complicated and has higher level of serious adverse events. Therefore, PTNS can be considered an acceptable alternative for the long-term treatment with good satisfaction level and less serious complications as compared to SNS.

In our study, more than $40 \%$ of the subjects discontinued treatment after 6 years due to non-medical reasons (Figure 2), indicating that although the therapy is beneficial still $40 \%$ eventually do not receive it due to practical reasons. We suspect that by minimizing the practical reasons for stopping treatment, more patients will continue for long term treatment. This could be done by allowing patients to treat themselves at home by means of an implant. The first few pilot studies have recently been published with promising results. [21-23] The RENOVA iStim $^{\text {TM }}$ system (Bluewind Medical Ltd.; Herzliya Israel) showed clinical success rate of $71 \%$ after 6 months based on reduction in the number of leaks and/or voids and reduction in the number of episodes with degree of urgency. [22] The eCOIN ${ }^{\mathrm{m}}$ (Valencia Technologies Corp.; Valencia, CA) showed similar success rates, 71\% relative median reduction in the number of urgency urinary incontinence (UUI) episodes after 12 weeks of treatment. [23] Long-term safety and efficacy outcomes are yet unknown. However Janssen et al. published data at 9 years follow up period after implantation of the first tibial nerve stimulation implant (Urgent SQ) for OAB indications. It was demonstrated that six out of seven implanted patients still had sensory and loco-motor responses on stimulation and all implants were still intact with no migration or displacement. $[24,25]$ These results are promising for the treatment of OAB with a tibial implantable device.

This study is the first to present a large number of patients in a real life setting. Physicians and patients should be aware of the fact that if initial response to PTNS is good, the likelihood of maintaining this treatment benefit in the next few years is high. Patients tend to quit PTNS maintenance treatment due to multiple reasons, such as physical strain or inconveniencies associated with visiting the hospital. This information is relevant for patients and professionals in their decision making and also highly support the need of development implantable tibial neurostimulation devices. 
The fact that this study is a retrospective single center study poses limitation on reaching solid conclusion. Therefore a prospective and possibly multi-institutional study is warranted.

\section{CONCLUSION}

The real-world data we describe are in line with earlier published work in terms of success rate of OAB treatment by PTNS. We demonstrated that PTNS is a successful long term therapy modality. However $>40 \%$ of the patients quitted during maintenance treatment due to non-medical reasons. 



\section{REFERENCES}

1. Abrams, P., et al., The standardisation of terminology in lower urinary tract function: report from the standardisation sub-committee of the International Continence Society. Urology, 2003. 61(1): p. 37-49.

2. Irwin, D.E., et al., Population-based survey of urinary incontinence, overactive bladder, and other lower urinary tract symptoms in five countries: results of the EPIC study. Eur Urol, 2006. 50(6): p. 1306-14; discussion 1314-5.

3. Kelleher, C.J., et al., A medium-term analysis of the subjective efficacy of treatment for women with detrusor instability and low bladder compliance. $\mathrm{Br}$ J Obstet Gynaecol, 1997. 104(9): p. 988-93.

4. Lawrence, M., et al., Immediate-release oxybutynin versus tolterodine in detrusor overactivity: a population analysis. Pharmacotherapy, 2000. 20(4): p. 470-5.

5. Hampel, C., Long-Term Management of Overactive Bladder with Antimuscarinic Agents. European Urology Supplements, 2007. 6(5): p. 432-437.

6. McGuire, E.J., et al., Treatment of motor and sensory detrusor instability by electrical stimulation. J Urol, 1983. 129(1): p. 78-9.

7. Cooperberg, M.R. and M.L. Stoller, Percutaneous neuromodulation. Urol Clin North Am, 2005. 32(1): p. 71-8, vii.

8. Klingler, H.C., et al., Use of peripheral neuromodulation of the S3 region for treatment of detrusor overactivity: a urodynamic-based study. Urology, 2000. 56(5): p. 766-71.

9. Govier, F.E., et al., Percutaneous afferent neuromodulation for the refractory overactive bladder: results of a multicenter study. J Urol, 2001. 165(4): p. 1193-8.

10. van Balken, M.R., et al., Posterior tibial nerve stimulation as neuromodulative treatment of lower urinary tract dysfunction. J Urol, 2001. 166(3): p. 914-8. 
11. Vandoninck, V., et al., Posterior tibial nerve stimulation in the treatment of urge incontinence. Neurourol Urodyn, 2003. 22(1): p. 17-23.

12. Vandoninck, V., et al., Percutaneous tibial nerve stimulation in the treatment of overactive bladder: urodynamic data. Neurourol Urodyn, 2003. 22(3): p. 227-32.

13. Karademir, K., et al., A peripheric neuromodulation technique for curing detrusor overactivity: Stoller afferent neurostimulation. Scand J Urol Nephrol, 2005. 39(3): p. 230-3.

14. Nuhoglu, B., et al., Stoller afferent nerve stimulation in woman with therapy resistant over active bladder; a 1-year follow up. Int Urogynecol J Pelvic Floor Dysfunct, 2006. 17(3): p. 204-7.

15. van Balken, M.R., Percutaneous tibial nerve stimulation: the Urgent PC device. Expert Rev Med Devices, 2007. 4(5): p. 693-8.

16. Sirls, E.R., et al., Percutaneous Tibial Nerve Stimulation in the Office Setting: Real-world Experience of Over 100 Patients. Urology, 2018. 113: p. 34-39.

17. Peters, K.M., et al., Percutaneous tibial nerve stimulation for the long-term treatment of overactive bladder: 3-year results of the STEP study. J Urol, 2013. 189(6): p. 2194-201.

18. Peters, K.M., et al., Randomized trial of percutaneous tibial nerve stimulation versus Sham efficacy in the treatment of overactive bladder syndrome: results from the SUmiT trial. J Urol, 2010. 183(4): p. 1438-43.

19. van Kerrebroeck, P.E., et al., Results of sacral neuromodulation therapy for urinary voiding dysfunction: outcomes of a prospective, worldwide clinical study. J Urol, 2007. 178(5): p. 2029-34.

20. van Voskuilen, A.C., et al., Long term results of neuromodulation by sacral nerve stimulation for lower urinary tract symptoms: a retrospective single center study. Eur Urol, 2006. 49(2): p. 366-72. 
21. van Breda, H.M.K., et al., A New Implanted Posterior Tibial Nerve Stimulator for the Treatment of Overactive Bladder Syndrome: 3-Month Results of a Novel Therapy at a Single Center. J Urol, 2017. 198(1): p. 205-210.

22. Heesakkers, J., et al., A novel leadless, miniature implantable Tibial Nerve Neuromodulation System for the management of overactive bladder complaints. Neurourol Urodyn, 2018. 37(3): p. 1060-1067.

23. MacDiarmid, S., et al., Feasibility of a Fully Implanted, Nickel Sized and Shaped Tibial Nerve Stimulator for the Treatment of Overactive Bladder Syndrome with Urgency Urinary Incontinence. J Urol, 2019. 201(5): p. 967-972.

24. Janssen, D.A., F. Farag, and J.P. Heesakkers, Urgent-SQ implant in treatment of overactive bladder syndrome: 9-year follow-up study. Neurourol Urodyn, 2013. 32(5): p. 472-5.

25. van der Pal, F., et al., Implant-Driven Tibial Nerve Stimulation in the Treatment of Refractory Overactive Bladder Syndrome: 12-Month Follow-up. Neuromodulation, 2006. 9(2): p. 163-71. 
17

$\nabla \Delta$

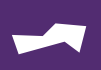
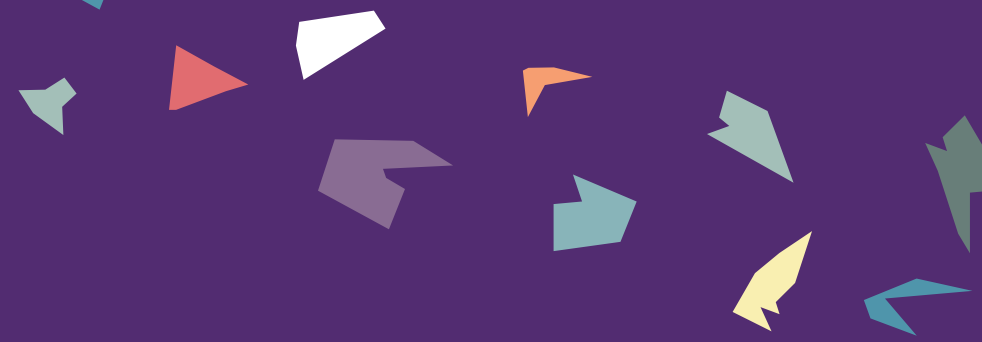

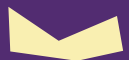

$\circ$

。

$\circ \circ$

$\circ$

$\circ \circ$

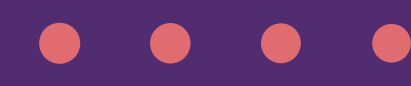

$\circ \circ$

$\begin{array}{lllllll}0 & 0 & 0 & 0 & 0 & 0 & 0\end{array}$

$\circ 0$

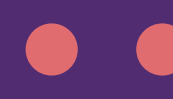

00

0

0

C

0

0

0

0

0

0

0

0

0

0

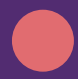

$\bigcirc$

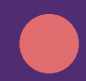

0
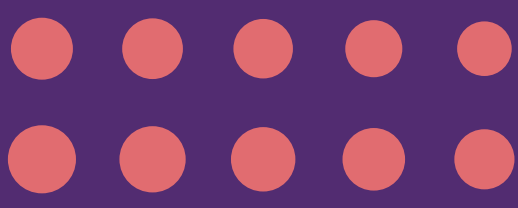

Auteurs:

Te Dorsthorst MJ, van Balken MR, Janssen DA, Heesakkers JPFA, Martens FMJ

\section{Tijdschrift:}

Ther Adv Urol. 2021 Aug 31 


\section{ABSTRACT}

Introduction and objectives: Overactive bladder syndrome $(O A B)$ is defined as urinary urgency, with or without urgency urinary incontinence, and often associated with urinary frequency and nocturia, in the absence of any pathological or metabolic conditions that may cause or mimic OAB. The aim of this study was to evaluate the long-term real life adherence of transcutaneous tibial nerve stimulation (TTNS) in the treatment of OAB, patient satisfaction of the treatment and reasons for quitting therapy.

Materials and methods: In this single center study all patients who had a positive effect on percutaneous tibial nerve stimulation (PTNS) and continued to home based treatment with TTNS since 2012 were included for analysis. Patients were retrospectively asked to fill out a questionnaire regarding satisfaction, reasons for quitting and additional or next line of therapy.

Results: We included 42 patients for this study, $81 \%$ of these patients were female $(n=34)$. The median age was 67 years (range $36-86)$. Most of the patients $(64 \%$, $n=27$ ) were diagnosed with $O A B$ wet. The median TTNS treatment persistence was 16 months (range 1-112 months). Reasons and percentages for stopping therapy were: $55 \%$ stopped treatment due to loss of effect, $24 \%$ stopped because of preferring other type of neuromodulation. Mean satisfaction score (scale 1-10) in patients who continued TTNS was $6.2(n=9, S D$ 1,30) versus $5.4(n=29$, SD 2.24) for patients who quit therapy. We did not find a statistically significant difference between the two groups $(p=0.174)$.

Conclusion: TTNS, although effective in short-term, on the long-term is not. In combination with a low satisfaction rate among patients the need for improvement of $O A B$ treatment modalities keeps existing. 


\section{INTRODUCTION}

Overactive bladder syndrome (OAB) is defined by the ICS as urinary urgency, with or without urgency urinary incontinence, and often associated with urinary frequency and nocturia, in the absence of any pathological or metabolic conditions that may cause or mimic OAB. [1] OAB treatment starts according to guidelines with behavioral therapy and if needed supplemented with drug treatment. When drug treatment is unsuccessful, next line of treatment consists of percutaneous tibial nerve stimulation (PTNS) or intravesical Onabotulinum Toxin A injections or sacral nerve stimulation (SNS). [2] Success rates of PTNS were described by Peters et al. in the first sham-controlled trial for PTNS. They described $43 \%$ improvement of urinary urgency, $48 \%$ improvement of urinary frequency, $38 \%$ improvement of UUI and an overall improvement of 55\% based on GRA-scale (global response assessment) after 13 weeks of treatment. [3] However, one of the main disadvantages of PTNS is the fact that patients have to come over to the hospital for their treatment. Secondly, once PTNS treatment is quitted patient's complaints will return and therefore patients need maintenance therapy. [4]

Home-based treatment with transcutaneous stimulation of the tibial nerve (TTNS) could solve these problems. TTNS uses a surface electrode, instead of a needle, to stimulate the tibial nerve, which can be self-applied by patients. [5] Previous studies showed that TTNS in study context is an effective treatment option in the treatment of idiopathic OAB. [5-8] In particular, Ramirez et al. showed noninferiority in the decrease of daytime frequency voiding in patients with idiopathic $\mathrm{OAB}$ and DO in their randomized controlled trial comparing PTNS versus TTNS. Both techniques improve symptoms and to a large extent QoL. Moreover, the perception of improvement did not differ between PTNS and TTNS. [8] However, real life data related to efficacy and continuation of the treatment on the longer term are scarce.

The aim of this study was to evaluate the long-term real life adherence of patients to TTNS for the treatment of $O A B$, including patient satisfaction and reasons for stopping TTNS. 


\section{MATERIALS \& METHODS}

In this single center study all patients who had positive effect on PTNS and continued to home based treatment with TTNS since 2012 were included. Patients were retrospectively asked to fill out a questionnaire (supplementary data) regarding satisfaction, reasons for quitting and additional or next line therapy. All patients were included in our single center university hospital. All patients started with at least 7 treatment sessions of PTNS (median 18, range 7-49 weeks) once a week followed by evaluation session with their urologist. If there was a subjective improvement of their OAB complaints patients were asked to continue for homebased TTNS treatment. Instructions for homebased TTNS were given by a specialized nurse and evaluation was performed two weeks after the start of TTNS therapy. During this follow up moment it was evaluated if they needed an extra training. Thereafter, patients continued with maintenance therapy with TTNS on their own demand without specific follow up.

Inclusions criteria for this study were patients with PTNS followed by TTNS. All patients who started PTNS and/or TTNS under the age of 18 were excluded for analysis as were patients with mental or physical limitations for filling out the questionnaire (i.e., Alzheimer's, post-CVA with physical limitations, illiterate). Before the questionnaires were sent, patients were called to participate in the study. When patients could not be reached, they were defined as lost to follow up.

Baseline criteria and extra study details were retrieved from patient electronical files after receiving their informed consent. The questionnaire which was sent to all patients is included in the supplementary data. Statistical analysis was performed by using SPSS 22.0 (SPSS, Chicago, IL). Kaplan-Meier curves were used to estimate the survival of TTNS. Discontinuing of TTNS was used as an endpoint. T-test was performed to determine statistical significance between the mean satisfaction score (scale 1-10) of both patient groups. Patients who continued the treatment versus patients who quitted treatment. This study was approved by the local medical ethics review committee. Written informed consent was obtained from all patients for use of clinical data in research. 


\section{RESULTS}

\section{Baseline criteria}

A total of 78 patients underwent PTNS followed by TTNS in our University Medical Center. Questionnaires were sent to 50 patients. Reasons and numbers for not including in the study were as follows: 15 patients were lost to follow up, 6 patients had died, 7 patients were physically or mentally not competent to fill out the questionnaire. Out of our 50 patients who met the inclusion and exclusion criteria 8 patients did not respond to our request to fill out the questionnaires. Finally, we included 42 patients for this study (response rate intention to treat 55\%, response rate per protocol $84 \%$ ). Figure 1 shows the patient flow.

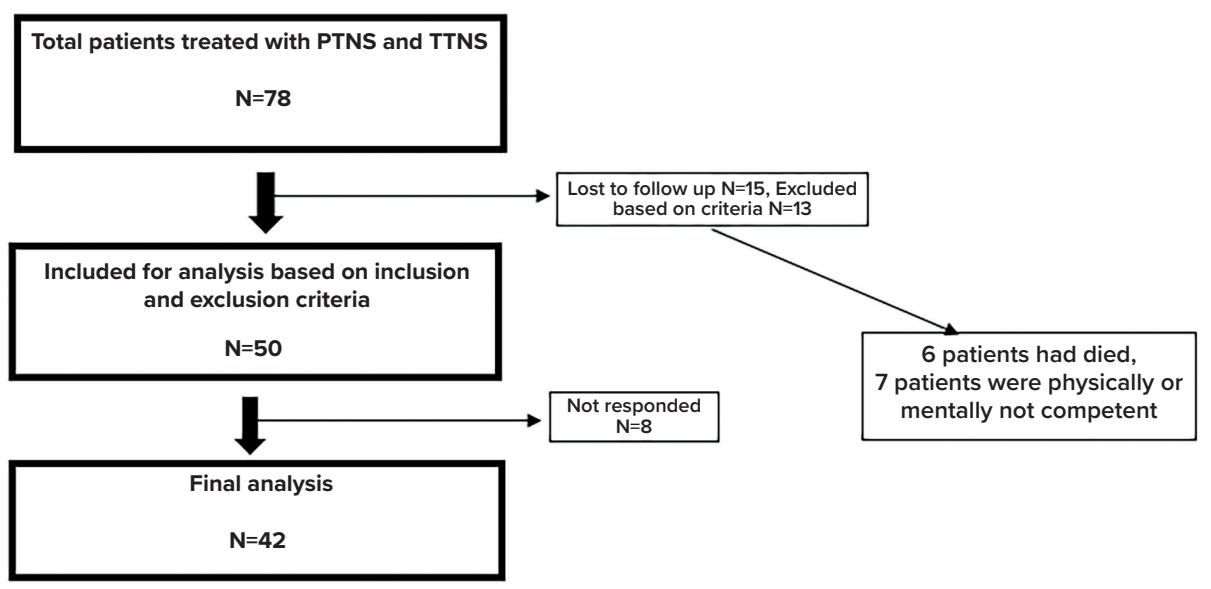

Figure 1. Study flow, patient inclusion/ exclusion and number of patients final analysis.

42 Patients were included, $81 \%$ were female $(n=34)$. The median age was 67 years (range 36-86). Most of the patients $(64 \%, n=27)$ were diagnosed with OAB wet, followed by OAB dry $(19 \%, n=8)$ and neurogenic origin $(17 \% n=7) .67 \%(n=28)$ of the included patients had previous medication and pelvic floor therapy, 31\% $(n=13)$ had medication only. For one patient it was unclear what treatment was received prior to the PTNS. 


\section{PTNS analysis}

All patients received weekly PTNS sessions prior to their treatment with TTNS. The median duration of their PTNS treatment was 18 weeks (range 7-49 weeks). We could not determine the duration of the treatment for 3 patients. As these patients were treated in an hospital near their home instead of our referral center.

\section{TTNS analysis}

All patients continued with TTNS after their PTNS treatment. The median TTNS treatment persistence was 16 months (ranges 1-112 months). Figure 2a illustrates the overall survival of TTNS treatment in all patients. Figure $2 \mathrm{~b}$ illustrates the survival per category of OAB. (OAB wet, OAB dry and neurogenic origine). Unfortunately, due to low numbers we could not perform any other statistics. During treatment, $45 \%$ of the patients used TTNS on a daily basis followed by $27.5 \%$ of the patients who were using it 3-6 times a week and $22.5 \%$ who were using the system 1-2 times per week. Only a small percentage, $5 \%$, used it less than once a week. Twenty-one percent continued treatment, reasons and percentages for quitting therapy are shown in Figure 3. Main reason to discontinue TTNS was loss of effect (55\%).

A

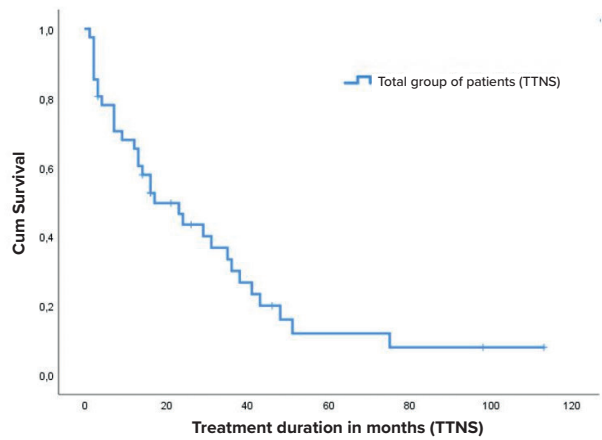

B

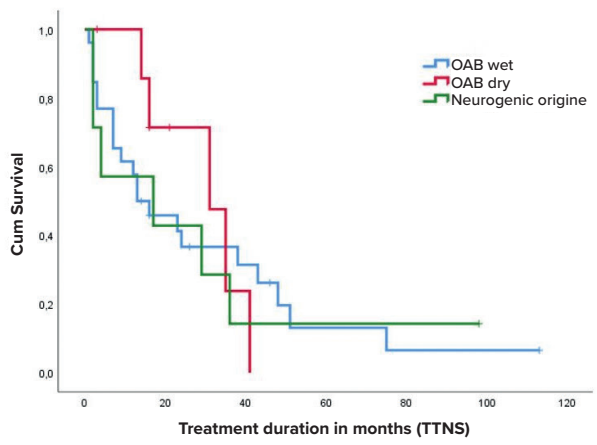

Figure 2a. Treatment duration of TTNS in months among all patients ( $n=42)$, figure $2 b$. Treatment duration of TTNS in months specified per category (OAB wet $n=26, O A B$ dry $n=8$, neurogenic $n=7$ ) 


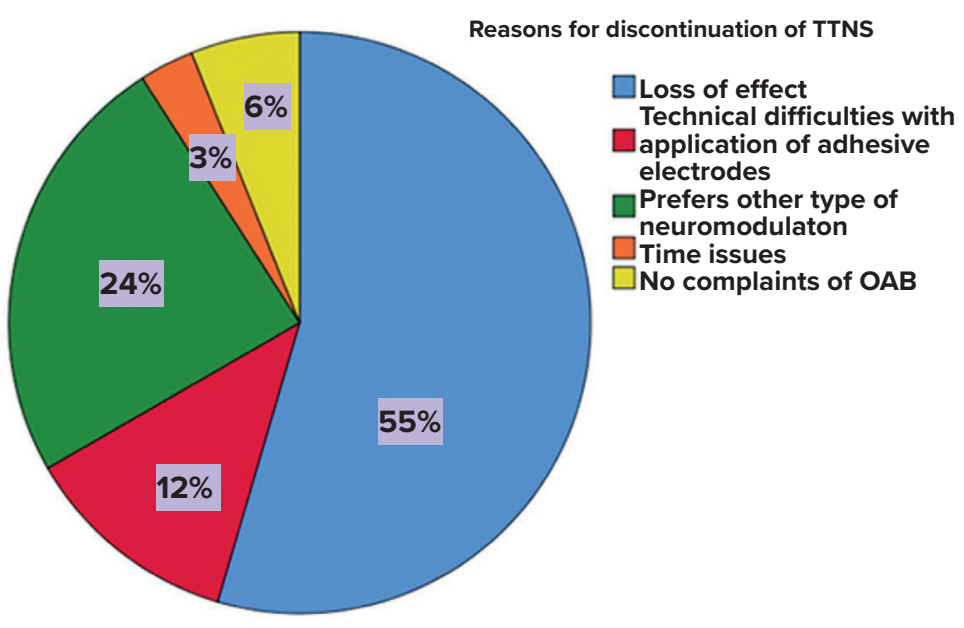

Figure 3. Reasons for discontinuation of TTNS (N=33).

During TTNS treatment almost $62 \%$ of the patients did not use any other form of treatment, $36 \%$ of the patients used medication as additional therapy and in $2 \%$ it was unknown. The mean satisfaction score (scale 1-10) which all patients rated their TTNS treatment was $5.6(n=38, S D 2,07)$. Mean treatment score in patients who continued TTNS was 6.2 ( $n=9$, SD 1,30) versus 5.4 ( $n=29$, SD 2.24) for patients who quitted therapy. We did not find a statistically significant difference between the two groups $(p=0.174)$. If patients did stop TTNS, one third did not receive or continued with a different OAB treatment. When they opted for a different treatment, they mainly choose PTNS (21\%), PTNS implant (18\%), Onabotulinum Toxin A injections (12\%), Medication (9\%) or sacral neuromodulation (6\%).

\section{DISCUSSION}

We report that in this real life study the median treatment persistence of TTNS is only 16 months after start treatment. Moreover, 55\% quit their therapy because of loss of effect over time while most of them are treating themselves on a daily base. These results illustrate the main short comings of TTNS over time. TTNS has a positive effect on OAB symptoms, which as shown for short term follow up by Booth et al. in their sham controlled TTNS study and Schreiner et al. in their RCT where patients received TTNS in addition to standard therapy (bladder training, PFMT). [9, 10] Although TTNS is successful at start, we observed that most patients do not continue with their treatment in the long term due to various reasons listed above. 
If we compare our real life data regarding long-term treatment efficacy to existing studies, we do see slightly different outcomes. Leroux et al. [7] describe in their study a mean TTNS persistence of 8.3 months, $29 \%$ of their patients continued for over 12 months. Only $16 \%$ continued for 18 months or over, comparing to our median follow up of 16 months. Only $17 \%$ of their patients continued treatment with TTNS during their end of study moment, whereas we found $21 \%$. Reasons for this difference could be explained by the number of patients included in both studies but also by the differences in design of both studies. However, it can be concluded that the results from both studies show that TTNS treatment persistence is currently not satisfactory.

Comparing our long-term TTNS therapy adherence data to real life PTNS data, we do not see a large difference in outcome. As mentioned above, median treatment persistence in our study was 16 months $(n=42)$. In real life PTNS studies $(n=183)$ the median follow up of patients during maintenance treatment is 18 months. [11] Sirls et al. describe in their real-world study that $55 \%$ of their patients continued maintenance PTNS treatment after 3 months. [12] However, the reasons for discontinuation of PTNS differ from TTNS mainly because of the logistic intensity (frequent clinical visits) of the PTNS treatment compared to TTNS. [11]

The main reason for TTNS discontinuation was loss of efficacy or lack of sufficient symptom relief. This is in line with other publications. Leroux describes that $70 \%$ of their patients stopped due to lack of sufficient symptom relief. [7] They further mentioned compliance difficulty and becoming asymptomatic as reasons for discontinuation. This could be the reason why in their series $70 \%$ had loss of effect is higher compared to the $55 \%$ in our study.

In this study we could only quantify the level of satisfaction rate of patients by recall for both treatment periods with PTNS and TTNS. Patients rated their TTNS treatment generally with an overall 5.6 (scale 1-10) report grade. This fairly low score, plus the fact that patients often preferred a different form of tibial nerve neuromodulation (24\%) suggests that other forms of tibial nerve neuromodulation had more satisfactory outcomes. These observations are in contrast to a RCT published by Martin Garcia et al. followed by a non-inferiority study by RamirezGarcia et al. [6, 8] Both studies concluded no statistical difference in efficacy outcome and quality of life questionnaires in TTNS versus PTNS. 
Posterior tibial neuromodulation and as a part of this TTNS, has proven their efficacy over the years in the treatment of OAB. [3, 9, 13] However, similar to other $O A B$ treatment modalities, long term therapy adherence is poor and alternative treatment options are scarce. Mostly, OAB patients stop therapies because of side effects or lack of efficacy on the longer-term. $[11,14]$ In our view this is also the case for TTNS in a real life setting. Limitations of our study are the number of patients which were included and single center study. As shown in Figure 2B there could be some differences between $O A B$ categories. However our numbers were to low and this poses a limitation on reaching a solid conclusion. Hopefully, a more patient tailored, minimally invasive treatment modality could enhance the persistence and adherence among the current OAB treatment modalities in the future. Currently, developments for tibial nerve stimulation by implantable devices are therefore of interest. [15-17]

\section{CONCLUSION}

Although many publications report positive effect of TTNS on patients suffering from $O A B$ in short term follow up, TTNS in the long-term is not that effective in real life. In combination with a low satisfaction rate, the need for other OAB treatments is still persistent. In order to appreciate the value of treatment modalities, also for $\mathrm{OAB}$, more research in the real-world setting is needed. 


\section{REFERENCES}

1. Abrams, P., et al., The standardisation of terminology of lower urinary tract function: report from the Standardisation Sub-committee of the International Continence Society. Am J Obstet Gynecol, 2002. 187(1): p. 116-26.

2. Gormley, E.A., et al., Diagnosis and treatment of overactive bladder (nonneurogenic) in adults: AUA/SUFU guideline. J Urol, 2012. 188(6 Suppl): p. 2455-63.

3. Peters, K.M., et al., Randomized trial of percutaneous tibial nerve stimulation versus Sham efficacy in the treatment of overactive bladder syndrome: results from the SUmiT trial. J Urol, 2010. 183(4): p. 1438-43.

4. van der Pal, F., et al., Percutaneous tibial nerve stimulation in the treatment of refractory overactive bladder syndrome: is maintenance treatment necessary? BJU Int, 2006. 97(3): p. 547-50.

5. Manríquez, V., et al., Transcutaneous posterior tibial nerve stimulation versus extended release oxybutynin in overactive bladder patients. A prospective randomized trial. European Journal of Obstetrics \& Gynecology and Reproductive Biology, 2016. 196: p. 6-10.

6. Martin-Garcia, M. and J. Crampton, A single-blind, randomized controlled trial to evaluate the effectiveness of transcutaneous tibial nerve stimulation (TTNS) in Overactive Bladder symptoms in women responders to percutaneous tibial nerve stimulation (PTNS). Physiotherapy, 2019. 105(4): p. 469-475.

7. Leroux, P.-A., et al., Transcutaneous tibial nerve stimulation: 2 years follow-up outcomes in the management of anticholinergic refractory overactive bladder. World Journal of Urology, 2018. 36(9): p. 1455-1460.

8. Ramírez-García, l., et al., Efficacy of transcutaneous stimulation of the posterior tibial nerve compared to percutaneous stimulation in idiopathic overactive bladder syndrome: Randomized control trial. Neurourol Urodyn, 2019. 38(1): p. 261-268. 
9. Booth, J., et al., A feasibility study of transcutaneous posterior tibial nerve stimulation for bladder and bowel dysfunction in elderly adults in residential care. J Am Med Dir Assoc, 2013. 14(4): p. 270-4.

10. Schreiner, L., et al., Randomized trial of transcutaneous tibial nerve stimulation to treat urge urinary incontinence in older women. Int Urogynecol J, 2010. 21(9): p. 1065-70.

11. te Dorsthorst, M.J., J.P.F.A. Heesakkers, and M.R. van Balken, Long-term real life adherence of percutaneous tibial nerve stimulation in over 400 patients. Neurourology and Urodynamics, 2020. 39(2): p. 702-706.

12. Sirls, E.R., et al., Percutaneous Tibial Nerve Stimulation in the Office Setting: Real-world Experience of Over 100 Patients. Urology, 2018. 113: p. 34-39.

13. Peters, K.M., et al., Percutaneous tibial nerve stimulation for the long-term treatment of overactive bladder: 3-year results of the STEP study. J Urol, 2013. 189(6): p. 2194-201.

14. D'Souza, A.O., et al., Persistence, adherence, and switch rates among extended-release and immediate-release overactive bladder medications in a regional managed care plan. J Manag Care Pharm, 2008. 14(3): p. 291-301.

15. MacDiarmid, S., et al., Feasibility of a Fully Implanted, Nickel Sized and Shaped Tibial Nerve Stimulator for the Treatment of Overactive Bladder Syndrome with Urgency Urinary Incontinence. J Urol, 2019. 201(5): p. 967-972.

16. te Dorsthorst, M., et al., 3-Year Follow-Up, of a New Implantable Tibial Nerve Stimulator for the Treatment of Overactive Bladder Syndrome (OAB). J Urol, 2020: p. 101097ju0000000000001024.

17. Sievert, K.D., et al., New novel chronic tibial neuromodulation (CTNM) treatment option for OAB significantly improves urgency (UI)/urge urinary incontinence (UUI) and normalizes sleep patterns: Initial results. European Urology, Supplements, 2017. 16 (3): p. e994. 
17

$\nabla \Delta$

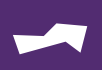


$\Delta$

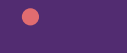

at

ata

.

$2:$

$2:$

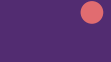




\section{ABSTRACT}

Background: To evaluate the long term follow up in terms of safety and usability of the Urgent-SQ system (implantable tibial nerve stimulator) in patients without strict study regime and absence of follow up by the sponsor.

Materials \& Methods: Between 2002 and 2004 eight patients were implanted with the Urgent-SQ system. Seven patients were included in previous follow up studies. One patient had loss of efficacy before 1 year of follow up. During this study, all patients who were included in the previous follow-up studies $(n=7)$ were contacted to be interviewed regarding efficacy, usability and safety.

Results: Five out of seven patients were available for assessment, mean age was 72 years (range 65-82). Two patients were considered lost to follow up. None of the interviewed patients reported safety issues, new adverse events or local discomfort. One of the patients was able to visit the hospital for efficacy. However, treatment could not be performed due to deficiency of the external or internal component. All patients did not perform self-stimulation anymore due to external stimulator deficiency $(n=2)$ or loss of effect $(n=3)$.

Conclusion: 18 year follow up of the Urgent-SQ implant demonstrates a high safety profile. However, efficacy after 18 years is lacking in $60 \%$ whereas in $40 \%$ the therapy cannot be applied because the external stimulator is deficient. In addition to effectiveness and safety assessment, producers should find a solution for long term continuation of technical support. This will increase the lifespan of the implant and allows the patient to continue the treatment.

Keywords: Overactive bladder (OAB), implant, tibial nerve stimulator, incontinence, urge 


\section{INTRODUCTION}

Overactive bladder syndrome (OAB) is a condition characterized by "urinary urgency, often accompanied with frequency and nocturia, with or without urgency urinary incontinence in the absence of proven infection or other obvious pathology" according to the ICS terminology. [1] The prevalence of OAB is rising with age and approximately $43 \%$ of women 40 years and older do have signs of OAB. Besides, women are twice as likely affected by OAB. $[2,3]$

In the treatment of $O A B$, percutaneous electrical stimulation of the tibial nerve (PTNS) is one of the regular third line therapies after behavioral therapy and medication. PTNS efficacy was proven in sham-controlled studies and has efficacy ranges between 55\%-80\%. [4-6] Since a few years implantable tibial nerve stimulators have been developed by several companies. However, the first pilot study with a tibial nerve implant was already performed between 2002 and 2004 with the so called Urgent-SQ device.

The Urgent-SQ system consists of an external stimulator and an internal body. The external stimulator is an external electromagnetic pulse generator and has radiofrequency transmission. The internal body of the Urgent-SQ is without battery and consist of an electromagnetic pulse receiver and a body with two leads containing monopolar electrodes (figure 1.). [7] It was derived from the Finetech Brindley device used for sacral anterior root stimulation. The first study was performed by van der Pal et al. During this study the main focus was the effect of a tibial implant on $O A B$ symptoms. Long-term data on tibial nerve stimulation for $O A B$ were not available at that time.
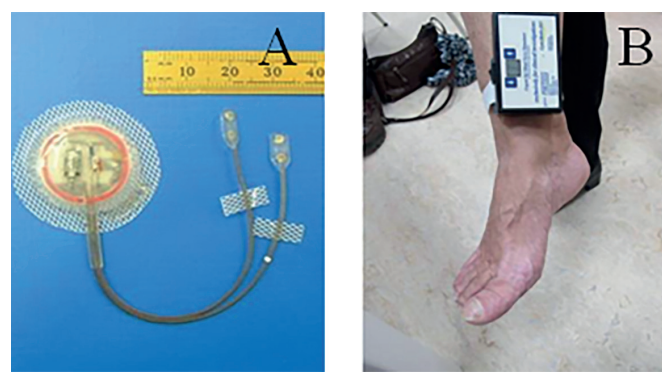

Figure 1a. Internal body with electromagnetic pulse receiver. Figure $1 b$ Position of the external stimulator with electromagnetic pulse generator on the ankle. [1] 
Results published by van der Pal were promising. The 1 year follow up demonstrated significant improvement of voiding parameters and quality of life. [8] Subsequently, the 9 year follow up study by Janssen et al. demonstrated the high safety profile of the Urgent-SQ system. This open label study reported that 3 patients were still using the system. Six of the seven patients still had sensory and loco-motor responses on stimulation when tested. [7]

However, the patients who were included in the study between 2002 and 2004 , still had the implant in place and theoretically could make use of it, if there was still a positive response on stimulation and the external stimulators was still functioning properly. The aim of this study is to assess the long term safety and usability of the Urgent-SQ system (implantable tibial nerve stimulator) in patients without a strict study regime and absence of follow up by the industry and caretakers.

\section{PATIENTS \& METHODS}

In total, eight patients underwent an implantation procedure with the Urgent-SQ between 2002 and 2004. One of the implanted patients had unexplainable loss of efficacy after 6 months of follow up. This patient underwent an explantation of the implant, was dropped out of all studies and was considered unsuccessful. [8]

This 18 year follow up study included the seven patients who still had their implant in situ and were also included in the previous 1-year and 9 year follow up studies as reported before. [7,8] The hospital's local ethical committee approved the study.

During this study, patients were interviewed through a standardized discussion with a physician by phone. This discussion consisted of questions regarding efficacy, durability and safety of the Urgent-SQ system. Table 1. summarizes the questions patients were asked. Results were compared to the former published papers (1-year and 9 year follow up). In addition, patients who reported sensory and loco-motor responses at 9 year follow up $(n=3)$ were asked to visit the hospital. During this visit physical examination was performed including stimulation of the implant with FineTech-Brindley External Controller@ due to absence of the original Urgent-SQ external controller. 
Do you still use the Urgent-SQ implant? If not, since when?

What is the reason for not using the implant anymore?

Did you concern any safety issues the past years? (i.e. explantation)

Do you have any walking or mobility difficulties?

Do you experience any pain or discomfort at the site of the implant?

Can you see or palpate the implant?

Table 1. Primary subjective outcomes of safety and daily life usability of the Urgent-SQ device.

\section{RESULTS}

Results were obtained from 5 of 7 patients (60\% female). Mean age of these patients at 18 years follow up was 72 years \pm 8 (range 65-82). The two other patients could not be contacted and were considered lost to follow up. Both patients were responders after 1 year of follow up and one of them was still using the system at 9 year follow up.

All five patients, included in this follow up study, did not use the system anymore due to external stimulator deficiency $(n=2)$ or loss of effect $(n=3)$. Patients who reported external stimulator deficiency were satisfied with the treatment and used it frequently until deficiency. After quitting the therapy the complains of urge/ urge-incontinence increased again in all patients $(n=5)$. Patients are on different treatment nowadays varying from botulin toxin $A$ injections, to medication or alternative medicine. Only patient 2 (Table 2.) was able to visit the hospital. During physical examination the implant was not visible from the outside. Palpation of the ankle and implant area was not painful. Unfortunately, we did not see any sensory and/or loco-motor responses during test stimulation.

Regarding safety, all patients $(n=5)$ reported no explantations or other surgical interventions during the extended follow up period. Other serious adverse events or adverse event due to the implant, external stimulator or implant procedure were not mentioned. Patients did not report any local problems at the site of the implant. None of the patients had problems with discomfort or pain at the implant site during resting state, nor during walking/ exercises. Most of the patients $(3 / 5)$ could feel the implant from the outside, but could not see the implant. During palpation by themselves, no patient reported any pain or discomfort. These results are largely in line with the published 9 year follow up data. There was one patient who reported sporadic spontaneous sensory response during 9 year follow up, 
but this was not reported during the present study. Table 2 shows an evaluation of the results regarding response, pain and patients who still use the Urgent-SQ system comparing to 1 year and 9 year follow up studies.

\begin{tabular}{|c|c|c|c|c|c|c|c|c|c|c|c|}
\hline & \multirow{2}{*}{ Sex } & \multirow[t]{2}{*}{ Age* $^{*}$} & \multicolumn{3}{|c|}{1 year follow up } & \multicolumn{3}{|c|}{9 year follow up } & \multicolumn{3}{|c|}{18 year follow up } \\
\hline & & & Response & Pain & $\begin{array}{l}\text { In } \\
\text { use }\end{array}$ & Response & Pain & $\begin{array}{l}\text { In } \\
\text { use }\end{array}$ & Response & Pain & $\begin{array}{l}\text { In } \\
\text { use }\end{array}$ \\
\hline P1 & $M$ & 66 & + & - & + & + & - & - & $\mathrm{n} / \mathrm{a}$ & - & $-A$ \\
\hline P2 & $\mathrm{F}$ & 82 & + & - & + & + & - & + & - & - & - B \\
\hline P3 & $\mathrm{F}$ & 83 & + & - & + & - & - & - & $\mathrm{n} / \mathrm{a}$ & $\mathrm{n} / \mathrm{a}$ & $\mathrm{n} / \mathrm{a}$ \\
\hline P4 & $\mathrm{F}$ & 63 & + & - & + & + & - & + & $\mathrm{n} / \mathrm{a}$ & $\mathrm{n} / \mathrm{a}$ & $\mathrm{n} / \mathrm{a}$ \\
\hline P5 & $M$ & 67 & + & - & + & + & - & $-c$ & $\mathrm{n} / \mathrm{a}$ & - & $-A$ \\
\hline P6 & $\mathrm{F}$ & 65 & - & - & - B & - & - & - B & - & - & - B \\
\hline P7 & $\mathrm{F}$ & 79 & + & - & + & + & - & + & $\mathrm{n} / \mathrm{a}$ & - & $-A$ \\
\hline P8 & $\mathrm{F}$ & 81 & - & - & - & - & - & - & - & - & - \\
\hline
\end{tabular}

Table 2. Primary outcomes of pain, response and durability of use of the Urgent-SQ device during past studies.

*Age during 18 year follow up moment.

A: Treatment not effective anymore

B: Device deficiency

c: Started treatment again after 9 year follow up control

$P 3$ and P4 were considered lost to follow up in the present study.

P6 had unexplained loss of efficacy within 1 year after implantation;

$P 8$ was explanted after 1 year of $F U$ 


\section{DISCUSSION}

In this study, the primary goal was to evaluate the long term effect of tibial nerve stimulation by an implant on OAB symptoms in terms of safety and usability of the experimental Urgent-SQ implant. Patients $(n=5)$ reported no (serious) adverse events during follow up period.

Firstly, none of the patients $(\mathrm{n}=5)$ who were included in this study reported any complaints or discomfort at the implant site. Therefore, we conclude that the Urgent-SQ is a well-tolerated implant on the longer term.

Secondly, we wanted to evaluate the fate of patients and implants after terminating follow up because of a study protocol by clinicians and without support from industry. In this small group of patients efficacy of the device was lacking because of technical failure of the external device $(40 \%)$ or because of lack of proper response. Patient 2 did not have sensory and/or loco-motor responses during this study visit, however the reason for failure is unclear. This may have to do with lack of physiological response of the patient e.g. because of fibrotic tissue. Another reason is breakdown of internal components of the implant (i.e., leads or electromagnetic pulse receiver) or because stimulation of the implant was not done with the original external stimulator. The Urgent-SQ external stimulator used the same, but simplified, technology as the Brindley external stimulator.

The absence of long term technical support after the initial study period raises two concerns. Firstly, the inability to unravel the cause of the non-functioning. Secondly, the absence of spare parts or new components to continue treatment in patients who responded earlier without technical failures of the device.

All patients did subjectively report a worsening of symptoms after technical failure of the external stimulator. Comparing these results to other devices with longer follow up periods as well, we do see a large difference in efficacy outcome. [9,10] Peeters et al. reported a 41\% (88/217) re-intervention rate in their long term SNM (sacral neuromodulation) study after a median follow up of 4 years only. In our follow up study $(n=5)$ we mentioned 2 patients (40\%) who did respond to the therapy on the longer term, but had to quit because of external stimulator deficiency. Nevertheless, it is hard to combine these results, because of differences in technical specificities of the devices, number of patients and study designs. Moreover, SNM components and support are part of an established and 
commercially available therapy providing more possibilities to analyze and update the system technically.

The advantages of home-based treatment for OAB with a tibial implant could not be confirmed by this study beyond 9 years. The reason perhaps is the open label follow up study, without technical support and with a small number of patients that finally were not lost to follow up.

In addition, the longevity of the tibial implant including the external components should be one of the main concerns for newer implanted PTNS devices. Recently, a pilot study confirmed the efficacy and improvement in quality of life on the longer term follow up (3-year) of a new tibial nerve implant.[11] For the future, a larger trial is needed to confirm first of all the theoretical benefits regarding home based tibial nerve stimulation by an implant in terms of effectivity and safety in the first years of follow up. Secondly, and probably of even more importance, long-term technical support should be guaranteed by the sponsor to provide patients the opportunity to benefit from treatment as long as possible. Recently, the European Union has revised the legal framework regarding medical devices. Since May 2021 the Medical Devices Regulation (MDR) is replacing the Medical Device Directives (MDD). The primary goal is to increase safety and effectiveness among others by reinforcing surveillance and management of the entire medical device. Risk management is defined as a continuous iterative process throughout the entire lifecycle of a device, requiring regular systematic updating. This implies that for medical devices, including neuromodulation implants, there is a shift from one time approval for introduction of the device, to a lifetime checking of safety and functionality. [12] Hopefully, this will extend the safety and longevity of an tibial nerve implant that contributes to patient satisfaction for OAB treatments in the longer term. It can also save costs in the long run which is also very relevant. [13] Moreover, guaranty of long-term support will encourage patients to participate in future studies. 


\section{CONCLUSION}

This paper demonstrates the long term follow up of the Urgent-SQ implant. It shows a high safety profile without any new adverse or serious adverse events during the maximum 18 year follow up period. Technical failure of the external stimulator (40\%) is the dominant factor of therapy failure beyond 9 years. Longterm technical support should be guaranteed by manufacturers who introduce implantable devices. In addition to assessment of effectiveness and safety for introduction of device, we need a plan for the period after the study in the context of patient follow up and continuing technical support. 


\section{REFERENCES}

1. Haylen BT, de Ridder D, Freeman RM, et al. An International Urogynecological Association (IUGA)/International Continence Society (ICS) joint report on the terminology for female pelvic floor dysfunction. International urogynecology journal. 2010 Jan;21(1):5-26.

2. Coyne KS, Sexton CC, Bell JA, et al. The prevalence of lower urinary tract symptoms (LUTS) and overactive bladder (OAB) by racial/ethnic group and age: results from OAB-POLL. Neurourology and urodynamics. 2013 Mar;32(3):230-7.

3. Onukwugha E, Zuckerman IH, McNally D, et al. The total economic burden of overactive bladder in the United States: a disease-specific approach. Am J Manag Care. 2009 Mar;15(4 Suppl):S90-7.

4. Govier FE, Litwiller S, Nitti V, et al. Percutaneous afferent neuromodulation for the refractory overactive bladder: Results of a multicenter study. Journal of Urology. 2001;165(4):1193-1198.

5. Peters KM, Carrico DJ, Perez-Marrero RA, et al. Randomized Trial of Percutaneous Tibial Nerve Stimulation Versus Sham Efficacy in the Treatment of Overactive Bladder Syndrome: Results From the SUmiT Trial. Journal of Urology. 2010 Apr;183(4):1438-1443.

6. Vandoninck V, Van Balken MR, Finazzi Agro E, et al. Posterior tibial nerve stimulation in the treatment of urge incontinence. Neurourology and urodynamics. 2003;22(1):17-23.

7. Janssen DA, Farag F, Heesakkers JP. Urgent-SQ implant in treatment of overactive bladder syndrome: 9-year follow-up study. Neurourology and urodynamics. 2013 Jun;32(5):472-5.

8. van der Pal F, van Balken MR, Heesakkers JP, et al. Implant-Driven Tibial Nerve Stimulation in the Treatment of Refractory Overactive Bladder Syndrome: 12-Month Follow-up. Neuromodulation. 2006 Apr;9(2):163-71.

9. Brindley GS, Rushton DN. Long-term follow-up of patients with sacral anterior root stimulator implants. Paraplegia. 1990 Oct;28(8):469-75. 
10. Peeters K, Sahai A, De Ridder D, et al. Long-term follow-up of sacral neuromodulation for lower urinary tract dysfunction. BJU international. 2014 May;113(5):789-94.

11. te Dorsthorst M, Digesu GA, Tailor V, etal. 3-Year Follow-Up, of a New Implantable Tibial Nerve Stimulator for the Treatment of Overactive Bladder Syndrome (OAB). The Journal of urology. 2020 Apr 9:101097ju0000000000001024.

12. UNION TEPATCOTE. REGULATION (EU) 2017/745 OF THE EUROPEAN PARLIAMENT AND OF THE COUNCIL of 5 April 2017 on medical devices, amending Directive 2001/83/EC, Regulation (EC) No 178/2002 and Regulation (EC) No 1223/2009 and repealing Council Directives 90/385/EEC and 93/42/ EEC. Official Journal of the European Union. 2017 26th of may 2021.

13. Ganz ML, Smalarz AM, Krupski TL, et al. Economic costs of overactive bladder in the United States. Urology. 2010 Mar;75(3):526-32, 532.e1-18. 
47

$>\Delta$

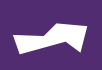

$\gamma$
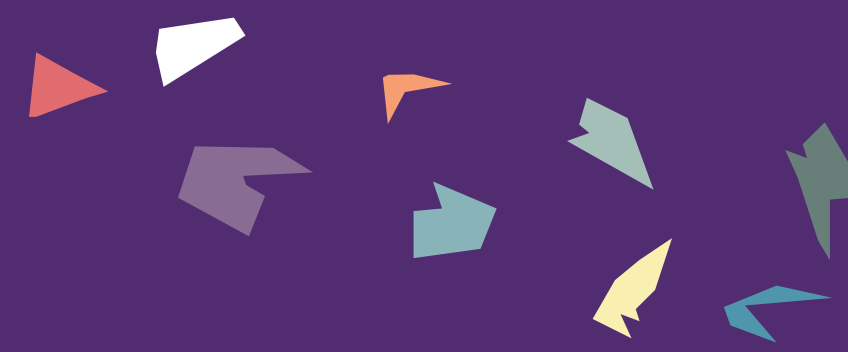

$\Delta$

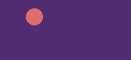

a

$\circ$

.

$\circ \circ$

$\circ$

$\circ \circ$

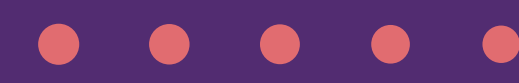

$\begin{array}{lllllllll}0 & 0 & 0 & 0 & 0 & 0 & 0 & 0\end{array}$

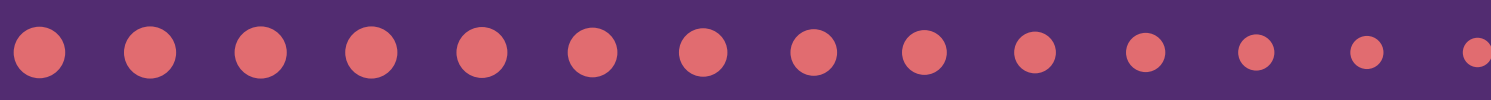

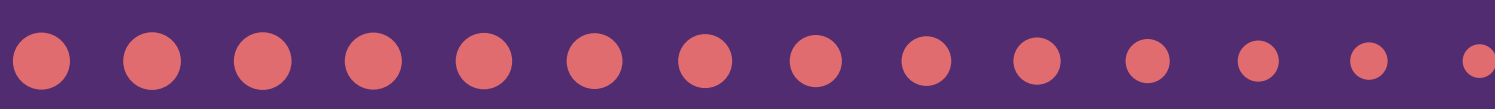

000000000000.

(1)
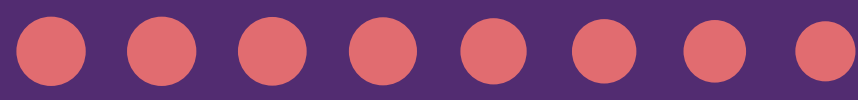

\section{Auteurs:}

Te Dorsthorst MJ, van Balken MR, Heesakkers JPFA.

\section{Tijdschrift:}

Curr Opin Urol. 2020 Jul;30(4):513-518. 


\section{ABSTRACT}

Purpose of review: Overactive Bladder Syndrome (OAB) is a chronic condition which can be treated by tibial nerve stimulation. This review will focus on the technical aspects, advantages, drawbacks and limitations of the latest available applications of posterior tibial nerve stimulation.

Recent findings: We describe the technical aspects of recent developed implants and techniques of tibial nerve stimulation in a transcutaneous, percutaneous and minimal invasive way. All different treatment options have advantages and disadvantages based on type of surgery, energy transfer, impedance, treatment setting options, risk of migration and patient usability which are described in this review. Only devices with data that are publically available were included.

Summary: New technologies are on their way in the field of tibial nerve stimulation for the treatment of OAB. Technical aspects are important to demonstrate safety and efficacy and user friendliness in order to obtain high acceptance of the various devices. 


\section{INTRODUCTION}

Overactive Bladder Syndrome (OAB) is a chronic condition which has for patients a large social burden. It is a problem which affects the quality of life of patients significantly and comes with large financial costs for patients and our healthcare system. $[1,2]$ According to the ICS terminology patients with OAB have urinary urgency, usually accompanied by frequency and nocturia, with or without urgency incontinence, in the absence of urinary tract infection or other obvious pathology. [3]

OAB can be treated by tibial nerve stimulation. Acupuncture is perhaps the oldest form of neuromodulation since the practice of stimulating energy streams comes very close to genuine tibial nerve stimulation. $[4,5]$ This technique was introduced more than 2000 years ago in Chinese medicine. [5] Wilhelmus Ten Rhyne was the first physician who published about this way of treatment in his "Dissertatio de Arthritide: Mantissa Schematica: De Acupunctura: Et orationes tres." During this treatment with fine needles on certain pre-established points, one tries to restore the "energetic harmony" by stimulating the Sanyinjiao point (SP-6). [6] In case of tibial nerve stimulation the tibial nerve is stimulated most likely at exactly the same spot as SP-6. It is likely that with electro-acupuncture, the same physiological effects are obtained as with posterior tibial nerve stimulation. [7]

This review will focus on the technical aspects, advantages, drawbacks and limitations of the latest available applications of posterior tibial nerve stimulation. We will investigate the ideal form of tibial nerve stimulation based on latest applications. The ideal form of tibial nerve stimulation is in our opinion home-based treatment and easy to operate for the patient. An implant, from our point of view should be easy to implant and should have an external energy source. Preferable, the implant has a long lifespan without surgical re-interventions, no leads and a minimal chance of migration. Moreover there should be no interference with other diagnostics or treatments and accessible in terms of costs of the treatment. 


\section{PERCUTANEOUS TIBIAL NERVE STIMULATION}

Since the introduction of Percutaneous Tibial Nerve Stimulation (PTNS) in 1999, a lot of studies evaluated the efficacy and therapeutic outcomes of PTNS in the treatment of $\mathrm{OAB}$. During the past years the way of performing the treatment has not been changed. Pulse width and frequency are fixed, respectively at $200 \mu$ s and $20 \mathrm{~Hz}$. However, pulse intensity can be changed during treatment up to 9mA.[8]

Most studies are performed by using the Urgent $\mathrm{PC}{ }^{\circledR}$ system. However recently Kobashi et al. published their data about a new minimally invasive option using the NURO system (Medtronic, Minneapolis, MN). In their single arm study they investigated the efficacy of PTNM (percutaneous tibial neuromodulation) after 12 weekly sessions (30 minutes). [9] They included 121 patients in their study (mean age 64.8), 116 patients completed all 12 sessions. UUI (urge urinary incontinence) episodes decreased significantly with 2.4 after 12 sessions. A UUI responder rate (defined as $>50 \%$ reduction in UUI episodes comparing to baseline) of $77.6 \%$ was shown and a complete continence rate of $39.7 \%$. There were no serious adverse events noted. Adverse events mentioned were mainly device site pain $(3.3 \%, 4 / 121)$ and pain in the extremity $(3.3 \%, 4 / 121)$. [9] Parameter settings were not included in the published data.

Similar to the Urgent-PC, the NURO system, still holds the main disadvantage of the time investment for the patients. First, patients have to undergo 12 weekly treatments, followed by maintenance treatments depending on their clinical symptoms. Typically, maintenance PTNS is performed once a month in the hospital, as PTNS cannot be done by patients in their own environment. [10] Another objection for patients could be the "needle" in the ankle during every treatment.

However, recent research from Cardozo et al. describes patient's preferences in the treatment of refractory overactive bladder. In their study they found that $98 \%$ of their study population ( $n=127$ ) was willing to try PTNS and that in $57 \%$ PTNS was the most preferred therapeutic option after oral medication, compared to $34 \%$ for sacral neuromodulation and $9 \%$ for Botulin toxin injection. [11] 


\section{TRANSCUTANEOUS TIBIAL NERVE STIMULATION}

\section{GEKO}

The GEKO ${ }^{{ }^{\top m}}$ (Firstkind Limited, Buckinghamshire, UK) was introduced as a selfapplicating skin-adhering ambulatory device. The tibial nerve is transcutaneous stimulated like with TENS however the GEKO is self-applicating which increases the mobility of patients during treatment comparing to other TENS systems. It was originally developed for the prevention of deep vein thrombosis. [12, 13] Recently fecal incontinence and OAB have been studied in a pilot trial exploring outcomes. [14] In this open label OAB study, patients were randomized between once daily or once weekly treatment sessions of 30 minutes. The area of stimulation was 5 centimeters cephalad to the medial malleolus. The parameters during treatment were set at an amplitude of $27 \mathrm{~mA}$ and a frequency of $1 \mathrm{~Hz}$. The pulse width was increased between 70 and $560 \mu$ s (7 settings). [14]

Seth et al. reported a responders rate of $53 \%$ based on Global Response Assessment (GRA) and International Consultations on Incontinence Questionnaires (ICIQ-OAB and ICIQ-LUTS). In their 3-day voiding diary outcomes they did not show any significant difference between their groups (weekly treatment versus daily). Number of leakages in their combined group decreased to 1.3/24h after 12 weeks of treatment versus $2.5 / 24 \mathrm{~h}$ at baseline.

The advantage of the system is the non-invasive nature and high rates of patient satisfaction in usability terms. [14] Disadvantages of this modality may be the fixed parameter settings and the loss of efficacy because of higher impedance of the skin. Besides, patients have to attach the device by themselves which can lead to suboptimal positioning and less effective treatment.

Further investigation of this system's efficacy in the field of OAB is warranted to compare the GEKO system to other published treatment modalities and controls.

\section{TIBIAL NERVE IMPLANTS FOR TREATMENT OF OAB}

\section{BLUEWIND RENOVA SYSTEM}

The Bluewind RENOVA system is a wireless battery-free tibial nerve stimulation system. The system consists of three components: implant, external control unit (ECU) and clinician programmer (CP). Patients are provided with the stimulator, a $25 \mathrm{~mm}$ implant with small fixating wings to prevent migration of the implant. 
The implant is fixated near the tibial nerve, in an open surgical procedure under local anesthesia. Following recovery, the CP is used to program the ECU for treatment. Patient specific treatment set-up can be selected by the clinician based on motor and/or sensory response to optimize therapeutic outcome. Treatment set-up can be set with a pulse width of between 50 and 800 microseconds, a frequency of up to $40 \mathrm{~Hz}$, and an amplitude range of 0 to $9 \mathrm{~mA}$. Patients wear the ECU only during treatment sessions. The ECU provides the implant with the energy needed (closed-loop system) for treatment and allows the patient to adjust the amplitude in a range between the minimum and maximum tolerable level set by the clinician. $[15,16]$

In a first study a response rate of $71 \%$ during 6 months FU period was described. One procedure related serious adverse event occurred that lead to explantation of the device. Recently, 3-year results were published. Seventy-five percent of the patients who continued in an extended study were still responders after 36-months post system activation. [17]

Advantage of the Bluewind RENOVA system is the closed loop system. As far as we know it is the only system which uses a closed-loop which ensures the transferred energy from ECU to implant is stable during treatment sessions. Another advantage of the system is a decreased risk of migrations is less because of the suture holes near the implant and its size.

Disadvantage of the system is the open surgery procedure. Compared to other percutaneous or injectable implants the open procedure, although minimally invasive, is more invasive than its counterparts.

\section{BIONESS STIMROUTER}

The Bioness Stimrouter Neuromodulation system was initially intended for use in chronic pain patients. This device can be easily implanted under local anesthesia near the desired peripheral nerve. [18, 19] The Bioness Stimrouter consists of a specially crafted lead that is transcutaneous powered by an external pulse transmitter (EPG). The implanted lead contains a receiver, electrodes and anchoring system. [19] During implantation ultrasound or fluoroscopic imaging may be used to assist lead placement of the stimulation probe which is used to perform a test stimulation in order to insure correct targeting of the peripheral nerve. After placement confirmation, the introducer set is placed over the stimulation probe and the probe is replaced with the stimulation lead. Finally, the proximal end of the lead is buried subcutaneously $2 \mathrm{~cm}$ from to the desired site of the EPG. [18, 20] 
Patients wear the EPG on the skin during stimulation of the tibial nerve. A patient programmer can be used to change parameter settings and tracks usage. [19] Parameters which were used during the chronic pain study varied with phase duration $7-500 \mu / \mathrm{sec}$, pulse rate $1-200 \mathrm{~Hz}$ and treatment time 10 minutes up to 12 hours. [18] During the chronic pain study no device related SAE were found, however 5 patients had the device explanted due to dissatisfaction with the efficacy, 1 due to development of chronic dermatitis/sensitivity to the electrode patch and 1 lead rejection. [18]

Advantage of the Stimrouter is the minimally invasive surgery to implant the lead designed with anchors to prevent migration. Patients do have only two small incisions in their lower leg. Another advantage of this system is the possibility to add up to eight different treatment/stimulation programs in the patient programmer. Because of this the treatment is patient specific and based on patient's preferences.

Disadvantage of the system is the loss of energy due to the use of surface electrodes for energy transfer. The lead simply transfers the energy from the superficial end (close to EPT) to the electrodes, passively. Therefore, it is likely that the optimal amplitude will have a 5-10 times higher value in daily practice comparing to test stimulation during implantation.

At present, no studies of this neuromodulation system have been published in the field of OAB. A prospective, multi-center, randomized, double-blinded study is ongoing.

\section{ECOIN}

One of the new implantable neuromodulation devices is the eCoin ${ }^{\circledR}$ (Valencia Technologies Corp., Valencia, California). The implantation of the $\mathrm{eCoin}^{\circledR}$ is a minimal invasive open procedure whereby a leadless and battery powered device is implanted under local anesthesia to the medial aspect of the lower leg. The device is nickel sized in a $23 \mathrm{~mm}$ titanium case (diameter), thickness $2.4 \mathrm{~mm}$.

After implantation the device provides automatically 30-minute treatment sessions every 2 days for 12 weeks. Afterwards, the intensity of treatment is lowered to every 15 days. There is no action from the patient necessary to start a treatment session, the device starts the treatment automatically. During the treatment sessions patients can adjust the amplitude from 0.5-15 mA with an external controller. Other parameters are fixed: 0.2 millisecond pulse width and 20 pulses per second. [21] 
Recently, first 6 months results ( $N=46)$ were published by MacDiarmid et al. During 6 months FU, $67 \%$ of the patients were defined as responders based on their 3-day voiding diary. Eleven of these patients reported during the 6 months FU that they did not experience any UUI episodes anymore. Patients reported an improvement of three folds of the minimal important difference base on the I-QOL and PGI-I at baseline and 6 months FU. [21] Regarding safety issues, Macdiarmid et al. reported 2 cases of explantation of the device. One patient wished to undergo explantation following cellulitis and the second because the patient noted device migration 1 $\mathrm{cm}$ posterior which led to lack of stimulation. [21]

Advantage of this device is the relative short and easy implantation procedure compared to SNM or other devices. The battery powered system could be an advantage because it does not need patient involvement to be powered, which theoretically means $100 \%$ compliance. On the other hand, battery powered means it has to be replaced, which requires additional surgeries for patients - much like sacral neuromodulators, only more frequently due to the small size of the battery.

A disadvantage of the system is the fixed treatment session. Patients can't increase the number of treatment sessions based on their own preferences/worsening of symptoms. The treatment session starts automatically (during maintenance treatment) every 15 days which could also be during a moment the patient is not in the position to undergo treatment. Another disadvantage is the possibility of migration which could lead to decreased stimulation of the tibial nerve. This could be as well a challenge for the future. However long-term results are necessary to confirm efficacy and safety.

\section{STIMGUARD}

Another implantable device is the minimally invasive chronic device of StimGuard LLC $^{\circledR}$. Patients receive an implanted stimulator with embedded receiver through a $5 \mathrm{~mm}$ skin incision. The energy source is a small, external, rechargeable transmitter, which is worn by the patient. The external energy source is connected to an external antennae and is worn near the internal antenna of the implant. [22] The system uses an open-loop system which implies the energy which is given from the wearable to the electrode is stable but not secondarily monitored by the external unit. [23] Patients are asked to use the implant during the night, with a maximum treatment durability of 8 hours. [24] 
First published results were obtained from 2 groups of patients. Group 1 (2014) consisted of 2 male patients with neurogenic lower urinary tract dysfunction. The second group (2016) consisted of 1 male patient with spina bifida and 5 female patients with $\mathrm{OAB}$. Both patients of the first group were completely dry two months post-op. However, both of them quitted because of deterioration of their comorbidity. In one of the patients, the electrode migrated. In the second group $(\mathrm{N}=6)$ five patients reported improvement, UUI episodes decreased from $2.1 /$ day at baseline to $2.5 /$ month at 3 months post-op. One male patient was a non-responder and as result, was excluded due to lack of improvement. [24]

The main benefit of this device is the possibility for patients to have their treatment overnight. However, migration could be a major problem, as noted in this smallscale reporting. Momentarily a study comparing StimGuard CAN-stim versus Medtronic Interstim ${ }^{\circledR}$ is conducted.

\section{CONCLUSION}

In conclusion, new technologies are on their way in the field of tibial nerve stimulation for the treatment of OAB. Table 1 summarizes all devices with their technical specifications, advantages and disadvantages. The new developments focus on small, battery free devices that are easy to operate and can be positioned in the least invasive or non-invasive ways. The activation software should be flexible in fine-tuning and should also be able to give feedback on the use and optimization of the stimulation specifications. Based on our idea of ideal tibial nerve stimulation, we can conclude the ideal implant is not yet found. However, close to ideal based on advantages and disadvantages of the implant are the Bluewind RENOVA $^{\circledR}$ system and the Stimguard ${ }^{\circledR}$. Demonstration of the safety and efficacy on the long-term and in larger scale trials is needed to confirm our conclusion. As well as the benefit of computerized feedback and the possibility to have multiple changeable treatment programs. 


\begin{tabular}{|c|c|c|c|c|c|}
\hline & $\begin{array}{l}\text { GEKO }^{\mathrm{TM}} \\
{[14]}\end{array}$ & $\begin{array}{l}\text { Stimrouter } \\
{[18,19]}\end{array}$ & $\begin{array}{l}\text { eCoin }{ }^{\circledR} \\
{[21]}\end{array}$ & $\begin{array}{l}\text { Bluewind } \\
\text { RENOVA }^{\circledR} \\
{[15,16]}\end{array}$ & $\begin{array}{l}\text { Stimguard }{ }^{\circledR} \\
{[22-24]}\end{array}$ \\
\hline Size & $15 \mathrm{~cm}$ & $15 \mathrm{~cm}$ & $2.3 \mathrm{~cm}$ & $2.5 \mathrm{~cm}$ & $12 \mathrm{~cm}$ \\
\hline $\begin{array}{l}\text { Duration of } \\
\text { stimulation }\end{array}$ & $\begin{array}{l}\text { Daily or } \\
\text { weekly }\end{array}$ & $\begin{array}{l}\text { Up to } 12 \\
\text { hours / day }\end{array}$ & $\begin{array}{l}30 \mathrm{~min} / \\
2-15 \text { days, }\end{array}$ & $\begin{array}{l}30 \text { minutes } \\
\text { tid }\end{array}$ & $\begin{array}{l}8 \text { hours / } \\
\text { day }\end{array}$ \\
\hline $\begin{array}{l}\text { Pulse width } \\
\text { ( } \mu \mathrm{sec})\end{array}$ & $70-560$ & $7-500$ & & $50-800$ & $50-500$ \\
\hline $\begin{array}{l}\text { Pulse } \\
\text { amplitude } \\
\text { (mA) }\end{array}$ & 27 & $1-200$ & $0.5-15$ & $0-9$ & $0-15$ \\
\hline $\begin{array}{l}\text { Pulse rate } \\
(\mathrm{Hz})\end{array}$ & 1 & & & $0-40$ & $2-1500$ \\
\hline $\begin{array}{l}\text { External } \\
\text { component }\end{array}$ & $\begin{array}{l}\text { TENS - } \\
\text { External } \\
\text { pulse } \\
\text { generator } \\
\text { with } \\
\text { adhesive } \\
\text { surface } \\
\text { electrodes. }\end{array}$ & $\begin{array}{l}\text { Adhesive } \\
\text { external } \\
\text { pulse } \\
\text { transmitter. } \\
\text { Patient } \\
\text { programmer. }\end{array}$ & $\begin{array}{l}\text { No external } \\
\text { component. }\end{array}$ & $\begin{array}{l}\text { Wearable } \\
\text { unit with leg } \\
\text { band. }\end{array}$ & $\begin{array}{l}\text { External } \\
\text { device in a } \\
\text { sleeve at the } \\
\text { ankle. }\end{array}$ \\
\hline \multirow[t]{2}{*}{$\begin{array}{l}\text { Energy } \\
\text { transfer }\end{array}$} & \multirow[t]{2}{*}{$\begin{array}{l}\text { Trans- } \\
\text { cutaneous }\end{array}$} & \multirow[t]{2}{*}{$\begin{array}{l}\text { Electrical } \\
\text { field through } \\
\text { surface } \\
\text { electrodes. }\end{array}$} & \multirow[t]{2}{*}{$\begin{array}{l}\text { Battery } \\
\text { powered. }\end{array}$} & $\begin{array}{l}\text { Magnetic } \\
\text { resonance } \\
6.78 \mathrm{MHz} \\
\text { ISM band }\end{array}$ & $\begin{array}{l}\text { Magnetic } \\
\text { resonance } \\
915 \mathrm{MHz} \\
\text { ISM band }\end{array}$ \\
\hline & & & & Closed-loop & Open-loop \\
\hline
\end{tabular}

Table 1. Summary of technical aspects new implantable tibial nerve stimulators. 


\begin{tabular}{|c|c|c|c|c|c|}
\hline & $\begin{array}{l}\text { GEKO }^{\text {TM }} \\
{[14]}\end{array}$ & $\begin{array}{l}\text { Stimrouter } \\
{[18,19]}\end{array}$ & $\begin{array}{l}\text { eCoin }{ }^{\circledR} \\
{[21]}\end{array}$ & $\begin{array}{l}\text { Bluewind } \\
\text { RENOVA }^{\circledR} \\
{[15,16]}\end{array}$ & $\begin{array}{l}\text { Stimguard }^{\circledR} \\
{[22-24]}\end{array}$ \\
\hline \multirow{5}{*}{ Advantage } & $\begin{array}{l}\text { 1. No sur- } \\
\text { gery. }\end{array}$ & $\begin{array}{l}\text { 1. } 8 \text { Tre- } \\
\text { atment } \\
\text { programs. }\end{array}$ & $\begin{array}{l}\text { 1. Operates } \\
\text { automati- } \\
\text { cally. }\end{array}$ & $\begin{array}{l}\text { 1. Tailored } \\
\text { settings. }\end{array}$ & $\begin{array}{l}\text { 1. Treatment } \\
\text { overnight. }\end{array}$ \\
\hline & & $\begin{array}{l}\text { 2. Com- } \\
\text { puterized } \\
\text { feedback on } \\
\text { use. }\end{array}$ & 2. Leadless. & $\begin{array}{l}\text { 2. No migra- } \\
\text { tion. }\end{array}$ & $\begin{array}{l}\text { 2. Tailored } \\
\text { settings. }\end{array}$ \\
\hline & & $\begin{array}{l}\text { 3. No } \\
\text { implanted } \\
\text { battery. }\end{array}$ & & $\begin{array}{l}\text { 3. Com- } \\
\text { puterized } \\
\text { feedback on } \\
\text { use. }\end{array}$ & $\begin{array}{l}\text { 3. No } \\
\text { implanted } \\
\text { battery. }\end{array}$ \\
\hline & & & & 4. Leadless. & \\
\hline & & & & $\begin{array}{l}\text { 5. No } \\
\text { implanted } \\
\text { battery. }\end{array}$ & \\
\hline \multirow{4}{*}{ Disadvantage } & $\begin{array}{l}\text { 1. Fixed am- } \\
\text { plitude and } \\
\text { frequency. }\end{array}$ & $\begin{array}{l}\text { 1. Loss of } \\
\text { energy due } \\
\text { to use of } \\
\text { surface gel }\end{array}$ & $\begin{array}{l}\text { 1. Non-re- } \\
\text { chargeable } \\
\text { battery. }\end{array}$ & \multirow[t]{4}{*}{$\begin{array}{l}\text { 1. Open- } \\
\text { procedure }\end{array}$} & $\begin{array}{l}\text { 1. No } \\
\text { anchoring } \\
\text { system. }\end{array}$ \\
\hline & $\begin{array}{l}\text { 2. High im- } \\
\text { pedance. }\end{array}$ & pads. & $\begin{array}{l}\text { 2. Fixed } \\
\text { stimulation }\end{array}$ & & \multirow{3}{*}{$\begin{array}{l}2 . \text { Long lead } \\
\text { requiring } \\
\text { tunneling. }\end{array}$} \\
\hline & $\begin{array}{l}\text { 3. No com- } \\
\text { puterized } \\
\text { feedback. }\end{array}$ & $\begin{array}{l}2 . \text { Long lead } \\
\text { requiring } \\
\text { tunneling. }\end{array}$ & $\begin{array}{l}\text { parameters } \\
\text { 3. Requires } \\
\text { replacement } \\
\text { surgeries. }\end{array}$ & & \\
\hline & & & $\begin{array}{l}\text { 4. No com- } \\
\text { puterized } \\
\text { feedback on } \\
\text { use }\end{array}$ & & \\
\hline
\end{tabular}

Table 1. Summary of technical aspects new implantable tibial nerve stimulators. 



\section{REFERENCES}

1. Irwin, D.E., et al., Population-based survey of urinary incontinence, overactive bladder, and other lower urinary tract symptoms in five countries: results of the EPIC study. Eur Urol, 2006. 50(6): p. 1306-14; discussion 1314-5.

2. Stewart, W.F., et al., Prevalence and burden of overactive bladder in the United States. World J Urol, 2003. 20(6): p. 327-36.

3. Haylen, B.T., et al., An International Urogynecological Association (IUGA)/ International Continence Society (ICS) joint report on the terminology for female pelvic floor dysfunction. Int Urogynecol J, 2010. 21(1): p. 5-26.

4. Wazir, J., et al., Efficacy of acupuncture in the treatment of chronic prostatitischronic pelvic pain syndrome: a review of the literature. International Urology and Nephrology, 2019.

5. White, A. and E. Ernst, A brief history of acupuncture. Rheumatology, 2004. 43(5): p. 662-663.

6. Langevin, H.M. and J.A. Yandow, Relationship of acupuncture points and meridians to connective tissue planes. Anat Rec, 2002. 269(6): p. 257-65.

7. Minni, B., et al., Bladder instability and enuresis treated by acupuncture and electro-therapeutics: early urodynamic observations. Acupunct Electrother Res, 1990. 15(1): p. 19-25.

8. van Balken, M.R., Percutaneous tibial nerve stimulation: the Urgent PC device. Expert Rev Med Devices, 2007. 4(5): p. 693-8.

9. Kobashi, K., et al., A Prospective Study to Evaluate Efficacy Using the Nuro Percutaneous Tibial Neuromodulation System in Drug-Naive Patients With Overactive Bladder Syndrome. Urology, 2019. 131: p. 77-82.

10. Peters, K.M., et al., Percutaneous tibial nerve stimulation for the long-term treatment of overactive bladder: 3-year results of the STEP study. J Urol, 2013. 189(6): p. 2194-201. 


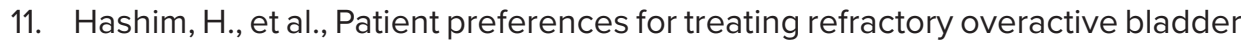
in the UK. Int Urol Nephrol, 2015. 47(10): p. 1619-27.

12. Tucker, A., et al., Augmentation of venous, arterial and microvascular blood supply in the leg by isometric neuromuscular stimulation via the peroneal nerve. Int J Angiol, 2010. 19(1): p. e31-7.

13. Summers, J.A., et al., The geko ${ }^{\text {TM }}$ electro-stimulation device for venous thromboembolism prophylaxis: a NICE medical technology guidance. Applied health economics and health policy, 2015. 13(2): p. 135-147.

14. Seth, J.H., et al., Feasibility of using a novel non-invasive ambulatory tibial nerve stimulation device for the home-based treatment of overactive bladder symptoms. Translational andrology and urology, 2018. 7(6): p. 912-919.

15. Heesakkers, J., et al., A novel leadless, miniature implantable Tibial Nerve Neuromodulation System for the management of overactive bladder complaints. Neurourol Urodyn, 2018. 37(3): p. 1060-1067.

16. van Breda, H.M.K., et al., A New Implanted Posterior Tibial Nerve Stimulator for the Treatment of Overactive Bladder Syndrome: 3-Month Results of a Novel Therapy at a Single Center. J Urol, 2017. 198(1): p. 205-210.

17. te Dorsthorst, M., et al., 3-Year Follow-Up, of a New Implantable Tibial Nerve Stimulator for the Treatment of Overactive Bladder Syndrome (OAB). J Urol, 2020: p. 101097ju0000000000001024.

18. Deer, T., et al., Prospective, Multicenter, Randomized, Double-Blinded, Partial Crossover Study to Assess the Safety and Efficacy of the Novel Neuromodulation System in the Treatment of Patients With Chronic Pain of Peripheral Nerve Origin. Neuromodulation, 2016. 19(1): p. 91-100.

19. Guzman-Negron, J.M. and H.B. Goldman, New Devices and Technologies for the Management of Overactive Bladder. Current Urology Reports, 2017. 18(12): p. 94. 
20. Deer, T.R., J.E. Pope, and M. Kaplan, A novel method of neurostimulation of the peripheral nervous system: The StimRouter implantable device. Techniques in Regional Anesthesia and Pain Management, 2012. 16(2): p. 113-117.

21. MacDiarmid, S., et al., Feasibility of a Fully Implanted, Nickel Sized and Shaped Tibial Nerve Stimulator for the Treatment of Overactive Bladder Syndrome with Urgency Urinary Incontinence. J Urol, 2019. 201(5): p. 967-972.

22. Karl-Dietrich Sievert, T.K., Stefan DeWachter, Novel Chronic Tibial Neuromodulation Treatment Option for Overactive Bladder Significantly Improves Urgency/Urge Urinary Incontinence and Normalises Sleep Patterns: Initial Results. EMJ, 2017(5 [1]): p. 58-60.

23. StimGuard Medical Corporation https://www.stimguard.com/index.html, @ 2019

24. Sievert, K.D., et al., New novel chronic tibial neuromodulation (CTNM) treatment option for $\mathrm{OAB}$ significantly improves urgency (UI)/urge urinary incontinence (UUI) and normalizes sleep patterns: Initial results. European Urology, Supplements, 2017. 16 (3): p. e994. 
17

$\nabla \Delta$

$\sim$

$\checkmark$
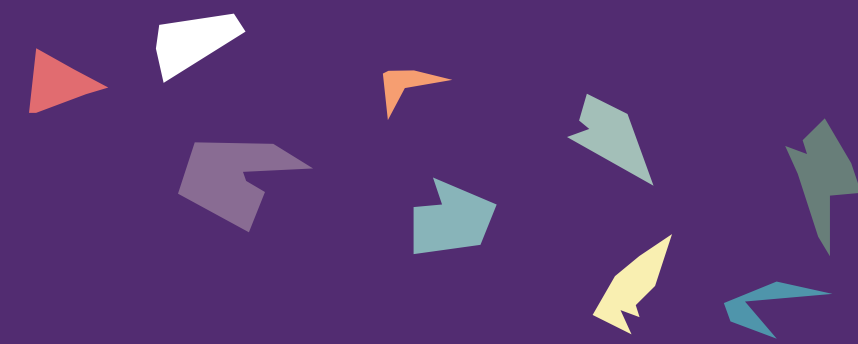

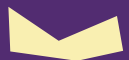

$+\frac{10}{2}$

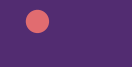

and

:

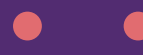

$2: 2$

:

$2: 2$

and

$\circ \circ$

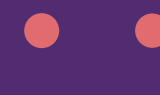

(1)

.

(

$\circ$

$\circ<$

(a)

0

0

$\circ$

$\circ$

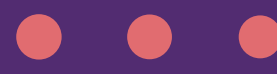

$\circ 0$

000

00

C

0

00

0

$O 0$

0

0

0

0

0

0

0

0

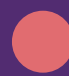

0

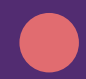

0

0

0
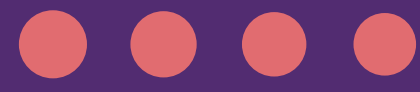

\section{Auteurs:}

Te Dorsthorst MJ, Digesu GA, Tailor V, Gore M, van Kerrebroeck PE, van Breda HMK, Elneil S,

Heesakkers JPFA.

\section{Tijdschrift:}

J Urol. 2020 Sep;204(3):545-550.
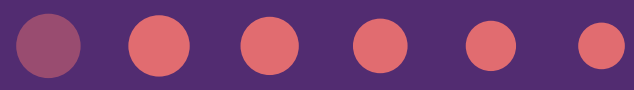


\section{ABSTRACT}

Purpose: The objective of this study was to evaluate the 3-year safety and efficacy of the BlueWind Medical RENOVA ${ }^{\text {tw }}$ iStim system for the treatment of OAB.

Materials and Methods: All patients who were previously implanted with the RENOVA $A^{\text {m }}$ system were offered continued participation. The primary long term study endpoint was to evaluate the safety profile based on incidence of serious adverse events (system and/or procedure related). This was measured by the impact and frequency of serious adverse event (SAE). The secondary endpoints included clinical improvement compared to baseline and quality of life improvement compared to baseline at 36 months. This was measured by 3-day voiding diary and quality of life questionnaires at certain timepoints.

Results: Twenty of the thirty-four OAB patients who were previously implanted with the RENOVA' system have consented to continuation to this 3-year followup study. The mean age was 56.1 years and $80 \%(\mathrm{~N}=16)$ of the study cohort was female. The overall treatment success rate was $75 \%$ at 36 months in both the perprotocol $(n=16)$ and the ITT analyses $(n=20)$. In total, $73 \%$ of the patients reported improvement in $\mathrm{HRQL}$ scores above the minimal important difference of 10 points.

Conclusion: This 3-year follow-up study using the BlueWind RENOVA ${ }^{m}$ iStim system for the treatment of OAB symptoms confirms the long term good safety profile with no technical failures reported. There is lasting efficacy of the treatment mirrored by a sustained positive impact on patients' quality of life. 


\section{INTRODUCTION}

Overactive bladder syndrome (OAB) describes a combination of patient reported symptoms including urinary urgency with or without urinary incontinence, frequency and nocturia. $[1,2] \mathrm{OAB}$ is well known among physicians as a condition which does not always respond to conservative treatments such as behavioral therapy and oral medication. The next line of treatment for refractory OAB can include percutaneous tibial nerve stimulation (PTNS).[3] The exact mechanism of action of PTNS is still unclear. The accepted notion is that PTNS indirectly intervenes in the neural pathways of the lower urinary tract and most likely modulates higher spinal and/or brain reflexes to treat OAB symptoms. [4-6]

PTNS has a success rate of $56-63 \%$ in clinical setting based on voiding diaries, quality of life scores or willingness to continue. [7-10] Patients, however, often have to continue maintenance PTNS treatments to prevent a relapse in symptoms. Once patients quit their PTNS therapy the treatment effects will extinguish over time. [9, 11] This major disadvantage not only burdens the patient but also the healthcare system. It has been reported that a substantial proportion of patients who are treated with maintenance PTNS end their therapy because of physical strain or difficulties with visiting the hospital. [12] An implantable tibial neurostimulation device can overcome the above drawbacks if it can be used by patients in their home environment.

BlueWind Medical has developed a miniature tibial neurostimulator device; RENOVA $^{\text {tm }}$ iStim System, which has already demonstrated a 6 month low risk safety profile and improvement in OAB symptoms and patient quality of life. [2, 13] Long-term data on the use of tibial nerve implants for OAB are scarce. Janssen et al. reported 9-year long-term results of an implantable device for tibial nerve stimulation, initially implanted into 8 patients. [14] Out of these 8 patients 3 patients were still using the device on a regular basis with continued improvement in quality of life compared to baseline after 9 years of follow-up. There are no other published studies on long-term follow-up of implantable tibial nerve devices for the treatment of OAB.

The objective of this study was to evaluate the 3-year safety and efficacy of the BlueWind Medical RENOVA ${ }^{\mathrm{m}}$ iStim system for the treatment of OAB. 


\section{MATERIALS AND METHODS}

This study was designed as a long-term, extension, follow up study of the previously published prospective, self-controlled, interventional study. [2, 13] The study was approved by all ethical committees of the participating centers. All patients who were previously implanted with the RENOVA ${ }^{\text {TM }}$ system were offered continued participation into this 3-year follow-up study after again obtaining informed consent. There were no additional criteria for inclusion into the extended study. Participating patients were re-consented for this extended study 6 to 12 months after reaching the pilot-study endpoint of six months after the initial device activation and therefore first follow-up of patients in this study occurred 18 months post device activation. The extended study started on February 2017 and was completed during July 2018.

The RENOVA ${ }^{\text {Tm }}$ system consists of a wireless miniature implant and a wireless external control unit (non-implantable component). The system transmits electrical pulses to the tibial nerve. The implant has two electrodes, positioned on each of the implant's end. After implantation and a period of healing, the device is activated and the patient performs self-treatment at home with the external control unit (ECU). Implantation of the device has previously been described. [2] During the pilot study, patients were stimulated according to a pre-defined protocol described by Heesakkers et al. and van Breda et al. [2, 13] During the extended follow-up study patients did not treat themselves according to a preconceived protocol but deliberately according to their perceived need to stimulate. The patients decided when and for how long to stimulate but they were given advice based on their symptoms. This more lenient treatment regimen allows demonstrating how individually tailored treatment could be beneficial for patients.

The primary long-term study endpoint was to evaluate the incidence of serious adverse events (system and/or procedure related). This was measured by the impact and frequency of serious adverse event (SAE). The secondary endpoints included clinical improvement and quality of life compared to baseline at 36 months.

The long-term study had scheduled visits at 18, 24, 30 and 36 months post system activation. During these visits patients completed 3-day voiding diaries, and an overactive bladder symptom and health-related quality of life questionnaire (OABq $\mathrm{QOL})$. In addition, stimulation parameters were adjusted and optimized individually at each visit. $[15,16]$ 
Comparison of voiding parameters from a 3-day bladder diary (i.e. voiding, incontinence and urgency related parameters) to baseline results was carried out. Success was defined as $\geq 50 \%$ reduction in the number of leaks/day or number of voids/day or number of episodes with degree of urgency $>2$ or a return to $<8$ voids/day.

Statistical analysis was carried out using IBM SPSS statistics version 25 for all analyses. Descriptive statistics were calculated for the continuous and binary outcomes of interest. The paired t-test were used to find significant differences in continuous outcomes between baseline and each subsequent follow-up until 3 -years follow-up was completed. A p-value $<0.05$ was considered significant. Further, longitudinal analyses - mixed model regression models for continuous outcomes and generalized estimating equations (GEE) for binary outcomes - were performed to confirm results and conclusions, but only the unadjusted results are presented for ease of interpretation. The performance analysis was performed on both the per-protocol (PP) population as well as the intent to treat (ITT) population. The PP population consisted of all subjects with observed data at baseline and 36 months. The ITT population included patients with data from at least long-term follow-up (at 18, 24, 30 or 36 months) and the last observation carried forward (LOCF) technique was applied.

\section{RESULTS}

Twenty of the thirty-four OAB patients who completed the initial study with the RENOVA ${ }^{\text {tm }}$ system have consented to continue to the 3-year follow-up study. The mean age was 56.1 years and $80 \%(\mathrm{~N}=16)$ of the study cohort was female. Sixteen patients (80\%) had symptoms of urgency incontinence (UI) (wet OAB). The median duration of their OAB diagnosis was 8.5 years (range 1-27 years) before starting treatment with the RENOVA ${ }^{\text {m }}$ system. Median Body Mass Index was 26.4 (range 21.9-40.9).

Four patients (20\%), all diagnosed with wet OAB, did not reach the 36-month FU visit and were considered lost to follow-up. For the intent to treat analyses we used the last observation carried forward (LOCF) approach. 
Table 1 demonstrates the similarity between the pilot study cohort (34 patients) and the extended follow-up study cohort. The extended study cohort well represents the initial pilot study population in demographics, baseline OAB parameters, and success rates at 6 months.

\begin{tabular}{lll}
\hline & $\begin{array}{l}\text { Pilot study } \\
\mathbf{N = 3 4}\end{array}$ & $\begin{array}{l}\text { Extended study } \\
\mathbf{N}=\mathbf{2 0}\end{array}$ \\
\hline Overall success rate at 6 months & $71 \%$ & $70 \%$ \\
Wet patients & $29 / 34$ & $16 / 20$ \\
\hline Baseline voids & 12 & 12 \\
\hline Baseline leaks & 6.6 & 6.5 \\
\hline Mean age (years) & 54.1 & 56.1 \\
Gender (female) & $85 \%$ & $80 \%$ \\
\hline
\end{tabular}

Table 1. Demographics and baseline values for both study populations.

During the pilot-study the first follow up of patients was 1 month post activation scheduled and therefore earlier improvements were not monitored/recorded.

Clinically meaningful improvement with Urgent PC is often seen at 6 weeks, when treatment is once a week. [17] With increased treatment frequency, as is in our study, it is expected to demonstrate clinical meaningful results at earlier stage.

The pilot study results were previously published. [2] Briefly, clinical success was reported in $54.5 \%, 64.7 \%$ and $70.6 \%$ at the 1, 3, and 6 months follow-ups, respectively. One procedure related serious adverse event was reported. The patient experienced pain and swelling at the implantation site requiring oral antibiotic treatment. The implant was subsequently removed and the patient discharged with no further sequelae. All adverse events in the pilot study resolved between 1 day to approximately 3 months from their initiation (median: 8 days). [2] During the extended study there were no additional explantations and no serious adverse effects. There was no need for new surgical intervention, no device related events and other long-term complications during the extended study follow-up period.

Treatment success rates were analyzed for the overall impact on $O A B$ symptoms and individually for urinary frequency (UF) and urinary incontinence (UI). The overall treatment success rate was $75 \%$ at 36 months in both the per-protocol 
$(n=16)$ and the ITT analyses $(n=20)$. This result is similar to the overall success rates of the same group at 6 months $(70 \%)$ and to the whole pilot study cohort $(n=34)$ at 6 months (71\%). There is no significant difference from the 6 months in overall efficacy during the extended follow up $(p=0.513)$. (Figure 1.)

A

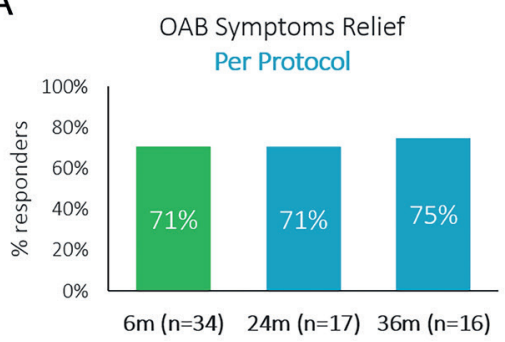

B

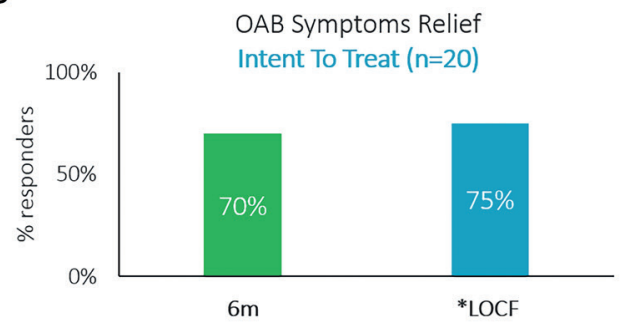

Figure 1. $O A B$ symptoms relief success rates: Figure $1 A$ - per protocol $(P P)$ analysis and $1 B$ - intent to treat (ITT) analysis. * LOCF- Last Observation Carried Forward, Mean follow-up duration of 34 months

In patients with wet $O A B(n=16)$ there was a significant reduction in the number of leaks per day from 6.6 leaks/day at baseline (pre-implantation) to 3.4 leaks/day at 36 months $(p<0.05)$. Pad use significantly decreased in patients with wet $O A B$ from 3.1 /day at baseline versus $1.9 /$ day at 36 months $(p<0.05)$. The average leak severity decreased from 1.79 at baseline to 1.2 at 36 months ( $p<0.05)$. (Figure 2.)

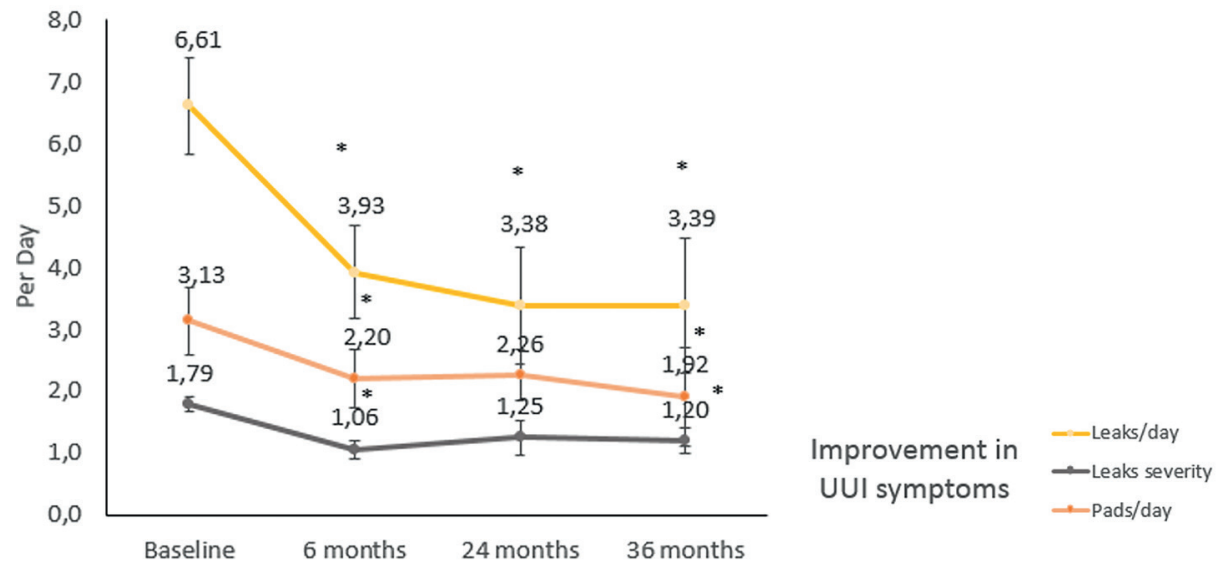

Figure 2. Improvement in wet $O A B$ symptoms during the study period in the per protocol analysis (n=16). * ${ }^{*} p<0.05$ 
The ITT analysis shows that $50 \%$ of wet OAB patients at 6 and 36 months experienced $>50 \%$ reduction in the number leaks per day. Per protocol analysis shows a $52 \%$ and $58 \%$ responders rate at 6 and 36 months respectively. From the wet OAB group, $75 \%$ of patients in the PP analysis and $80 \%$ in the ITT analysis had $>50 \%$ reduction in the number of large volume leaks at 36 months compared to $85 \%$ and $80 \%$ of patients at 6 months. (Figure 3 )
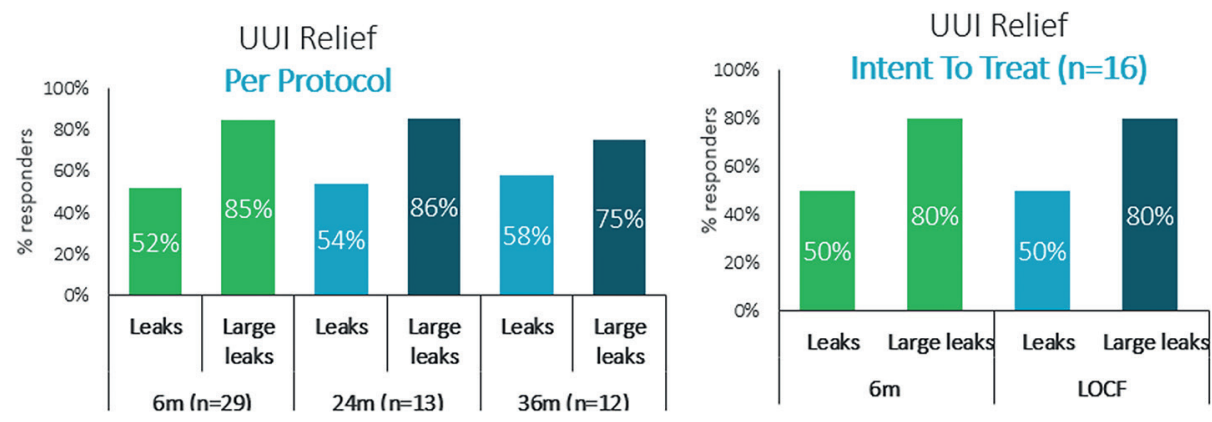

*LOCF- Last Observation Carried Forward, Mean follow-up duration of 34 months

Figure 3. Incontinence responder analysis in wet $O A B$ patients. Figure $3 A-$ per protocol (PP) analysis and $3 B$ - intent to treat (ITT) analysis.

In patients suffering from urgency frequency ( $\mathrm{n}=30$ at $6 \mathrm{~m}$ and $\mathrm{n}=15$ at 36 months) the average voided volume per void was significantly increased, from $162 \mathrm{~mL}$ at baseline to $191 \mathrm{~mL}$ at 36 -month follow up ( $p<0.05$ ). The number of voids per day remained significantly reduced from 12.04 at baseline to 9.35 and 9.38 at 6 and 36 months respectively $(p<0.05$, per protocol analysis, $n=30$ at $6 m$ and $n=15$ at 36 months). The improvement to the severity of urgency was assessed using the number of episodes with a degree of urgency $>2$ per day. This decreased significantly from 7.48 at baseline to 4.47 at 36 months follow up ( $p<0.05)$ (Figure 4). 

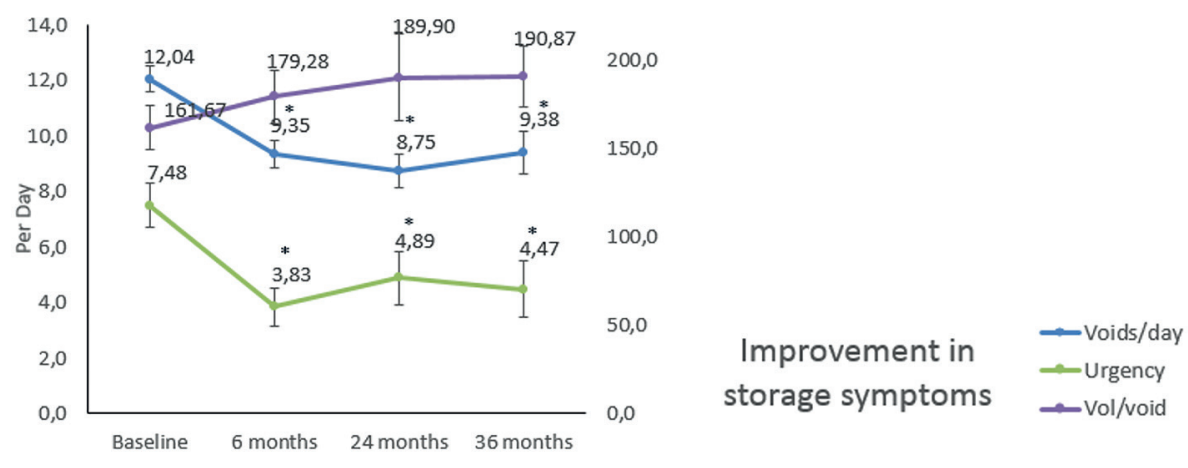

Figure 4. Improvement in storage symptoms in patients suffering from urgency frequency. (n=30 at 6 months, $n=17$ at 24 months and $n=15$ at 36 months) * $p<0.05$

Patients reported improvement in Health Related Quality of Life (HRQL) (Figure 5.) and all its subscales. (Figure 6) During 6-month FU, 75\% of the patients who were enrolled into the extension study reported improvement in HRQL scores above the minimal important difference of 10 points (MID). This effect was sustained during the extended $\mathrm{FU}$ with $73 \%$ of the patients $(\mathrm{n}=15)$ reporting continued improvement above the MID.

In addition, HRQL subscales such as symptom severity, concern and sleep demonstrated a statistically significant improvement at 36 months follow-up visit as compared to baseline $(\mathrm{P}<0.0001)$.

HRQL responders rate responders (>10 MID)

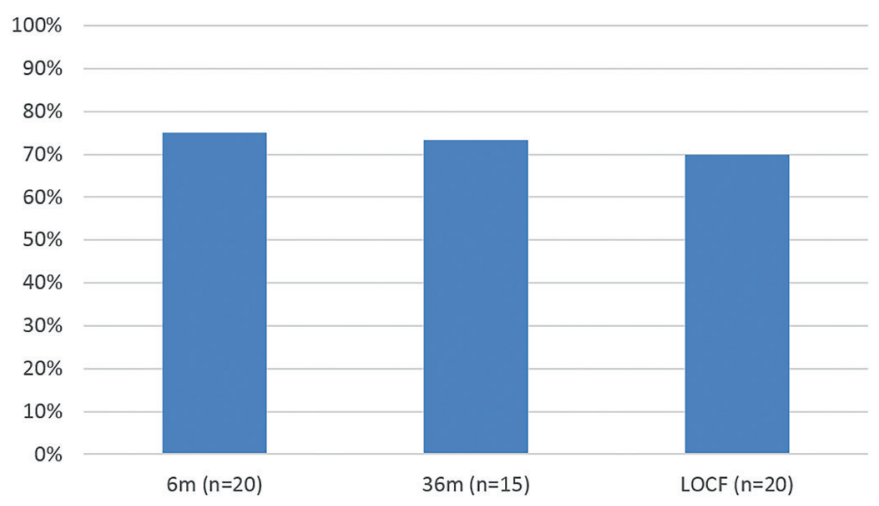

Figure 5. Improvement in Health Related Quality of Life (HRQL) above the minimal important difference (MID; 10 points) at 6, 36 months follow-ups and LOCF. 


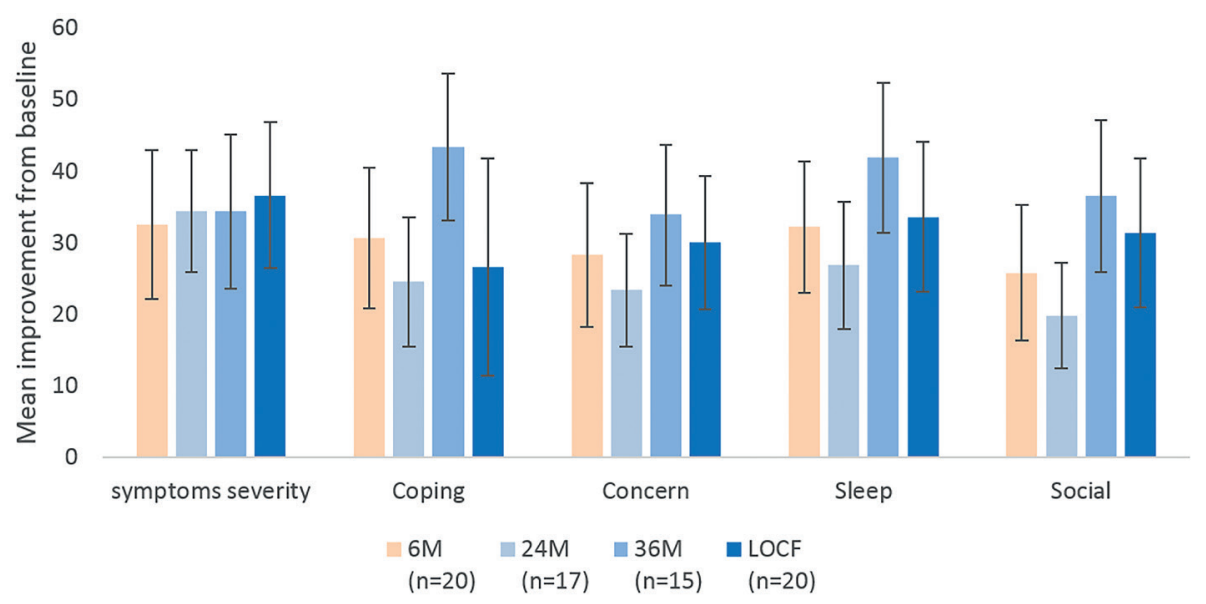

Figure 6. HRQL sub-scales mean improvement from baseline to 6, 24, 36 and last observation carried forward follow-ups. Symptoms severity, coping, concern, sleep and social mean improvement at each follow-up were compared to the baseline scores.

\section{DISCUSSION}

The treatment of $O A B$ in patients is still challenging for many health care professionals. There are several available treatments to reduce the symptoms of $\mathrm{OAB}$ with different advantages and disadvantages. However, many discontinue or become non-compliant with therapy because of side effects, un-meaningful reduction of their $O A B$ symptoms or no significant improvement to quality of life.

We demonstrate that the 20 patients who continued to the long-term follow-up well represent the initial 34 subjects pilot cohort with high similarities was in the two cohorts' demographics, baseline OAB parameters and 6 months success rates suggesting that the long-term follow up results are reliable and not subjected to bias that might be suspected in a small study cohort. Hence, we hereby demonstrate that the long-term per protocol results are highly comparable with the original 6 months per protocol results based on improvement in OAB symptoms. At 36 months, $75 \%$ of the patients still experienced successful treatment in regards to overall OAB symptoms' improvement, $50 \%$ and $80 \%$ of the patients experienced $>50 \%$ reduction in the number of leaks and large leaks, respectively, and $70 \%$ of the patients experienced improvement in quality of life scores. 
The study results confer sustained therapeutic benefit after 3 years of treatment and to the best of our knowledge is the first study to present long-term results of a modern state-of-the-art implantable tibial nerve neuromodulation device. Our results are comparable to treatment outcomes with alternative neuromodulation devices. MacDiarmid et al. report an overall treatment success rate of $67 \%$ at 6 months in their study using a battery powered tibial neuromodulation implant (eCoin ${ }^{\circledR}$, Valencia technologies). [18] In the RELAX-OAB study which uses a rechargeable sacral neuromodulation system, (Axonics ${ }^{\circledR}$ ), the overall success rate was $72 \%$ after 1 -year follow up. [19]

An important advantage of the Bluewind RENOVA system ${ }^{T M}$ is the safety profile. No SAE was observed during the extended 3-year study period, with the exception of one procedure related SAE within 30 days after implantation. Given the location of implant, shape and size of the device migration could be a potential concern. Sievert et al. reported migration of the electrode in 1 patient 1.5 years after implantation by using the antegrade approach (StimGuard LLC ${ }^{\circledR}$ ). [20] MacDiarmid et al. reported that 1 patient experienced $1 \mathrm{~cm}$ posterior migration of their study implant, which can affect the level of stimulation and response. [18] In the RELAXOAB study, Blok et al. reported migration of a lead in one patient 3-6 months after implantation. [19] We report no implant migration during a 3-year extended FU study. The risk of migration can be reduced by the Bluewind RENOVA system ${ }^{\text {TM }}$ due to the implant design which is leadless, wireless, and is sutured to the fascia at implantation.

In a Five-Year follow up report of OAB patients treated with Sacral Neuromodulation a 30.9\% surgical intervention rate was described which included revision, replacement and permanent explantation of any device components, with a $19.1 \%$ permanent explantation rate at 5 years. The top reason reported for permanent explantation was an $\mathrm{AE}$ (11.0\%), which was most often an ineffective therapeutic product (2.6\%). Other reasons included subject need for magnetic resonance imaging, lack or loss of efficacy and withdrawal of subject consent. [21]

The major advantage of the Bluewind RENOVA system ${ }^{\text {TM }}$ is the possibility for patients to perform self-stimulation at home based on clinical symptoms and each treatment is individually tailored per patient's needs and comfort. During the extend study it was observed that the frequency of treatment varied greatly from one patient to the other, ranging from 1 treatment per 4-6 weeks to treatments twice a day, with most patients choosing to treat between every day to every other day. 
The Bluewind RENOVA system ${ }^{\text {TM }}$ is implanted in a single stage procedure with a mean surgery time of 35 minutes in supine position, most commonly using local anesthesia. Five physicians from the pilot study were asked to evaluate the ease of the implantation procedure from 1 (very poor) to 5 (very good). The average of the physicians' answers was 4 ("good") indicating that that procedure's stages are easy to perform. As the device is battery-less the risk of replacement and revision surgery is much reduced compared to alternative neuromodulation methods such as sacral neuromodulation devices which need repeat procedures after an average of 8 years for battery replacement. [22]

\section{CONCLUSION}

This 3-year follow-up study using the BlueWind RENOVA ${ }^{\text {TM }}$ iStim system for the treatment of OAB symptoms confirms the long-term good safety profile with no technical failures reported. There is lasting efficacy of the treatment mirrored by a sustained positive impact on patients' quality of life. Whilst a larger randomized controlled designed study is warranted to strengthen the above conclusions, the results of this study are both positive and encouraging.

\section{SUPPLEMENTARY DATA}

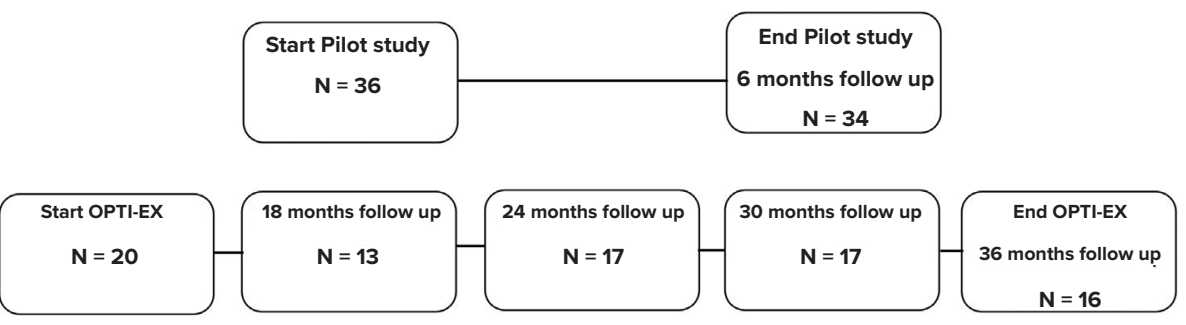




\section{REFERENCES}

1. Haylen, B.T., et al., An international urogynecological association (IUGA)/ international continence society (ICS) joint report on the terminology for female pelvic floor dysfunction. Neurourology and Urodynamics, 2010. 29(1): p. 4-20.

2. Heesakkers, J., et al., A novel leadless, miniature implantable Tibial Nerve Neuromodulation System for the management of overactive bladder complaints. Neurourol Urodyn, 2018. 37(3): p. 1060-1067.

3. Levin, P.J., et al., The efficacy of posterior tibial nerve stimulation for the treatment of overactive bladder in women: a systematic review. Int Urogynecol J, 2012. 23(11): p. 1591-7.

4. Janssen, D.A., et al., Clinical utility of neurostimulation devices in the treatment of overactive bladder: current perspectives. Med Devices (Auckl), 2017. 10: p. 109-122.

5. Govier, F.E., et al., Percutaneous afferent neuromodulation for the refractory overactive bladder: results of a multicenter study. J Urol, 2001. 165(4): p. 1193-8.

6. Burton, C., A. Sajja, and P.M. Latthe, Effectiveness of percutaneous posterior tibial nerve stimulation for overactive bladder: a systematic review and metaanalysis. Neurourol Urodyn, 2012. 31(8): p. 1206-16.

7. van der Pal, F., et al., Correlation between quality of life and voiding variables in patients treated with percutaneous tibial nerve stimulation. BJU Int, 2006. 97(1): p. 113-6.

8. van Balken, M.R., et al., Posterior tibial nerve stimulation as neuromodulative treatment of lower urinary tract dysfunction. J Urol, 2001. 166(3): p. 914-8.

9. Vandoninck, V., et al., Posterior tibial nerve stimulation in the treatment of urge incontinence. Neurourol Urodyn, 2003. 22(1): p. 17-23.

10. de Wall, L.L. and J.P. Heesakkers, Effectiveness of percutaneous tibial nerve stimulation in the treatment of overactive bladder syndrome. Res Rep Urol, 2017. 9: p. 145-157. 
11. van der Pal, F., et al., Percutaneous tibial nerve stimulation in the treatment of refractory overactive bladder syndrome: is maintenance treatment necessary? BJU Int, 2006. 97(3): p. 547-50.

12. te Dorsthorst, M.J., J.P.F.A. Heesakkers, and M.R. van Balken, Long-term real life adherence of percutaneous tibial nerve stimulation in over 400 patients. Neurourology and Urodynamics. n/a(n/a).

13. van Breda, H.M.K., et al., A New Implanted Posterior Tibial Nerve Stimulator for the Treatment of Overactive Bladder Syndrome: 3-Month Results of a Novel Therapy at a Single Center. J Urol, 2017. 198(1): p. 205-210.

14. Janssen, D.A., F. Farag, and J.P. Heesakkers, Urgent-SQ implant in treatment of overactive bladder syndrome: 9-year follow-up study. Neurourol Urodyn, 2013. 32(5): p. 472-5.

15. Coyne, K.S., et al., Determining the importance of change in the overactive bladder questionnaire. J Urol, 2006. 176(2): p. 627-32; discussion 632.

16. Jaeschke, R., J. Singer, and G.H. Guyatt, Measurement of health status. Ascertaining the minimal clinically important difference. Control Clin Trials, 1989. 10(4): p. 407-15.

17. Yoong, W., et al., Neuromodulative treatment with percutaneous tibial nerve stimulation for intractable detrusor instability: outcomes following a shortened 6-week protocol. BJU Int, 2010. 106(11): p. 1673-6.

18. MacDiarmid, S., et al., Feasibility of a Fully Implanted, Nickel Sized and Shaped Tibial Nerve Stimulator for the Treatment of Overactive Bladder Syndrome with Urgency Urinary Incontinence. J Urol, 2019. 201(5): p. 967-972.

19. Blok, B., et al., A prospective, multicenter study of a novel, miniaturized rechargeable sacral neuromodulation system: 12-month results from the RELAX-OAB study. Neurourol Urodyn, 2019. 38(2): p. 689-695. 
20. Sievert, K.D., et al., New novel chronic tibial neuromodulation (CTNM) treatment option for OAB significantly improves urgency (UI)/urge urinary incontinence (UUI) and normalizes sleep patterns: Initial results. European Urology, Supplements, 2017. 16 (3): p. e994.

21. Siegel, S., et al., Five-Year Followup Results of a Prospective, Multicenter Study of Patients with Overactive Bladder Treated with Sacral Neuromodulation. J Urol, 2018. 199(1): p. 229-236.

22. van Kerrebroeck, P.E., et al., Results of sacral neuromodulation therapy for urinary voiding dysfunction: outcomes of a prospective, worldwide clinical study. J Urol, 2007. 178(5): p. 2029-34. 
17

$\nabla \Delta$

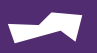
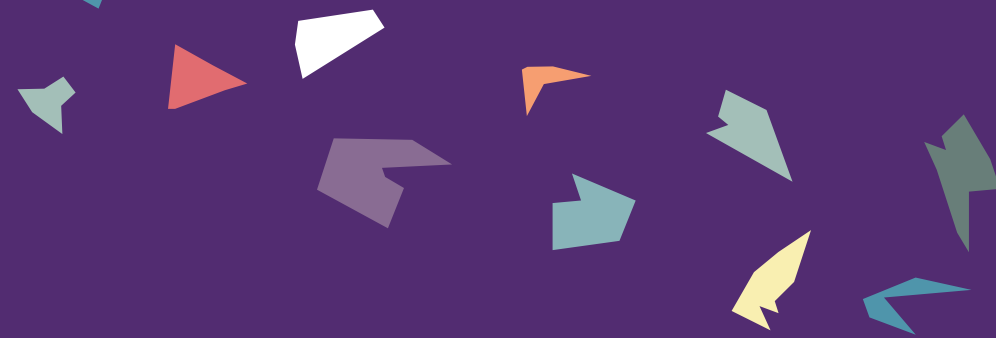

$\sim$

$\circ$

.

$\circ \circ$

$\circ$

$2: 2$

Y

$\circ \circ$

$\circ \circ$

$\circ$

$\circ 0$

$\begin{array}{lllllll}0 & 0 & 0 & 0 & 0 & 0\end{array}$

$\circ 0$

\section{0}

0

0

c

0

00

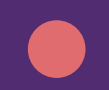

0

0

0

0

0

0

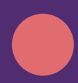

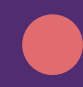

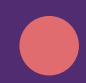

0

0

0

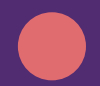

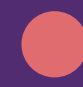
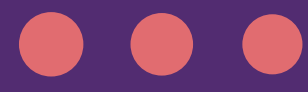

Auteurs:

te Dorsthorst MJ, Digesu GA, van Kerrebroeck PE, Elneil S, van Breda HMK, Janssen DJ, Martens FMJ, van Balken MR, Heesakkers JPFA
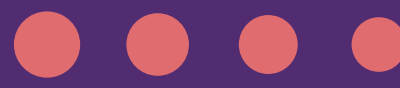

\section{Tijdschrift:}

Submitted
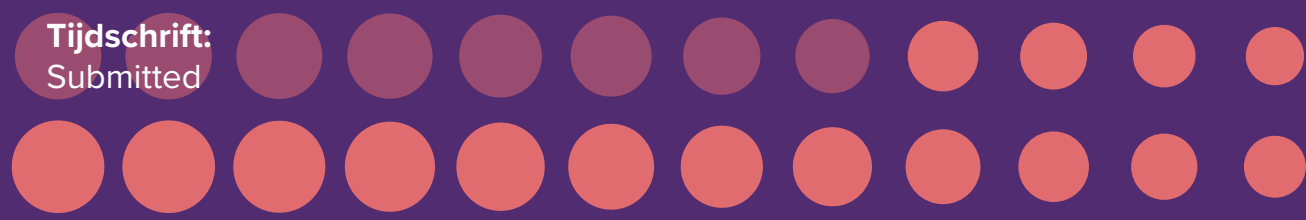


\section{ABSTRACT}

Purpose: The aim of this study was to demonstrate features predictive of treatment response for patient tailored OAB intervention with an implantable tibial neurostimulator using patient and technical prediction factors.

Materials and Methods: This study was designed as a follow up study based on parameter settings and patients' preferences during the pilot and extended study of the implantable tibial nerve stimulator (RENOVA ${ }^{\text {Tm }}$ iStim system). For this study we compared all treatment parameters (stimulation amplitude, frequency and pulse width) and usage data (duration of treatment) during the different follow up visits.

Results: We obtained usage data from a total of 32 patients who were implanted with the system between February and September 2015. Age, sex, BMI and previous experience with PTNS treatment were considered as possible prediction factors for treatment success. However, only BMI was considered a statistically significant prediction factor $(p=0.042)$. A statistically significant increase in mean treatment level was seen in the responder group during the 3 month follow up visit (mean: $6.7 \mathrm{~mA}$, SD 0,416) as compared to the initial system activation visit (mean: $5.8 \mathrm{~mA}, \mathrm{SD} 0,400)(p=0.049)$. No other visits demonstrated statistically significant changes in both groups (responders and non-responders) during the defined timepoints.

Conclusion: This data underscores the need to use patient tailored OAB treatment. $\mathrm{BMI}$ was found to be a negative predictive factor for treatment success. However, it was not possible to develop a specific responder model. A model predicting response to treatment could be useful for implementing shared decision making. 


\section{INTRODUCTION}

Overactive bladder $(\mathrm{OAB})$ is a chronic condition that characterized by urinary urgency, usually accompanied by frequency and nocturia, with or without urgency incontinence, in the absence of urinary tract infection or other obvious pathology according to the ICS terminology. [1]

The etiology and pathophysiology of OAB is still unclear. Over the years several new theories have emerged. However, still there is no clear understanding about the etiology and pathophysiology of OAB. This is one of the reasons why an appropriate long term treatment for $O A B$ has not yet been found. However, Peyronnet et al. recently described a new method of managing OAB. They conclude that various $\mathrm{OAB}$ phenotypes exist based on several different studies. [2-8] These OAB subtypes are determined by patient's comorbidities and existing theories/phenotypes. [2] These findings imply that a personalized approach should be considered when treating OAB patients versus the "one size fits all" strategy from a cost effectiveness and long-term compliance point of view.

Implantable tibial nerve stimulation using a wearable unit that activates and regulates the implant provides an excellent setting for a personalized approach since all parameters and treatment regimens can be adjusted using the patient's preference and subjective response to optimize the treatment outcome. Although results of the prior pilot clinical trial were previously published [9-11], this manuscript is the first to describe this new personalized patient centric treatment approach, specifically related to treatment settings and usability. This report aims to demonstrate the positive aspects of patient tailored OAB treatment using patient prediction and device related technical prediction factors during treatment. The following questions will be addressed: a) Do patients use the ability to change their treatment parameters? b) Do patients change their treatment regimen if allowed? c) Is parameter assessment and adjustments during follow up visits necessary in patient tailored treatment? d) Are there any predictive factors for treatment success based on technical or patient features for treatment of $O A B$ with a an implantable tibial neurostimulation device? 


\section{MATERIALS AND METHODS}

This study is based on a post hoc assessment of parameter settings and patient preferences during the previously published pilot and extended studies of the implantable tibial nerve stimulator (RENOVA ${ }^{\text {Tm }}$ system). $[9,11,12]$ The study was approved by all ethical committees of the participating centers. All patients who were previously implanted with the RENOVA ${ }^{\text {TM }}$ system were included in this study. However, only patients with available logs (usage data retrieved from the wearable external control unit), were included for final analysis. There were no other additional criteria for inclusion or exclusion. Subject enrollment for the pilot study was contingent upon satisfaction of all inclusion and exclusion criteria listed in previous study. [9] Inclusion criteria included OAB wet or OAB dry based on completion by the subject of a consecutive 3-day voiding diary and patient who has failed conservative treatments after at least 6 months of treatment (ie, lifestyle modification-fluid consumption, behavioral modification, and pharmacological therapy). [9]

The RENOVA ${ }^{\text {Tm }}$ system consists of a wireless miniature implant and a wireless wearable external control unit (non-implantable component). The system transmits electrical pulses to the tibial nerve. The implant has two electrodes, positioned on each end of the implant. After implantation and a period of healing, the device is activated (at 4 weeks post implant) and the patient performs self-treatment at home with the wearable external control unit (ECU). The implantation procedure of this device has previously been described. [2] During the pilot study (activation - 6 months follow up visit), the number of treatments per day was pre-defined in the study protocol described by Heesakkers et al. and van Breda et al. [9, 11] Patients were not allowed to alter the frequency of usage during the pilot study. During the extended follow-up study ( 6 to 36 months post system activation), subjects could volitionally adjust the number of treatments per day according to perceived responsiveness of self-experienced OAB symptoms. [12] Subjects were also allowed to alter treatment intensity (i.e. treatment level, stimulation current) throughout the complete study (pilot and extended).

Stimulation parameters including pulse width $(\mathrm{ms})$, frequency $(\mathrm{Hz})$, minimum sensation level (MSL) in $\mathrm{mA}$, maximum tolerable level (MTL) in $\mathrm{mA}$ and treatment level (TL, recommended amplitude based on minimum sensation and maximum tolerable level) in $\mathrm{mA}$, were established during the system activation (approximately 1 month post implantation). During follow up visits, after system activation, the 
system was adjusted based on patient's comfort (i.e. pain) and treatment effect (number of UUI recorded in voiding diary). Patients could change their treatment intensity level (downwards and upwards) within the predefined range of MSL and MTL set on their device by altering treatment current intensity on their ECU.

In this study, treatment parameters were assessed during follow up visits (activation, 1-month, 3-month, 6 months follow up). Logs retrieved during each follow-up visit provided parameter information during follow-up visits. Information regarding treatment settings and patient usability was retrieved from logs downloaded from the ECU during the follow up visits to clinic.

Statistical analysis was performed by using IBM SPSS statistics $25^{\circledR}$. Logistic regression was used for a prediction model. Multivariant analysis and $\mathrm{Chi}^{2}$ tests were used to compare differences in minimum sensation level (MSL), maximum tolerable level (MTL), treatment level $(T L)$ and usability testing during different timepoints and responder versus non-responder during 6 months follow up timepoint. Responders were defined as; $\geq 50 \%$ reduction in the number of incontinence episodes/day, or number of voids/day, or number of episodes with degree of urgency $>2$ or a return to $<8$ voids/day.

\section{RESULTS}

\section{Baseline results}

In this study we obtained usage data from a total of 32 subjects who were implanted between February and September 2015 in three different hospitals (two in the Netherlands, one in the UK). Twenty-eight of the included subjects were females (88\%), the median age of all study participants was 58 years (range 1878). Forty-four percent $(n=14)$ of the participants had previous PTNS, median BMI was 27,2 (range 21,5-40,9). Most of the patients did suffer from urgency urinary incontinence (UUI) with urinary frequency $(78 \%)$ followed by urinary frequency (UF) without incontinence (13\%) and urgency urinary incontinence (UUI) without frequency (9\%). At baseline (before implantation), patients with UUI had a mean of $6 \mathrm{UUl}$ episodes (SD 4,6) per day, and a mean of 12 (SD 3,0) voids per day. All baseline descriptive statistics are summarized in Table 1. 


\begin{tabular}{ll}
\hline Gender (\%) & Female: 88 \\
& Male: 12 \\
\hline Age (years) & 58 \\
\hline BMI (median) & 27,2 \\
\hline Type of OAB (\%) & UUI \& UF: 78 \\
& UF only: 13 \\
& UI only: 9 \\
\hline Leakages per day (baseline) & $6 /$ day \\
\hline Number of voids (baseline) & $12 /$ day \\
\hline Treatment sessions per week & $0-3$ times $16.7 \%$ \\
(extended study) & $4-6$ times: $72.2 \%$ \\
& $7-10$ times: $5.6 \%$ \\
\hline
\end{tabular}

Table 1. Descriptive statistics $(n=32)$

Treatment regimens and parameters settings

During the first 6 months, treatment regimen was fixed as described by Heesakkers et al. [9] However, during the extended study period patients $(n=18)$ regulated treatment (frequency of use), with a treatment frequency ranging between once every 6 weeks to 14 times per week. Most of the patients treated themselves between 4-6 times per week (72\%). Due to the small number of patients included in the extended study no further analysis on correlation between treatment frequency and treatment success could be determined.

During the system activation visit the median treatment level $(n=29)$ was set to $5.5 \mathrm{~mA}$ (range 1.58-8.0). Median treatment level during 6 month follow up visit in responders $(n=22)$ was set to $6.75 \mathrm{~mA}$ (range 2.79-8.5, $n=22$ ) which was equal $(6.75 \mathrm{~mA})$ to that of the non-responders group ( $\mathrm{n}=10)$ (range 1.13-8.5, $n=10$ ).

There was a statistically significant increase in the mean treatment level in the responder group during 3 months follow up (mean: $6.7 \mathrm{~mA}$, SD 0,416) as compared to their activation visit (mean: $5.8 \mathrm{~mA}$, SD 0,400) $(p=0.049)$. No other visits demonstrated statistically significant changes in either group (responders and non-responders) between the defined timepoints. Figure 1 shows mean treatment levels during the predefined timepoints (Activation, 1 month, 3 months and 6 months follow up) in responders and non-responders. 


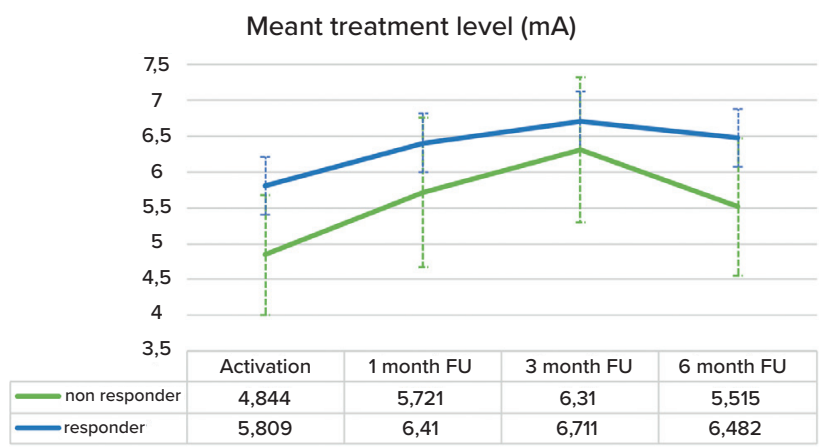

Figure 1. Mean treatment level in $m A$ during different timepoints, responder ( $n=22)$ versus nonresponder $(n=10)$. Statistical significance between activation and 3 month follow up in responders $(p=0.049)$.

Patient tailored treatment levels during home-treatment

During the first month of follow up, all patients adjusted at least once the treatment intensity of their ECU $(n=32)$. During the 6 months of follow up visit, logs demonstrated that $70 \%$ of the non-responders used treatment adjustment at least once during the overall treatment versus $42 \%$ of the responders. During the first 2 minutes of treatment, again $70 \%$ of the non-responders were altering treatment intensity as compared to only $32 \%$ of the patients in the responder group. After 2 minutes of therapy, only $32 \%$ of the responders were using treatment intensity alteration during 6 month follow up comparing to $50 \%$ of the patients in the nonresponder group.

\section{Prediction factors}

Age, sex, BMI and previous PTNS were considered as possible prediction factors for treatment success. However, only BMI was considered a statistically significant negative prediction factor $(p=0.042)$, with higher BMI correlating with lower response level to treatment. Table 2 summarizes the prediction factors and their p-value.

\begin{tabular}{ll}
\hline Prediction factor & P-value \\
Age & 0.51 \\
Gender & 0.40 \\
BMI & $0.042^{*}$ \\
\hline Previous PTNS & 0.77 \\
\hline
\end{tabular}

Table 2. Prediction factors for being responder. ${ }^{*} P<0.05$ was considered statistically significant. 


\section{DISCUSSION}

This study is the first to report and evaluate treatment settings, usability of homebased treatment, patient interaction with device, and prediction factors in the treatment of OAB by using a tibial nerve implantable neurostimulation system. Implantable tibial nerve stimulation continues be investigated. [12-14] Despite increasing reports of efficacy outcomes in smaller pilot studies, treatment settings and their influence on therapy success have not been previously analyzed.

One of the major findings in this study is that Body Mass Index was shown to be a negative prediction factor in the treatment success of tibial nerve stimulation with an implant. One device specific explanation for this could be that the distance (skin to implant) is larger in patients with a higher BMI and therefore voltage could be attenuated in the higher tissue volume. Guidelines have previously stressed lifestyle intervention and positive outcomes on incontinence and specifically overactive bladder, and the importance of patient engagement for treatment success has long been recognized. $[15,16]$ In this analysis, no other predictive factors for successful treatment were identified. Prior studies have also found no specific predictive factors for treatment success with percutaneous tibial nerve stimulation. Van Balken et al. found no factors to be predictive for treatment prognosis inclusive of sex, age, weight, Body Mass Index, indication for PTNS, duration of symptoms, types of prior treatment and stimulation parameters. [17] Their main negative prognostic factor for treatment success was poor mental health as reported by the SF-36 Mental Component Summary.

Based on the specific treatment modalities it was assumed that previous successful PTNS treatment is a positive predictive factor for treatment success in OAB with tibial implantation. However we could not confirm this in our analysis. One possible explanation is the relatively small number of patients with previous successful PTNS ( $n=14$ ) which were included in this study. Also, success criteria definition for PTNS have not been standardized and therefore historical PTNS success reporting could have led to mis-categorization of some patients. For example, successful PTNS treatment might have been concluded based upon a subjective questionnaire but diary data did not demonstrate a $50 \%$ reduction in voiding/incontinence episodes as per predefined outcomes success criteria for the trial. 
It is generally accepted that OAB usually requires long term treatment to achieve control of symptoms. [18] Compliance and continuation of the therapy is therefore of great importance for therapeutic success. Nevertheless, long term treatment persistence is typically low in chronic diseases, especially OAB. [19-21] Adherence and persistence to $O A B$ treatment is challenging and therefore patient centered treatment can potentially improve this aspect and allow optimal therapy result. The ability for the physician to refine treatment parameters during follow up visits by adjusting stimulation parameters such as Frequency $(\mathrm{Hz})$, Pulse Width (msec) and the range of amplitudes to tailor the treatment for each patient based on individual patient's stimulation sensation as well as treatment efficacy will improve the quality of the patient centered treatment. The logs provided by the system also allow the physician to monitor and verify treatment compliance including verifying technical issues. Thus, although there were no statistically significant differences in the treatment levels of the study cohort during follow up (except for increase in treatment level at 3 month follow-up), adjustments of treatment parameters were performed by each patient throughout the study to improve treatment success.

We believe that further investigation of the different parameters (i.e. frequency and pulse width) in correlation with treatment response should be reported by clinical trials. The ability to change their treatment intensity (amplitude) within a predetermined range is clearly important as demonstrated in this trial, with nonresponders using this feature more frequently than responders, emphasizing the need of patient involvement with their therapy and highlighting the importance of patient centric therapy.

A limitation of this study is the small sample size. A larger sample size perhaps would have allowed delineation of predicative factors correlated with treatment success. Having predictive factors could be of great importance in counseling the patient for personalized OAB treatment. These predictive factors in combination with the further ongoing research in the onset of OAB [2] could be the cornerstone of personalized OAB treatment instead of the "one-treatment-fits-all" theory, perhaps allowing earlier utilization of this therapy in the treatment paradigm. 


\section{CONCLUSION}

It was not possible to develop a specific responder model for $O A B$ treatment using and implantable tibial neurostimulation system. A responder model could be useful for implementing shared decision making with the patient. Although, similar to other neuromodulation reports, BMI was found to be a negative prediction factor for this treatment modality, no other predictive factors could be obtained. The need for patient tailored healthcare is critical and might improve the long-term treatment outcome and compliance for each patient. Possibly new multicenter studies with larger number of patients will shed light on a better predictive model in the treatment of $O A B$ using an implantable tibial neurostimulation device. 


\section{REFERENCES}

1. Abrams, P., et al., The standardisation of terminology of lower urinary tract function: report from the Standardisation Sub-committee of the International Continence Society. Neurourol Urodyn, 2002. 21(2): p. 167-78.

2. Peyronnet, B., et al., A Comprehensive Review of Overactive Bladder Pathophysiology: On the Way to Tailored Treatment. Eur Urol, 2019. 75(6): p. 988-1000.

3. Hubeaux, K., et al., Autonomic nervous system activity during bladder filling assessed by heart rate variability analysis in women with idiopathic overactive bladder syndrome or stress urinary incontinence. J Urol, 2007. 178(6): p. 2483-7.

4. Bunn, F., et al., Is there a link between overactive bladder and the metabolic syndrome in women? A systematic review of observational studies. Int J Clin Pract, 2015. 69(2): p. 199-217.

5. Klausner, A.P. and W.D. Steers, Corticotropin releasing factor: a mediator of emotional influences on bladder function. J Urol, 2004. $172(6$ Pt 2): p. 2570-3.

6. Hanna-Mitchell, A.T., et al., Do we need to know more about the effects of hormones on lower urinary tract dysfunction? ICl-RS 2014. Neurourol Urodyn, 2016. 35(2): p. 299-303.

7. Malykhina, A.P., et al., Do the urinary bladder and large bowel interact, in sickness or in health? ICI-RS 2011. Neurourol Urodyn, 2012. 31(3): p. 352-8.

8. Aragón, I.M., et al., The Urinary Tract Microbiome in Health and Disease. Eur Urol Focus, 2018. 4(1): p. 128-138.

9. Heesakkers, J., et al., A novel leadless, miniature implantable Tibial Nerve Neuromodulation System for the management of overactive bladder complaints. Neurourol Urodyn, 2018. 37(3): p. 1060-1067.

10. te Dorsthorst, M.J., J.P.F.A. Heesakkers, and M.R. van Balken, Long-term real life adherence of percutaneous tibial nerve stimulation in over 400 patients. Neurourology and Urodynamics, 2020. 39(2): p. 702-706. 
11. van Breda, H.M.K., et al., A New Implanted Posterior Tibial Nerve Stimulator for the Treatment of Overactive Bladder Syndrome: 3-Month Results of a Novel Therapy at a Single Center. J Urol, 2017. 198(1): p. 205-210.

12. te Dorsthorst, M.J., et al., 3-Year Follow-Up, of a New Implantable Tibial Nerve Stimulator for the Treatment of Overactive Bladder Syndrome (OAB). J Urol, 2020: p. 101097ju0000000000001024.

13. MacDiarmid, S., et al., Feasibility of a Fully Implanted, Nickel Sized and Shaped Tibial Nerve Stimulator for the Treatment of Overactive Bladder Syndrome with Urgency Urinary Incontinence. J Urol, 2019. 201(5): p. 967-972.

14. Sievert, K.D., et al., New novel chronic tibial neuromodulation (CTNM) treatment option for OAB significantly improves urgency (UI)/urge urinary incontinence (UUI) and normalizes sleep patterns: Initial results. European Urology, Supplements, 2017. 16 (3): p. e994.

15. Subak, L.L., et al., Weight loss to treat urinary incontinence in overweight and obese women. N Engl J Med, 2009. 360(5): p. 481-90.

16. Link, C.L., et al., The association of adiposity and overactive bladder appears to differ by gender: results from the Boston Area Community Health survey. J Urol, 2011. 185(3): p. 955-63.

17. van Balken, M.R., H. Vergunst, and B.L. Bemelmans, Prognostic factors for successful percutaneous tibial nerve stimulation. Eur Urol, 2006. 49(2): p. 360-5.

18. Abrams, P., et al., Overactive bladder significantly affects quality of life. Am J Manag Care, 2000. 6(11 Suppl): p. S580-90.

19. Yu, Y.F., et al., Persistence and adherence of medications for chronic overactive bladder/urinary incontinence in the california medicaid program. Value Health, 2005. 8(4): p. 495-505. 
20. Sexton, C.C., et al., Persistence and adherence in the treatment of overactive bladder syndrome with anticholinergic therapy: a systematic review of the literature. Int J Clin Pract, 2011. 65(5): p. 567-85.

21. Andrade, S.E., et al., Discontinuation of antihyperlipidemic drugs--do rates reported in clinical trials reflect rates in primary care settings? $\mathrm{N}$ Engl J Med, 1995. 332(17): p. 1125-31. 
4

$\nabla<$

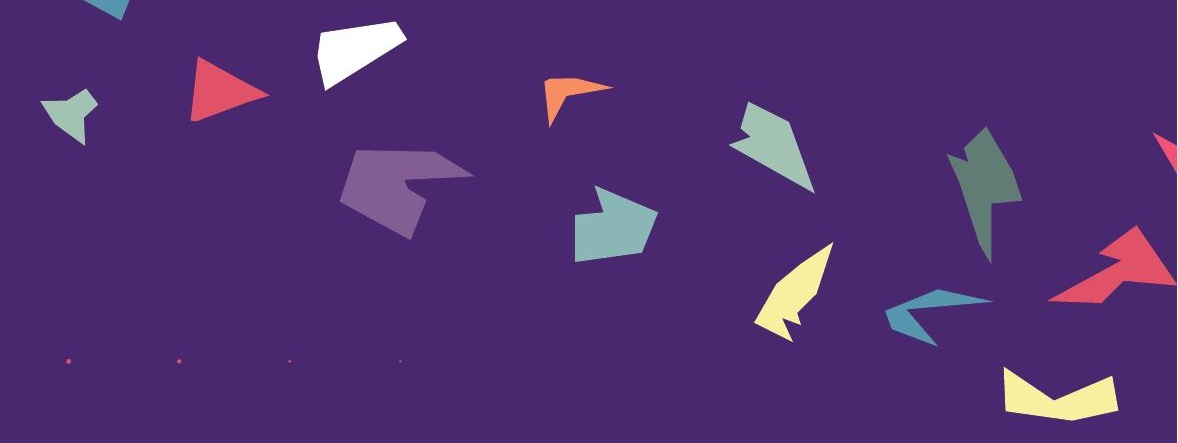

$\circ \quad 0 \quad 0 \quad 0 \quad 0 \quad 0 \quad 0 \quad 0$

$\begin{array}{llllllllllllll} & 0 & 0 & 0 & 0 & 0 & 0 & 0 & 0 & 0 & 0 & 0 & 0 & .\end{array}$

$\begin{array}{llllllllllllll}0 & 0 & 0 & 0 & 0 & 0 & 0 & 0 & 0 & 0 & 0 & 0 & 0 & 0\end{array}$

$\begin{array}{llllllllllllll}0 & 0 & 0 & 0 & 0 & 0 & 0 & 0 & 0 & 0 & 0 & 0 & 0 & 0\end{array}$

0000000000000000

0000000000000000

00000000000000

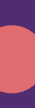

0

0

0

0

00000

000

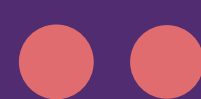

0

0

0

0

0

000

0

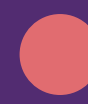

0
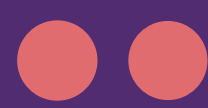

0

0

0

0

0

0

0

00
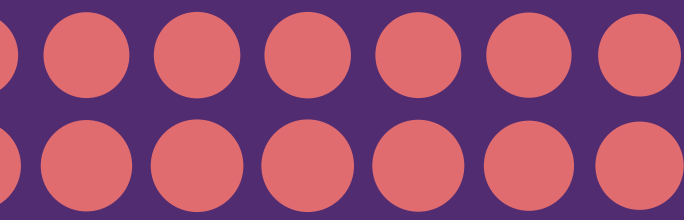

1000000000000

1000000000000

1000000000000

1000000000000

1000000000000 


\section{AIM OF THIS THESIS}

The goal of this thesis is to better understand the current values of tibial nerve stimulation for treatment of overactive bladder syndrome (OAB) in the various ways of performing. It is attempted to outline the advantages and disadvantages of all forms of tibial nerve stimulation in the treatment of OAB. This is done by reviewing the newest and older insights for implantable devices In addition, the real life outcomes of the current treatment modalities (percutaneous tibial nerve stimulation and transcutaneous nerve stimulation) have also been examined. Together, this gives a picture of the current real life situation of patients treating themselves with tibial nerve stimulation. Additionally, it provides a picture for the near future in terms of patient tailored health care.

In this chapter I will first summarize our main findings. These findings will be highlighted specifically in the context of tibial nerve stimulation, critically appraised, and compared to relevant literature. Several important challenges inherent to the treatment of $O A B$ by tibialis stimulation will then be outlined. Further I will describe the implication of our findings for healthcare professionals. Lastly, some future perspectives in the field of $O A B$ and the various treatment options will be discussed.

\section{SUMMARY OF MAIN FINDINGS}

Real life outcomes of tibialis stimulation in the treatment of OAB

Chapter $\mathbf{2}$ describes the real life results of percutaneous tibial nerve stimulation in a non-study population. In total 402 patients were included. Indications for starting PTNS for these patients were OAB-wet or OAB- dry. Patients who quitted during maintenance PTNS mostly choose Botulinum toxin A (14\%) or mirabegron (10\%) as next line of treatment in OAB, or nothing (57\%). Our real life data showed comparative percentages of success in the treatment of OAB by PTNS compared to former published data in study populations. This study with a follow up of over 10 years showed that PTNS is also successful on the long term. However, we also found that more than $40 \%$ of the patients stopped maintenance treatment due to nonmedical reasons. We concluded that, despite the long term efficacy of PTNS that has been proven in this study, the need for a more patient tailored treatment modality is still there. 
Subsequently, the real life adherence and patient experiences data of transcutaneous tibial nerve stimulation (TTNS) in our single center was described in chapter 3. All patients who had a positive effect on percutaneous tibial nerve stimulation (PTNS) and continued with home based treatment with TTNS were included. Patients were retrospectively asked to fill out a questionnaire regarding satisfaction, reasons for quitting and additional or next line of therapy. Fortytwo patients were included for this study, $81 \%$ were female. Most of the patients $(64 \%, n=27)$ were diagnosed with OAB wet. We found a median TTNS treatment persistence of 16 months (range 1-112 months) which was in line with previous published literature in study-populations. Again, most of the patients stopped therapy due to loss of effect or they preferred another type of neuromodulation. Apart from patients who were satisfied with TTNS we found as well disappointing rates of efficacy. Patients generally rated their TTNS treatment with an overall 5.6 (scale 1-10, $n=38$, SD 2,07). We concluded that, although TTNS is successful at start, we observed that most patients do not continue with their treatment in the long term due to various reasons. And again, the combination of a low satisfaction rates with poor long term efficacy outcomes ensured that the desire for better patient tailored treatment modalities kept remained.

Implantable tibial nerve devices in the treatment of $O A B$

One of the pioneers in the field of patient tailored treatment of OAB by tibial nerve stimulation was the Urgent-SQ system. The first pilot with this specific implantable system was already performed between 2002 and 2004. The Urgent-SQ system consists of an external stimulator and an internal body. The external stimulator is an external electromagnetic pulse generator and has radio-frequency transmission. The internal body of the Urgent-SQ consist of an electromagnetic pulse receiver and a body with two leads containing monopolar electrodes. Previous publications demonstrated a high safety and efficacy profile after 1 and 9 year of follow up. The aim of this study was to evaluate the long term follow up in terms of safety and usability of the Urgent-SQ system (implantable tibial nerve stimulator) in patients without strict study regime and in the absence of follow up by the industry. (Chapter 4) During this study, patients were interviewed through a standardized discussion with a physician by phone. All five patients, included in this follow up evaluation, did not use the system anymore due to external stimulator deficiency $(n=2)$ or loss of effect $(n=3)$. Patients who reported external stimulator deficiency were satisfied with the treatment and reported they had used it frequently until device deficiency occurred. After quitting the therapy the complains of urge/ urgeincontinence increased again in all patients $(n=5)$. It was concluded that in addition 
to effectiveness and safety, sponsors need a structured plan for the period after the study for continuing technical support. This will increase the lifespan of the technical equipment and allows the patient to continue their beneficial treatment. Because of this lack of technical support, the advantages of home-based treatment for OAB with a tibial implant could not be confirmed in this long term study.

Since a few years the field of tibial nerve stimulation became of interest for several companies that developed small implantable neurostimulators. In chapter $\mathbf{5}$ the newest tibial nerve implants that have reached the phase of clinical testing, were examined more closely. The technical aspects and techniques of recent developed implants were evaluated in this review. All different treatment options have advantages and disadvantages based on type of surgery, energy transfer, impedance, treatment setting options, risk of migration and patient usability. Based on these above described technical aspects the following systems were reviewed: Stimrouter, GEKO, eCoin, Bluewind RENOVA and Stimguard. In summary, new developments focus on small, battery free devices that are easy to operate and that can be positioned in the least invasive manner, are on their way. However, based on the concept of ideal patient tailored tibial nerve stimulation, it can be concluded the perfect implant yet has to be developed but developments are promising.

Based on the advantages and disadvantages as described in chapter $\mathbf{5}$ we can conclude the Bluewind RENOVA system is currently one of the most elegant implants in the treatment of OAB by a tibial nerve implant. The RENOVA system consists of a wireless miniature implant and a wireless external control unit (nonimplantable component). The system transmits electrical pulses to the tibial nerve. The implant has two electrodes, positioned on each of the implant's end. After implantation and a period of wound healing, the device is activated and the patient performs self-treatment at home with the external control unit (ECU). In chapter 6 the three year safety and efficacy results of the pilot study was reported. Twenty patients consented to continue tot the three year follow up study. Most patients again were suffering from OAB wet (80\%). The study results confer sustained therapeutic benefit after three years of treatment. The overall treatment success rate was $75 \%$ at 36 months post activation. Regarding safety we reported no additional explantations and no serious adverse effects. There was no need for new surgical intervention. Overall it could be concluded that the Bluewind Renova system confirms the long term good safety and efficacy profile. 
In chapter 7 the beneficial features of patient tailored OAB treatment with an implantable tibial device was described. Parameter settings (i.e. treatment level in $m A$ ) which were set during activation and follow up visits were analyzed per patient and patient groups (responder versus non-responders). There were no statistical differences regarding system parameter settings in responders versus non-responders during the 6 months efficacy end-point of our study. There was a statistically significant increase in mean treatment level in the responder group during three months (mean: $6.7 \mathrm{~mA}, \mathrm{SD} 0,416$ ) of follow up as compared to their activation treatment level (mean: $5.8 \mathrm{~mA}$, SD 0,400) however clinical significance is low. Besides BMI there are no other prediction factors for success. Age, gender, $\mathrm{BMI}$ and previous PTNS were considered as prediction factors. However, only BMI was the only significant negative prediction factor in our study cohort. One device specific explanation for this could be that the distance (skin to implant) is larger in patients with a higher BMI and therefore voltage could be attenuated in the higher tissue volume. Although this does not rule out other potential predictive factors, we concluded that it was not possible to develop a specific responder model based on this study. One of the main factors for this is the small sample size $(n=32)$.

\section{CRITICAL APPRAISAL}

PTNS has proven its efficacy over the years and therefore has acquired its place in the treatment spectrum of OAB. Peters et al. were the first in their SUmiT trial who performed a double blind multicenter RCT. They compared PTNS versus sham through 12 weeks of therapy. [1] These results provided us strong clinical evidence that there is a therapeutic effect on OAB symptoms by stimulating the posterior tibial nerve. From then on, several reviews stated efficacy rates between 37\% and $93 \%$. [2-4] In additions in terms of patient preferences, a study from Hashim et al. reported that $57 \%$ of their patients preferred PTNS as a therapeutic option compared to $34 \%$ for sacral neuromodulation and $9 \%$ for Botulinum toxin A (BTA). [5] However, till 2018 all results were based on study protocols and follow up. In this case, patients do have strict regime in terms of appointments with the study team and their physician. This can influence the results during the study period versus on the longer term without well-defined study follow up. In 2018, Sirls et al. were the first who described real life results from their cohort. [6] Their results are in line with our results as discussed in chapter 2. In the results from this real life study we show the benefits of PTNS in terms minimal invasive and cheap treatment modality compared to other surgical or drug therapies and could be considered as an effective treatment modality for long-term treatment. $[7,8]$ In 
comparison, OAB pharmacologic therapies have a higher rate of discontinuation within 1 year (mean 70\%). [9-11] However, we described as well the main shortcomings of PTNS in terms of discontinuation due to nonmedical reasons. Still $40 \%$ of our subjects described in chapter $\mathbf{2}$ discontinued treatment due to nonmedical reasons. Because of this one could state that PTNS in its current form is not the right treatment for OAB. One of the shortcomings of PTNS in its current form is its time-consuming profile for both the patient and the caregiver. The patient has to travel to the hospital and complete the therapy for at least 30 minutes and the caregiver has to perform the needle placement. The possibility for home-based treatment should be available in the near future for patients on maintenance PTNS treatment. This way it is friendlier for both parties, patients and caregiver. One possible solution could be training of patients in inserting the PTNS needle their selves.

One of the main benefits of transcutaneous tibial nerve stimulation is homebased treatment. As previously discussed, one of the shortcomings of PTNS in its current form is its time-consuming profile for both the patient and the caregiver. During transcutaneous tibial nerve stimulation patients can perform the treatment by themselves in their own time. Ramirez et al. were the first who reported noninferiority in the decrease of daytime frequency voiding in patients with idiopathic $\mathrm{OAB}$ and detrusor overactivity in their randomized controlled trial comparing PTNS versus TTNS. [12] This finding and the reported efficacy results from Booth et al. and Schreiner et al. [13, 14] suggest that TTNS is the optimum treatment modality in terms of efficacy, safety and long-term treatment compliance. According to Schreiner et al. $68 \%$ of the patients in the TTNS group reported cure or improvement versus $35 \%$ in the control group $(P=0.017)$. In addition, there was a significant improvement in most areas of Quality of life in TTNS patients. [14] However, the positive effect of TTNS on OAB symptoms as described by Schreiner et al. was performed in study-environment and short-term follow up. Chapter 4 reports that, although TTNS is successful at start, most patients do not continue with their treatment in the long-term mainly due to loss of effect over time (55\%). These real life data from our study show the short-comings of TTNS and are in line with previous published data from Leroux et al. [15] In addition, patients rated their OAB treatment with TTNS fairly low and often preferred a different form of tibial nerve modulation (24\%). Again, one could state that TTNS is not the right treatment for OAB on the long-term. A more patient tailored, minimally invasive treatment modality could enhance the persistence and adherence among the current OAB treatment modalities. 
In 2004, a long time before the introduction of small electronic implants, van der $\mathrm{Pal}$ et al. were the first who reported a patient specific treatment modality in tibialis nerve stimulation. The Urgent-SQ system was the first tibial implant in the treatment of OAB. With this technique patients could perform home-based treatment by using an implant and an external stimulator. Results described by van der Pal et al. were promising and Janssen et al. confirmed the long-term treatment efficacy. $[16,17]$ After 9 years of implantation 6 out of 7 patients still had sensory an loco-motor responses with stimulation. Unfortunately, as described in chapter 4 after 18 years follow up, none of the patients is using the system anymore. All patients did subjectively report a worsening of symptoms after discontinuation of their therapy which suggest the ongoing disease. One of main reasons for quitting therapy was technical failure of the external stimulator. Due to unavailability of the external stimulator no revisions were possible and this may have affected effective rate outcomes As stated in chapter 4, long-term technical support should be guaranteed by the sponsor. This in order to guarantee the possibility for patients to continue with their beneficial treatment. This will extend the longevity of an tibial nerve implant, contributes to patient satisfaction for OAB treatments in the longer term and, in the long run, most likely save costs. However, the successful results described by Janssen et al. suggest an implant could be beneficial as well on the longer term. Based on this we might conclude, a tibial nerve implant for the treatment of OAB could probably be effective in the long term, if there is good technical support.

New (start-up) companies expressed renewed interest in the field of tibial nerve stimulation in the treatment of OAB. In recent years, a few devices have been examined. Most results are based on short-term follow up. An example of this are the recently published results of the eCoin ${ }^{\circledR}$. [18] The eCoin ${ }^{\circledR}$ is a coin-shaped, battery powered, leadless tibial nerve stimulator. Automated stimulation sessions occur for 30-minute durations every 3 days for 18 weeks and every 4 days thereafter. The eCoin has a postulated average operating life of 3 years. The most recent efficacy data published, reported responder rates of $68 \% 48$ weeks post activation. This is in line with the reported data in chapter 6 regarding efficacy. However, in terms of long-term treatment follow up we cannot compare those studies. In chapter $\mathbf{6}$, we describe the longest follow up regarding new implantable tibial nerve stimulators. Twenty patients continued in the 3-year follow up study and reported sustained effect of their tibial nerve implant regarding OAB complaints. Seventy-five percent of the patients reported success rates after 36 months of treatment. Comparing these treatment modalities in terms of safety we do see similar results. 
Bluewind Renova system reported one procedure related serious adverse event during the pilot study, all other adverse events were resolved between 1 day to approximately 3 months form their initiation. [19] During the extended follow up study no other adverse or serious adverse events were reported. ECoin ${ }^{\circledR}$ report in their pivotal study 1 serious adverse event. The rate of device-related adverse events was approximately $15 \%$ at 28 and 52 weeks. Most device or procedure related adverse events were graded mild to moderate. [18] Currently, other devices did not report any long-term safety or efficacy data yet. StimGuard ${ }^{\circledR}$ (described in chapter 5) is in the process of the PROTECT Study, a multi-center, prospective, randomized, controlled, non-inferiority, clinical trial comparing StimGuard ${ }^{\circledR}$ with the Medtronic InterStim ${ }^{\circledR}$ System for sacral neuromodulation for the treatment of OAB. [20] Bioness Stimrouter (described in chapter 5) is currently conducting a randomized double-blinded, sham-controlled clinical trial involving approximately 180 patients at 20 sites over a total of 24 months. [21] The variety of these newly developed tibial nerve devices also provides a new perspective on patientspecific treatment. The variety of treatment options (i.e. treatment set-up, implant procedure, duration per treatment, automatic start versus patient handled start etc.) based on the specific characteristics per different device gives room for health care providers to choose the treatment based on their or patients preferences.

In line with the above described options for healthcare providers, the attitude towards the implementation of OAB healthcare is changing to a more patient centered view. There is not one single form of OAB but rather several OAB phenotypes based on the underlying mechanisms and pathophysiological cofactors. [22] For example, it is likely that a patient's medical history could specifically identify several of the pathophysiological cofactors (i.e. metabolic syndrome, affective disorder, gastrointestinal functional disorders). The existence of urgency with or without incontinence (OAB-dry versus OAB wet) could help in differentiation DO versus hypersensitivity driven urgency with possible therapeutic implications. [22] An example of this with little evidence is the use of Botulinum toxin $A$ in OAB dry patients. [23] This new diagnosis prism of OAB could shift the treatment of $O A B$ in the near future towards a more patient specific treatment modality. In the past, much research of PTNS as a OAB treatment modality has focused on finding a specific responder model for successful PTNS treatment. We found in our analysis (chapter 7) that only BMI as a negative responder for tibialis stimulation by using an implant. We expected that besides BMI, also age, gender, previous successful PTNS treatment would be a predictive factor. However, our cohort was too small to confirm these factors. Comparing these results to former published 
literature, there are still difficulties in identifying prediction factors. Rostaminia et al. recently published their results among 162 patients and a vast number of variables in an attempt to find prediction factors. [24] They concluded a baseline history of depression/anxiety; a higher first sensation to void during cystometry and severe baseline urgency urinary incontinence had higher odds of having a $\geq$ $50 \%$ subjective improvement. On the other hand, patients with higher maximum detrusor pressure on multichannel urodynamics and severe baseline nocturia demonstrated a significantly lower likelihood of $\geq 50 \%$ subjective improvement. [24] Especially, the baseline history of depression/anxiety and having an higher odds for $\geq 50 \%$ subjective improvement is in contrast with previous published work. Prognostic factors described by Van Balken et al. [25] showed a negative outcome on PTNS treatment in patients with a low SF-36 Mental Component Summary. They were prone to fail neuromodulation therapy in their study. Unfortunately, we could not confirm one of those statements regarding mental health and tibial nerve stimulation therapy outcome. In conclusion, it was not possible to develop a specific responder model in the treatment of OAB using an implantable tibial neurostimulation system. Such kind of responder model could be useful in clinics implementing shared decision making with the patient. Hopefully new multicenter studies with larger number of patients would shed some light on a better prediction model in the treatment of OAB by a tibial implantable neurostimulation device.

\section{FUTURE PERSPECTIVES}

The way of how we look at OAB (etiology and treatment)nowadays is changing. We previously thought that the urothelium-based hypothesis (Increased release of various neurotransmitters can release signaling molecules which can alter the actions on the afferent nerves including, urothelial nerve growth factor, ATP and prostaglandin subtype E2.) [26-28], Myogenic hypothesis (a range of triggers can generate localized detrusor contractions (micromotions), which can spread in the bladder wall through various routes of propagation) [29-31] or the neurogenic hypothesis (Bladder overactivity could be caused by various changes in central peripheral and neural pathways) [32] might explain the etiologyand pathophysiology. We now conclude: OAB should be seen as a complex, multifactorial symptom syndrome, resulting from multiple potential pathophysiological mechanisms causing a similar complex of symptoms. [22] There is not one form of OAB syndrome and not a one-size-fits-all treatment modality for patients suffering from OAB. [22] For decades caregivers are struggling with finding the best treatment modality for this group of patients. Specifically in terms of long term success rates 
with none/minor side effects. In this thesis we tried to emphasize the need for a more patient tailored treatment modality for the treatment of OAB. We mainly focused on tibial nerve stimulation which has proven his efficacy over years based on previous literature and as discussed in chapter 3 . However still after reading this thesis you could state that the optimum treatment modality specific for tibial nerve stimulation in OAB has not been discovered yet. The optimum treatment modality must obviously meet the safety and efficacy requirements during long term follow up but it should be as well patient and user friendly.

In addition to finding the ideal implant in the near future, we must also focus on the ideal patient. As stated before in this thesis we focused on tibial nerve stimulation for OAB. However, OAB is multifactorial and tibial nerve stimulation is not the only treatment modality for patients suffering from OAB. In the near future research should focus on cellular and molecular mechanisms of OAB symptoms to obtain different pathophysiological profiles. Nowadays most studies are focusing on overarching $O A B$ syndrome instead of OAB symptoms separately (i.e. urgency, frequency or UUI). [33] For example, most studies which are focusing on the cellular and molecular mechanism of OAB syndrome focus on the effect of nerve growth factor (NGF) in all OAB patients. Dagdeviren et al. are the first to describe the relationship of NGF and a specific phenotype of OAB, namely patients having $O A B$ and metabolic syndrome. In their research they found serum NGF levels were elevated in patients with both metabolic syndrome and OAB compared to the levels in the healthy controls. [34] In the future, we should combine the design of the patient tailored treatment algorithm as described by Peyronnet [22] with fundamental research as performed by Cartwright et al. in UUI separately. [35] Ideally, we could develop a specific responder model based on the patients etiology of $O A B$ and the best fitting treatment modality for this subtype of OAB in terms of efficacy, safety and usability for this specific OAB patient population based on detected biomarker profiles.

In addition, in the future we could focus on newer possibilities and ways of neuromodulation. The existing continuous stimulation as for example is currently done in SNS does have limitations as well.[36] Optogenetic neuromodulation uses light-responsive proteins to selectively turn on or off specific cell populations. [37] Park et al. were the first who found that we could use opsins specifically to stimulate or inhibit contraction of smooth-muscle cells in the bladder. Depolarization of the cells with the use of one opsin (channelrhodopsin-2) activated vesical contraction, whereas hyperpolarization with another (halorhodopsin) inhibited contraction. 
$[37,38]$ Based on these results the next step is to implement this in an animal model and further on in an human model. The main advantage of optogenetic neuromodulation in comparing to electrical neuromodulation is target-specificity. Mickle et al. introduced a wireless closed-loop system for neuromodulation of the bladder by optogenetics. [39] They used a closed-loop wireless system with a strain gauge wrapped around the bladder of freely moving rats. The strain gauge measures changes in resistance during bladder filling and emptying. When the bladder becomes overactive, a signal is sent to activate a small microscale inorganic light-emitting diode ( $\mu$-ILED), which, in turn, activates a light-sensitive archaeal protein, an opsin, to selectively reduce neural activity. This action delivers a corrective signal, thereby restoring normal bladder function. [37, 39] Results as described above look promising for the future however there are still a number of hurdles to overcome. One of the main limitation in the study of Mickle et al. for implementation in humans is the use of the stretchable strain gauge around the bladder (foreign body) and the fact that the human bladder is thicker in comparing to their animal model could cause problems by reduced light transmission. However, optogenetic neuromodulation could be a future alternative besides electrical neuromodulation in the treatment of OAB.

\section{CLOSING REMARKS}

We aimed to outline and explore the current status and future status of tibial nerve stimulation in the treatment of OAB. As shown throughout this thesis, many different treatment modalities are possible with each their own advantages versus disadvantages. During the development of this thesis I learnt a lot about the technical aspects of tibial nerve stimulation but I also learned from the different patients suffering from $O A B$ as well. During my clinical work in this research I saw the major impact of $\mathrm{OAB}$ and the even larger impact of incontinence on patient's lives. The impact of incontinence in their social life is many times greater than I expected before starting this research. The moments patients were satisfied with their treatment and told me they could finally do the things which are normal for everybody else made me realize that it is important to keep looking for better treatment modalities. I hope in 10 years from now we can say that we ruled out the bothersome OAB complaints for all patients who are daily suffering from OAB with tailor-made therapies. 


\section{REFERENCES}

1. Peters, K.M., et al., Randomized trial of percutaneous tibial nerve stimulation versus Sham efficacy in the treatment of overactive bladder syndrome: results from the SUmiT trial. J Urol, 2010. 183(4): p. 1438-43.

2. Burton, C., A. Sajja, and P.M. Latthe, Effectiveness of percutaneous posterior tibial nerve stimulation for overactive bladder: a systematic review and metaanalysis. Neurourol Urodyn, 2012. 31(8): p. 1206-16.

3. Moossdorff-Steinhauser, H.F. and B. Berghmans, Effects of percutaneous tibial nerve stimulation on adult patients with overactive bladder syndrome: a systematic review. Neurourol Urodyn, 2013. 32(3): p. 206-14.

4. Levin, P.J., et al., The efficacy of posterior tibial nerve stimulation for the treatment of overactive bladder in women: a systematic review. Int Urogynecol J, 2012. 23(11): p. 1591-7.

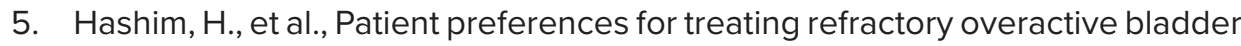
in the UK. Int Urol Nephrol, 2015. 47(10): p. 1619-27.

6. Sirls, E.R., et al., Percutaneous Tibial Nerve Stimulation in the Office Setting: Real-world Experience of Over 100 Patients. Urology, 2018. 113: p. 34-39.

7. van Balken, M.R., et al., Posterior tibial nerve stimulation as neuromodulative treatment of lower urinary tract dysfunction. J Urol, 2001. 166(3): p. 914-8.

8. Peters, K.M., et al., Percutaneous tibial nerve stimulation for the long-term treatment of overactive bladder: 3-year results of the STEP study. J Urol, 2013. 189(6): p. 2194-201.

9. Kelleher, C.J., et al., A medium-term analysis of the subjective efficacy of treatment for women with detrusor instability and low bladder compliance. Br J Obstet Gynaecol, 1997. 104(9): p. 988-93.

10. Lawrence, M., et al., Immediate-release oxybutynin versus tolterodine in detrusor overactivity: a population analysis. Pharmacotherapy, 2000. 20(4): p. 470-5. 
11. Hampel, C., Long-Term Management of Overactive Bladder with Antimuscarinic Agents. . European Urology Supplements, 2007(6(5)): p. 432-437.

12. Ramírez-García, I., et al., Efficacy of transcutaneous stimulation of the posterior tibial nerve compared to percutaneous stimulation in idiopathic overactive bladder syndrome: Randomized control trial. Neurourol Urodyn, 2019. 38(1): p. 261-268.

13. Booth, J., et al., A feasibility study of transcutaneous posterior tibial nerve stimulation for bladder and bowel dysfunction in elderly adults in residential care. J Am Med Dir Assoc, 2013. 14(4): p. 270-4.

14. Schreiner, L., et al., Randomized trial of transcutaneous tibial nerve stimulation to treat urge urinary incontinence in older women. Int Urogynecol J, 2010. 21(9): p. 1065-70.

15. Leroux, P.A., et al., Transcutaneous tibial nerve stimulation: 2 years follow-up outcomes in the management of anticholinergic refractory overactive bladder. World J Urol, 2018. 36(9): p. 1455-1460.

16. van der Pal, F., et al., Implant-Driven Tibial Nerve Stimulation in the Treatment of Refractory Overactive Bladder Syndrome: 12-Month Follow-up. Neuromodulation, 2006. 9(2): p. 163-71.

17. Janssen, D.A., F. Farag, and J.P. Heesakkers, Urgent-SQ implant in treatment of overactive bladder syndrome: 9-year follow-up study. Neurourol Urodyn, 2013. 32(5): p. 472-5.

18. Rogers, A., et al., Pivotal Study of Leadless Tibial Nerve Stimulation with eCoin ${ }^{\circledR}$ for Urgency Urinary Incontinence: An Open-Label, Single Arm Trial. J Urol, 2021: p. 101097ju0000000000001733.

19. Heesakkers, J., et al., A novel leadless, miniature implantable Tibial Nerve Neuromodulation System for the management of overactive bladder complaints. Neurourol Urodyn, 2018. 37(3): p. 1060-1067. 
20. CAN-stim compared to SNS in treatment of urinary urgency incontinence with wireless neuromodulation technology (PROTECT).

Available from: https://clinicaltrials.gov/ct2/show/NCT02577302.

21. Overactive bladder treatment using stimrouter neuromodulation system: a prospective randomized trial.

Available from: https://clinicaltrials.gov/ct2/show/NCT02873312?term=stimrouter.

22. Peyronnet, B., et al., A Comprehensive Review of Overactive Bladder Pathophysiology: On the Way to Tailored Treatment. Eur Urol, 2019. 75(6): p. 988-1000.

23. Apostolidis, A., et al., Can we create a valid treatment algorithm for patients with drug resistant overactive bladder (OAB) syndrome or detrusor overactivity (DO)? Results from a think tank (ICl-RS 2015). Neurourol Urodyn, 2017. 36(4): p. 882-893.

24. Rostaminia, G., et al., Predictors of successful percutaneous tibial nerve stimulation (PTNS) in the treatment of overactive bladder syndrome. Int Urogynecol J, 2019. 30(10): p. 1735-1745.

25. van Balken, M.R., H. Vergunst, and B.L. Bemelmans, Prognostic factors for successful percutaneous tibial nerve stimulation. Eur Urol, 2006. 49(2): p. 360-5.

26. W. Stuart Reynolds, J.A.C., Campbell-Walsh-Wein Urology. Overactive Bladder. Vol. 12. 2021, Philadelphia: Elsevier. 2637-2649.

27. Yoshimura, N., Lower urinary tract symptoms (LUTS) and bladder afferent activity. Neurourol Urodyn, 2007. 26(6 Suppl): p. 908-13.

28. Keay, S.K., L.A. Birder, and T.C. Chai, Evidence for bladder urothelial pathophysiology in functional bladder disorders. Biomed Res Int, 2014. 2014: p. 865463.

29. Brading, A.F., A myogenic basis for the overactive bladder. Urology, 1997. 50(6A Suppl): p. 57-67; discussion 68-73. 
30. Elbadawi, A., Functional pathology of urinary bladder muscularis: the new frontier in diagnostic uropathology. Semin Diagn Pathol, 1993. 10(4): p. 314-54.

31. Coolsaet, B.L., et al., New concepts in relation to urge and detrusor activity. Neurourol Urodyn, 1993. 12(5): p. 463-71.

32. de Groat, W.C., A neurologic basis for the overactive bladder. Urology, 1997. 50(6A Suppl): p. 36-52; discussion 53-6.

33. Siddiqui, N.Y., et al., Biomarkers Implicated in Lower Urinary Tract Symptoms: Systematic Review and Pathway Analyses. J Urol, 2019. 202(5): p. 880-889.

34. Dagdeviren, H. and H. Cengiz, Association between Metabolic Syndrome and Serum Nerve Growth Factor Levels in Women with Overactive Bladder. Gynecol Obstet Invest, 2018. 83(2): p. 140-144.

35. Cartwright, R., et al., Genome-Wide Association Study Identifies Two Novel Loci Associated with Female Stress and Urgency Urinary Incontinence. J Urol, 2021: p. 101097ju0000000000001822.

36. Kavvadias, T., et al., Management of device-related complications after sacral neuromodulation for lower urinary tract disorders in women: a single center experience. Arch Gynecol Obstet, 2017. 295(4): p. 951-957.

37. Kessler, T.M., L.A. Birder, and P. Gomery, Neuromodulation of Urinary Tract Function. N Engl J Med, 2019. 380(21): p. 2067-2069.

38. Park, J.H., et al., Optogenetic Modulation of Urinary Bladder Contraction for Lower Urinary Tract Dysfunction. Sci Rep, 2017. 7: p. 40872.

39. Mickle, A.D., et al., A wireless closed-loop system for optogenetic peripheral neuromodulation. Nature, 2019. 565(7739): p. 361-365. 
4

$\nabla<$

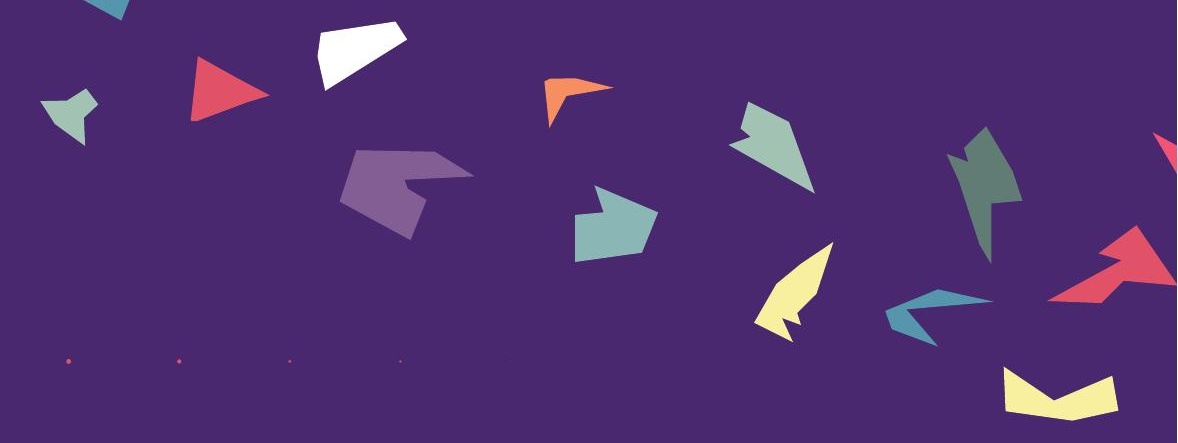

$\begin{array}{llllllllllllll}0 & 0 & 0 & 0 & 0 & 0 & 0 & 0 & 0 & 0 & 0 & 0 & 0 & 0\end{array}$

$\begin{array}{llllllllllllll}0 & 0 & 0 & 0 & 0 & 0 & 0 & 0 & 0 & 0 & 0 & 0 & 0 & 0\end{array}$

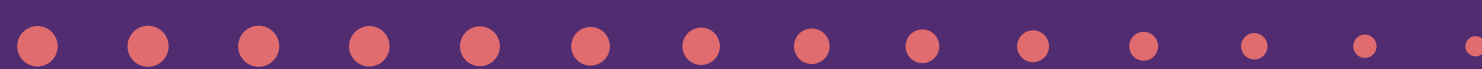

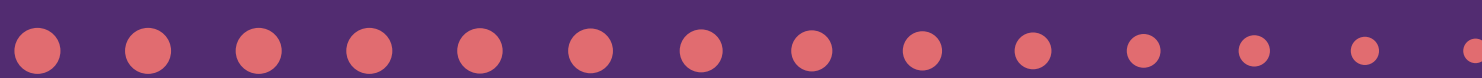

0000000000000000

000000000000000

00000000000000

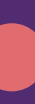

$\cdot \bullet$

00000000000000
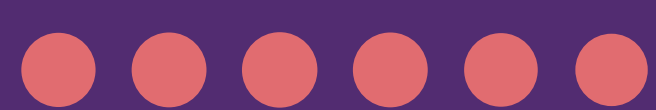

O

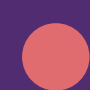

O

0

0

000
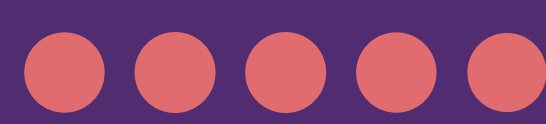

0

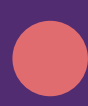

0

0

0

0

0

0
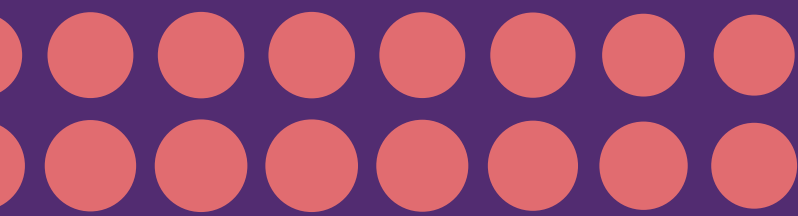

0

0

0

0

0

O

0
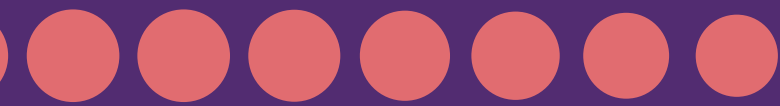

0

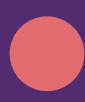

0

000 


$$
\text { ○ }
$$$$
000
$$
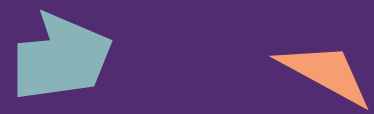

4

4
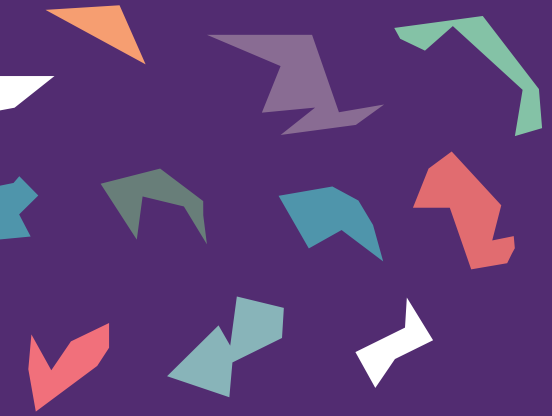

Nederlandse

Samenvatting

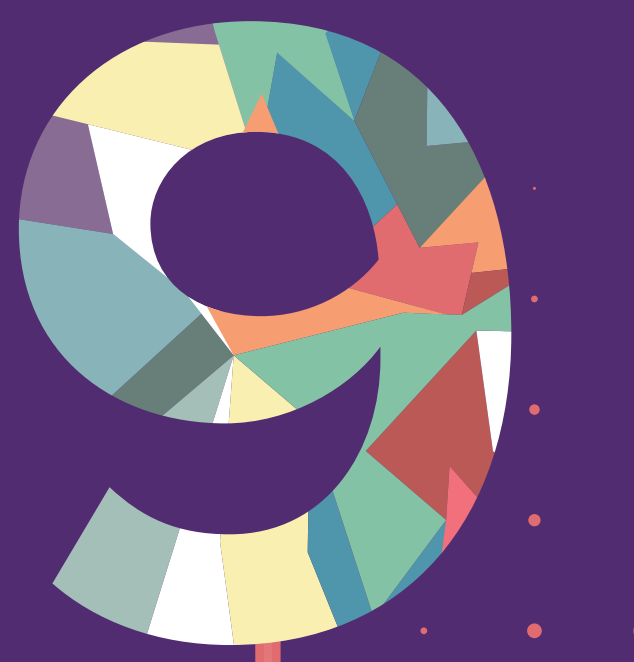




\section{REAL LIFE RESULTATEN VAN TIBIALIS STIMULATIE BIJ DE BEHANDELING VAN OAB}

In hoofdstuk 2 hebben we de real life resultaten beschreven van percutane tibialis zenuwstimulatie (PTNS) in een niet-studiepopulatie. In totaal hebben we 402 patiënten geïncludeerd. De indicatie voor het starten van PTNS voor deze patiënten was meestal overactieve blaas klachten (OAB) met incontinentie of OAB zonder incontinentie. Patiënten die stopten tijdens PTNS-onderhoudsbehandeling, kozen meestal voor Botox (14\%) of Mirabegron (10\%) als volgende behandeling bij $\mathrm{OAB}$, of geen verdere behandeling (57\%). Onze real life data lieten vergelijkbare percentages van succes zien bij de behandeling van OAB door PTNS in vergelijking met eerder gepubliceerde gegevens in onderzoekspopulaties. Dit onderzoek met een follow-up van meer dan 10 jaar toonde aan dat PTNS ook op lange termijn succesvol is. Daarnaast constateerden we echter ook dat meer dan $40 \%$ van de patiënten stopten tijdens onderhoudsbehandeling vanwege niet-medische redenen. We concludeerden dat ondanks het feit dat PTNS op lange termijn is bewezen, er nog steeds behoefte is aan een meer op de patiënt afgestemde behandelmethode.

Vervolgens hebben we in hoofdstuk $\mathbf{3}$ de real life data ten aanzien van effectiviteit en patiëntervaringen van transcutane tibialis zenuwstimulatie (TTNS) in ons centrum beschreven. We includeerden alle patiënten die een positief effect hadden op PTNS en continueerden met TTNS in de thuissituatie. Patiënten werden achteraf gevraagd een vragenlijst in te vullen over tevredenheid, redenen om te stoppen en aanvullende dan wel volgende therapielijnen welke zij zijn gestart. 42 patiënten werden geïncludeerd voor deze studie, $81 \%$ van deze patiënten was vrouw. Bij de meeste patiënten $(64 \%, n=27)$ werd OAB met incontinentie gediagnosticeerd als reden voor starten van de behandeling. We vonden een mediane duur van de TTNSbehandeling van 16 maanden (bereik 1-112 maanden), wat in overeenstemming was met eerder gepubliceerde literatuur in onderzoekspopulaties. De meeste patiënten stopten met de therapie vanwege verlies van effect of gaven de voorkeur aan een ander vorm van neuromodulatie. Qua tevredenheid vonden we ook tegenvallende resultaten. Patiënten beoordeelden hun TTNS-behandeling over het algemeen met een 5.6 (schaal 1-10). 
Concluderend, hoewel veel publicaties een positief effect van TTNS laten zien met een korte follow-up termijn is TTNS op de lange termijn in de praktijk niet zo effectief als gehoopt. Dus de combinatie van lage tevredenheidscijfers met slechte resultaten op de lange termijn zorgt ervoor dat de wens voor betere behandelingsmodaliteiten en met name behandelingen op maat blijft bestaan.

\section{IMPLANTEERBARE TIBIALIS STIMULATOREN IN DE BEHANDELING VAN OAB}

Een van de pioniers op het gebied van patiëntgerichte behandeling van $O A B$ door tibialis zenuwstimulatie was het Urgent-SQ-systeem. De eerste pilot met dit systeem werd al uitgevoerd tussen 2002 en 2004. Het Urgent-SQ-systeem bestaat uit een externe stimulator en een intern component. De externe stimulator is een elektromagnetische puls-generator en geeft radiofrequente transmissie. De interne component van de Urgent-SQ bestaat uit een elektromagnetische puls-ontvanger en een behuizing met twee draden met mono-polaire elektroden. Eerdere publicaties lieten een hoog veiligheids- en werkzaamheidsprofiel zien na 1 en 9 jaar follow-up. Het doel van de studie welke wordt beschreven in hoofdstuk 4, is om de follow-up op de lange termijn te evalueren (bruikbaarheid en veiligheid) van het Urgent-SQ-systeem, 18 jaar na de eerste implantatie. Tijdens dit onderzoek werden patiënten geïnterviewd door middel van een gestandaardiseerd telefonisch gesprek met een arts. We ontdekten dat alle vijf patiënten, welke in deze vervolgstudie waren opgenomen, het systeem niet meer gebruikten vanwege geen werkende externe stimulator $(n=2)$ of verlies van effect $(n=3)$. Patiënten welke gestopt waren omdat de externe stimulator niet meer werkte, waren tevreden met de behandeling en gebruikten deze vaak tot het defect. Na het stoppen van de therapie namen de klachten over aandrang / aandrang-incontinentie bij alle patiënten weer toe $(n=5)$. De voordelen van thuisbehandeling voor OAB met een tibialis implantaat konden door deze studie niet worden bevestigd, maar zijn wel veelbelovend. 
Sinds enkele jaren is het gebied van tibialis stimulatie van belang geworden voor verschillende medische bedrijven met implantaten. In hoofdstuk $\mathbf{5}$ hebben we de meest veelbelovende tibialis implantaten nader bekeken. We evalueerden in dit review de technische aspecten en technieken van recent ontwikkelde implantaten. Alle verschillende behandelingsopties hebben voor- en nadelen op basis van het type operatie, energieoverdracht, impedantie, behandelingsinstellingen, migratierisico en bruikbaarheid voor de patiënt. Op basis van deze hierboven beschreven technische aspecten hebben we de volgende systemen beoordeeld: Stimrouter, GEKO, eCoin, Bluewind RENOVA en Stimguard. We concludeerden dat nieuwe ontwikkelingen zich richten op kleine, batterijloze apparaten die gemakkelijk te bedienen zijn en welke op de minst invasieve of niet-invasieve manieren kunnen worden geplaatst. Op basis van het door ons gestelde eisen aan het ideale patiëntgerichte tibialis implantaat, kunnen we concluderen dat het ideale implantaat nog niet is ontwikkeld, maar we zijn dichtbij.

Op basis van de voor- en nadelen zoals beschreven in hoofdstuk $\mathbf{5}$ kunnen we concluderen dat het Bluewind RENOVA-systeem momenteel het dichtst bij het meest ideale implantaat komt. Het RENOVA-systeem bestaat uit een draadloos implantaat met een tweetal electroden en een draadloze externe enkelband (nietimplanteerbaar onderdeel). Het systeem zendt elektrische pulsen naar de tibialis zenuw. Na implantatie en een periode van wondgenezing wordt het apparaat geactiveerd en voert de patiënt thuis de behandeling uit met de externe oplaadbare enkelband (ECU). In hoofdstuk 6 rapporteerden we de driejarige veiligheids- en effectiviteitresultaten van de pilotstudie. Twintig patiënten stemden in om door te gaan met het driejarige vervolgonderzoek. De meeste patiënten leden opnieuw aan $\mathrm{OAB}$ met incontinentie (80\%). De studieresultaten lieten aanhoudend therapeutisch voordeel zien bij de patiënten. Het algehele succespercentage van de behandeling was 75\% 36 maanden na activering. Wat betreft veiligheid hebben we geen aanvullende explantaties en geen ernstige bijwerkingen vermeld. Er was geen nieuwe chirurgische ingreep nodig bij een van de patiënten. Met deze resultaten kunnen we concluderen dat het Bluewind Renova-systeem een goed veiligheids- en effectiviteitsprofiel op de langere termijn heeft. 
In hoofdstuk $\mathbf{7}$ hebben we de voordelen beschreven van een op de patiënt afgestemde OAB-behandeling met een tibialis implantaat. We beschreven geen statistische verschillen met betrekking tot systeemparameterinstellingen bij responders versus niet-responders op het 6 maanden eindpunt van de studie. Er was een statistisch significante toename van het gemiddelde behandelingsniveau in de responder-groep gedurende drie maanden follow-up in vergelijking met de activering, echter de klinisch relevante significantie hiervan is laag. Daarnaast hebben we beschreven dat er naast BMI geen andere voorspellende factoren zijn. Leeftijd, geslacht, BMI en eerdere behandelingen met PTNS werden beschouwd als voorspellende factoren. Echter alleen BMI werd als een negatieve voorspellingsfactor beschouwd. De conclusies die we hebben getrokken zijn: Het was niet mogelijk om op basis van dit onderzoek een specifiek respondermodel te ontwikkelen. Een van de belangrijkste factoren hierbij is de kleine steekproefomvang $(n=32)$. 
4

$\nabla<$

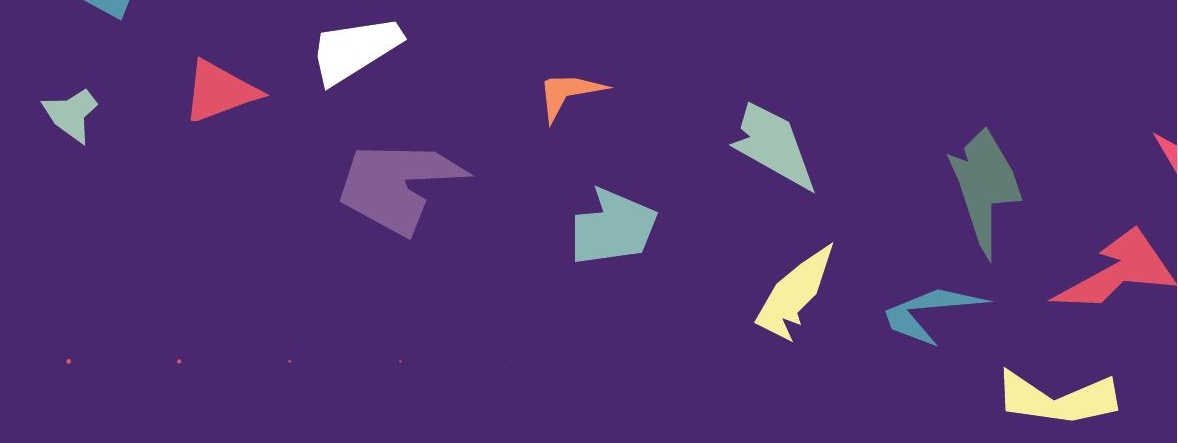

$\begin{array}{llllllllllllll}0 & 0 & 0 & 0 & 0 & 0 & 0 & 0 & 0 & 0 & 0 & 0 & 0 & 0\end{array}$

$\begin{array}{llllllllllllll}0 & 0 & 0 & 0 & 0 & 0 & 0 & 0 & 0 & 0 & 0 & 0 & 0 & 0\end{array}$

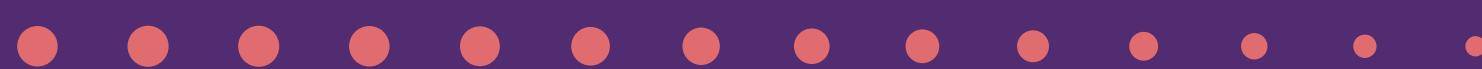

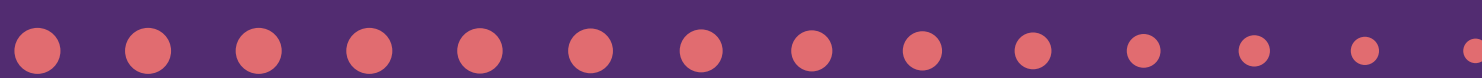

0000000000000000

000000000000000

00000000000000

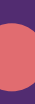

$\cdot \bullet$

00000000000000
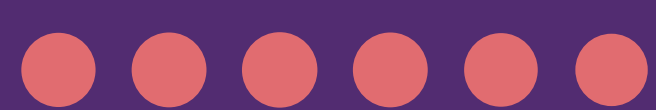

O

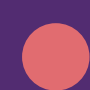

O

0

0

000
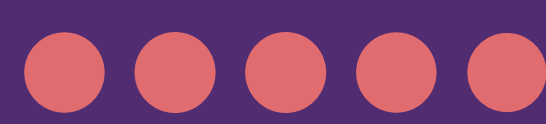

0

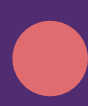

0

0

0

0

0

0
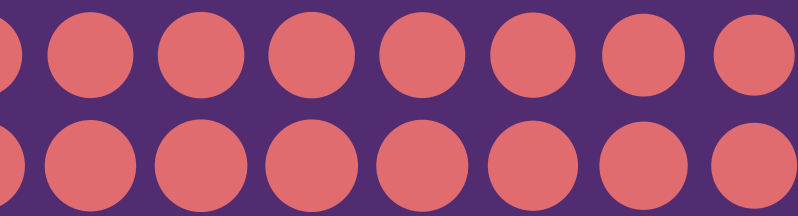

0

0

0

0

0

O

0
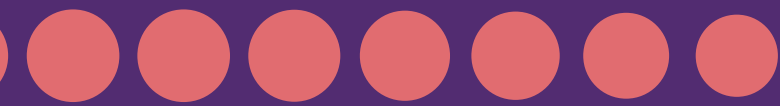

0

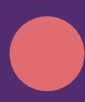

0

000 

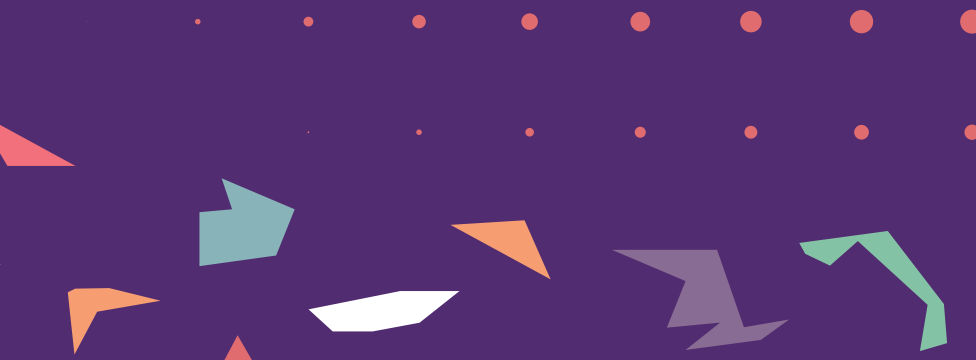

$\checkmark v$ 1
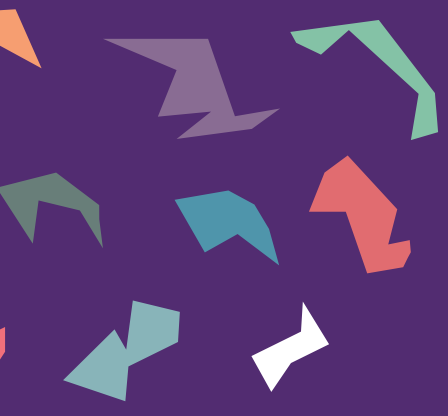

Appendices
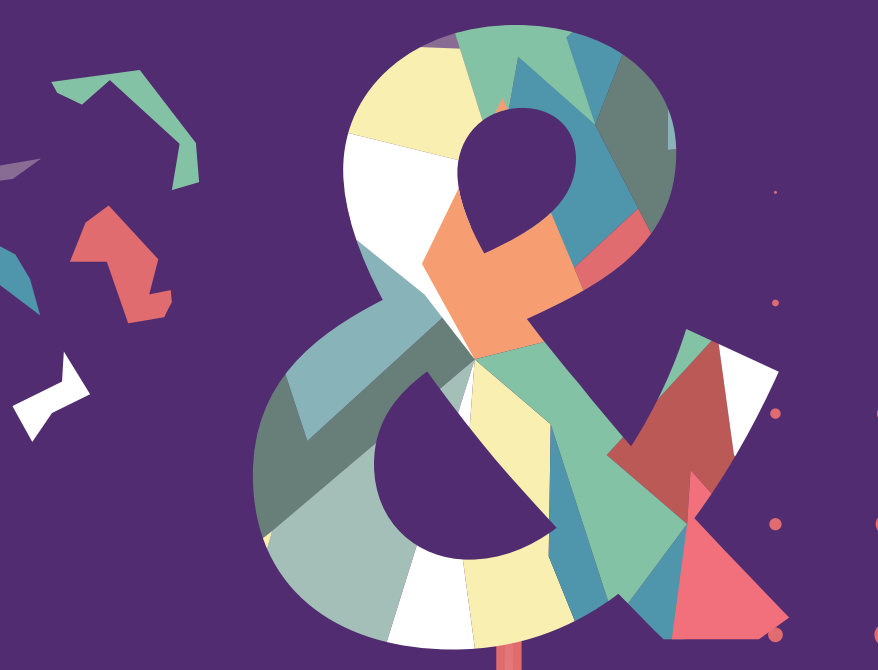

00

000

?

000

0000

O 0000

00000

000000

000000 



\section{BIBLIOGRAPHY}

te Dorsthorst MJ, van der Doelen MJ, Farag F, Martens FMJ, Heesakkers JPFA. Survival of the artificial urinary sphincter in a changing patient profile. World J Urol. 2019 May;37(5):899-906.

te Dorsthorst MJ, Heesakkers JPFA, van Balken MR. Long-term real life adherence of percutaneous tibial nerve stimulation in over 400 patients. Neurourol Urodyn. 2020 Feb;39(2):702-706.

te Dorsthorst MJ, Digesu GA, Tailor V, Gore M, van Kerrebroeck PE, van Breda HMK, Elneil S, Heesakkers JPFA. 3-Year Followup of a New Implantable Tibial Nerve Stimulator for the Treatment of Overactive Bladder Syndrome. J Urol. 2020 Sep;204(3):545-550.

te Dorsthorst $M J$, van Balken $\mathrm{M}$, Heesakkers J. Tibial nerve stimulation in the treatment of overactive bladder syndrome: technical features of latest applications. Curr Opin Urol. 2020 Jul;30(4):513-518.

te Dorsthorst MJ, van Balken MR, Janssen DJ, Heesakkers JPFA, Martens FMJ. Real life Patient Experiences of TTNS in the Treatment of Overactive Bladder Syndrome. Therapeutic Advances in Urology. January 2021.

te Dorsthorst MJ, Digesu GA, van Kerrebroeck PE, Elneil S, van Breda HMK, Janssen DJ, Martens FMJ, van Balken MR, Heesakkers JPFA. Patient Tailored Healthcare and Tibial Nerve Neuromodulation in the Treatment of Patients with Overactive Bladder Symptoms. Under review

te Dorsthorst MJ, Janssen DJ, Martens FMJ, van Balken MR, Heesakkers JPFA. What is the fate of patients with a neuromodulation implant who embarked on a clinical study? Submitted

te Dorsthorst MJ, Roelofs, A.W.T.M., Vrooman, O.P.J., van Balken M.R. Verwijden of verwijderen? De preputiumplastiek is een goed alternatief voor therapeutische circumcisie. Tijdschr Urol 9, 74-77 (2019).

te Dorsthorst MJ, Prins-van Uden, M., Niekel, R., van Balken M.R. Case report. Zinner-syndroom: een zeldzame oorzaak van agenesie van de nier. Tijdschr Urol 10, 9-12 (2020).

Heesakkers JPFA, te Dorsthorst MJ, Wagg A. The Safety and Tolerability of Fesoterodine in Older Adult Patients with Overactive Bladder: Safety of fesoterodine in older OAB patients. Accepted Canadian Geriatrics Journal. 


\section{LIST OF ABBREVIATIONS}

$A E$

BMI

BTA

CAMP

CP

DO

ECU

EPG

GRA-scale

HRQL

ICIQ

ICS

IDO

IP3

ITT

LOCF

LUTS

MDD

MDR

MID

MSL

MTL

NGF

OAB

PFMT

PLC

PP

PTNS

QOL

SAE

SNS

SP-6

TL

TTNS

UF

UI

UUI

$\mu$-ILED
Adverse event

Body Mass Index

Botulinum toxin type $A$

cyclic AMP

Clinician Programmer

Detrusor Overactivity

External Control Unit

external pulse transmitter

Global response assessment

Health Related Quality of life

International Consultations on Incontinence Questionnaires

International Continence society

Idiopathic Detrusor Overactivity

inositol triphosphate

Intent to treat

Last observation carried forward

Lower Urinary Tract Symptoms

Medical Device Directives

Medical Devices Regulation

Minimally Important Difference

Minimum sensation level

Maximum tolerable level

Nerve growth factor

Overactive bladder

Pelvic Floor Muscle Training

phospholipase $\mathrm{C}$

Per protocol

Percutaneous Tibial Nerve Stimulation

Quality of life

Serious adverse event

Sacral Nerve Stimulation

Sanyinjiao point

Treatment level

Transcutaneous Tibial Nerve Stimulation

Urinary frequency

Urinary incontinence

Urge Urinary Incontinence

Microscale inorganic light-emitting diode 


\section{CURRICULUM VITAE}

Manon Joyce te Dorsthorst was born on the 19th of December 1990 in Didam, the Netherlands. In 2009 she finished secondary school (Gymnasium) at St. Ludger college in Doetinchem. She subsequently studied Medicine at the Rijksuniversiteit Groningen from 2009 to 2016. In 2013 she went to Philadelphia and completed her research internship at the University of Pennsylvania at the department of radiation oncology. Thereafter, Manon performed her internships at the University Medical Center

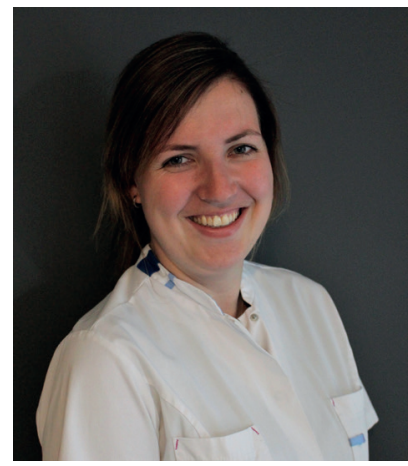
Groningen (UMCG) and Scheper Ziekenhuis (Emmen). In 2015 she went to St. Kizito Hospital in Mikumi, Tanzania, for her internships Tropical medicine and Social medicine. From 2016 she focused on Urology. She conducted her final internship at the department of Urology at the Isala, Zwolle. In June 2016 she obtained her medical degree.

After graduation, Manon started as a resident not in training at the department of Urology of the Slingeland Ziekenhuis, Doetinchem. Then, she continued as a resident not in training at the department of urology of the Martini Ziekenhuis, Groningen followed by the Rijnstate Ziekenhuis in Arnhem.

In 2019 she obtained a position as MD-PhD candidate at the department of Urology of the Radboud university medical center and Maastricht University medical Center under supervision of prof. dr. J.P.F.A. Heesakkers, dr. M.R. van Balken and dr. F.M.J. Martens. In July 2022 she will start her Urology residency program as a resident in General Surgery at Rijnstate hospital in Arnhem (supervisor: dr. J.H.P Lardenoije). She will continue her residency program at the Urology departments of the Radboud University Medical Center (supervisors: prof. dr. J.A. Witjes and dr. B.B.M. Kortmann) and Rijnstate hospital in Arnhem (supervisor: M.R. van Balken). 


\section{DANKWOORD (ACKNOWLEDGEMENTS)}

Het moment is daar, ik mag beginnen aan het schrijven van mijn dankwoord en dat doe ik met een grote lach van oor tot oor op mijn gezicht. Het proefschrift is klaar! Ontzettend trots ben ik op het eindresultaat van "mijn boekje". Promoveren doe je niet alleen en daarom zijn er ontzettend veel mensen die ik wil bedanken voor alle hulp en adviezen.

Graag wil ik alle patiënten en naasten bedanken welke hun medewerking hebben verleend aan de diverse studies in mijn proefschrift. Mede door $u$ is dit proefschrift tot stand gekomen.

Daarnaast wil ik natuurlijk ook mijn promotieteam ontzettend bedanken. Trots en vereerd ben ik dat ik van allen de eerste promovendus ben in de functie als promotor dan wel co-promotor.

Beste Prof. dr. J.P.F.A. Heesakkers, beste John, bedankt voor jouw begeleiding en betrokkenheid de afgelopen jaren. Voorafgaand aan dit promotietraject mocht ik al onderzoek met je doen en uiteindelijk resulteert dit alles in dit proefschrift. De maandagochtenden 07:30 uur na de overdracht waren niet mijn sterkste momenten voor een promotieoverleg echter na de koffie kwamen we toch altijd tot goede ideeën en vervolgplannen. Je kritische (artikelen vol track changes) en sturende houding daar waar nodig, hebben dit proefschrift mede gemaakt tot waar het nu staat. Ik wil je bedanken voor je vertrouwen, goede raad en geduld op de momenten dat ik even niet helemaal begreep welke kant we uit moesten. Dank voor de mogelijkheden die je me hebt aangereikt op basis van je vertrouwen in mijn kunnen!

Beste dr. M.R. van Balken, beste Michael, als ANIOS ben ik bij je begonnen in het Rijnstate. Een plan gemaakt voor de toekomst, een aantal keer dat plan bij moeten stellen maar altijd kon ik op je rekenen. Je steun, goede adviezen en kritische houding naar mij als jonge dokter en (diplomatieke) wetenschapper hebben me mede gevormd tot wie ik nu ben. Trots ben ik dat ik je eerste promovendus mag zijn en specifiek op dit onderwerp na de weg die we samen hebben afgelegd. Dank voor de adviezen en het meedenken op alle vlakken tijdens belangrijke momenten in mijn carrière en ik kijk uit naar mijn jaren als AIOS in het Rijnstate. 
Beste dr. F.M.J. Martens, beste Frank, met een switch van promotiestad kwam er ook een switch van dagelijks begeleider/promotieteam. Ik wil je bedanken dat je het tweede gedeelte van mijn promotie de dagelijkse begeleiding voor je rekening hebt genomen. Bedankt dat ik altijd even kon binnen vallen en dat je me altijd hebt gesteund. Dank voor je goede adviezen met het oog op de toekomst, altijd kritische blik op mijn werk en voor de gezellige borrels! Ik kijk er naar uit om nog meer van je te leren als AIOS urologie.

Graag bedank ik ook de leden van de manuscriptcommissie voor hun bereidheid om mijn proefschrift te lezen en te beoordelen: prof. dr. L.M.O. de Kort, Prof. dr. G.A. van Koeveringe, Prof. dr. W.F.F.A. Buhre. Thank you very much for your willingness to read and review my dissertation Prof dr. R.R. Dmochowski. Ik kijk uit naar de gedachtewisseling tijdens de verdediging.

Daarnaast wil ik al mijn medeauteurs zoals genoemd in de voorgaande hoofdstukken bedanken. In het bijzonder Dick Janssen en Jetske van Breda. Beste Dick, ontzettend bedankt voor het altijd meelezen, meedenken over mijn proefschrift. Daarnaast wil ik je ook ontzettend bedanken bij je hulp en opzet van het bitterreceptor project. Door jou heb ik naast klinisch onderzoek ook kennis mogen maken met het lab-werk! Dank dat je me de kans hebt gegeven om ook het lab-werk te mogen ontdekken. Beste Jetske, partyplanner vanaf het eerste moment! Wat heb ik veel aan je adviezen gehad over hoe een promotie in te stappen en vooral niet meteen ondersteboven te zijn van een COMPLEET rood terug gekregen artikel. Tijdens de kopjes koffie en lunchmomenten stond je altijd voor me klaar om me te helpen met mijn promotie perikelen maar ook verdere carrière!

Dear Bluewind collegues, many thanks for all the support I got from you during my Phd. I would like to thank especially Karin, Lori, Bar, Amit, Raz and Kevin for their help whenever and wherever help was needed. And last but not least I am going to miss al the retraining and advises. For Kevin in particular: I suggest and advise retraining necessary: "OK zakje" and "huis schilderen".

Daarnaast wil ik alle onderzoekscentra (UZ Antwerpen, Leuven, MUMC Maastricht, Radboud Nijmegen, Rijnstate Arnhem, UMC Utrecht en Isala Zwolle/Meppel), welke hebben meegedaan aan de OASIS-trial bedanken voor de hulp en inzet de afgelopen jaren bij het screenen en zien van patiënten op de poli. Ontzettend bedankt voor de prettige samenwerking. 
Een speciaal dank aan Danielle voor de goede gesprekken, de gezelligheid en kritische blik tijdens de "lekkere" kopjes koffie.

Dank ook aan alle medewerkers van het lab van de Experimentele Urologie voor de warme sfeer de goede koffiepauzes op elk moment van de dag en de mogelijkheid om ook het "tong"-project te starten en te begeleiden. In het bijzonder wil ik “lab-Kees”, Egbert, Jack, Gerald, Mirjam, Onno, Elze en Marion bedanken voor de hulp en steun bij het lab-project en mijn ontwikkeling.

Mijn hok dames (muggendokters) en heer, Manon, Elle, Sieb, Saskia, Maud en Merel. Dank voor de gezelligheid en het promotie ontwijkend gedrag vertonen op het hok. De vrijdagmiddag Wintersport spotify lijst van Manon zal voor altijd een toppertje blijven naast alle goede verhalen over muggen, vogels en nog veel meer tijdens etentjes en borrels. Daarnaast wil ik ook de (oud) arts-onderzoekers op het lab bedanken voor de prettige samenwerking; in het bijzonder Charlotte mijn functio-maatje, Gerben en Hossein.

Mijn dank gaat tevens uit naar de gehele staf Urologie, de AIOS, ANIOS en artsonderzoekers en secretariaat van het RadboudUMC. Bedankt voor de prettige samenwerking. Ik kijk er naar uit om te starten als AIOS urologie in het Nijmeegse!

Ook mijn oud-collega's uit het Rijnstate wil ik bedanken voor mijn tijd als ANIOS. Dankbaar ben ik dat ik hier verder heb mogen groeien en ontwikkelen als uroloog in spe en later als onderzoeker altijd een warm welkom had. Dank voor jullie betrokkenheid en adviezen. Ik heb genoten van mijn tijd bij jullie.

Beste Esther, Erich en Arno, dank voor het vertrouwen wat ik van jullie heb gekregen om als net afgestudeerd arts bij jullie in het Slingeland op de urologie echt dokter te mogen worden. Samen met de fantastische verpleging en secretaresses heb ik hier een ontzettend leuke, leerzame en waardevolle tijd gehad. Vriendschappen zijn ontstaan en anekdotes over voerdraden en wat patiënten hebben zijn voor het leven gemaakt.

Lieve vrienden en (schoon)familie, er is meer dan werken/promoveren, namelijk leven en heel veel genieten van leuke dingen. Ik mag me gelukkig prijzen dat ik dat met jullie al zoveel heb mogen meemaken en hopelijk nog veel meer ga beleven in de toekomst. Dank voor alle momenten dat jullie het promotie ontwijkend gedrag (POG) voor me hebben verzorgd. Dank voor alle feesten, festivals, diners, 
weekendjes weg, poolparty's en andere sportieve ondernemingen! Jullie steun gezelligheid en vaak ook flexibiliteit is ontzettend waardevol voor me.

“Hardloopmaatjes" Kirsten en Robin, dank dat jullie altijd geïnteresseerd waren in mijn wetenschappelijke doorbraken, gecombineerd met de vele avonden met “nozem" en natuurlijk voor jullie aanmoedigingen tijdens het hardlopen.

Debbie en Tauvik, dank dat jullie altijd de tijd hebben genomen voor het aanhoren van mijn geklaag over van alles en nog wat bij een veel te hoog opgestookte haard. Fijn dat jullie altijd geintresseerd waren in de onderzoeken en dagbesteding :).

Mischa en Marloes, nadat het begon als buren-borrel is het een echte vriendschap geworden. De vele avonden met drankjes en bitterballen in combinatie met goede gesprekken, de persoonlijke begeleiding in de Efteling, Stef Stuntpiloot en konijnenhok-avonturen zijn ontzettend waardevol voor mij. Binnenkort kom ik nog een paar zakken koffiebonen brengen vanwege alle corona koppen koffie die ik bij jullie heb gehad. Ontzettende bedankt voor jullie steun!

Lieve $\mathrm{Pa}$ en $\mathrm{Ma}$, bij iedere ingeving waar het pad weer een compleet andere route op ging dan jullie vooraf hadden gedacht kon ik rekenen op jullie steun. leder moment dat het even anders ging dan gedacht of wanneer ik weer eens twijfelde over mijn eigen kunnen waren jullie er om op te bouwen. Dank voor jullie onuitputtelijke betrokkenheid en verwennerij. En ja mam, morgen is er gewoon weer een boterham met hagelslag!

Iris en Berrend, ler wat ben ik blij dat je mijn paranimf wilt zijn. Ondanks Corona hebben we toch op vindingrijke manieren (binnen de regels)het borrelen proberen vol te houden. Dank voor al je legendarische verhalen na het weekend, je open houding, je geniale ideeën en vooral goede gesprekken. Door jou verleg ik zelfs op culinair gebied mijn grenzen. Met Ber aan je zijde gaan jullie het helemaal maken binnen de urologie! You rock!!

Marianne, Roel en (oes)Hannah, dankbaar ben ik voor alle momenten met speciaal-biertjes, de uitjank-momenten en het aanhoren van mijn klaagzang over van alles en nog wat. Jullie zijn toppers! Jullie nuchtere en relativerende blik heeft me meerdere malen de ogen doen openen. Wel wordt het weer tijd voor een potje badminton in Warsteiner met treintjes en sapjes! Lieve Marianne dank dat je mijn paranimf wilt zijn. 
Lieve Kees ("mijn eigen Kees"), wat een avontuur ben je aangegaan met me. Vanaf het begin dat we samen zijn wist je dat het niet "gewoon" zou zijn en je geduld altijd op de proef wordt gesteld door mij. Ik ben alweer ruim 8 jaar ontzettend blij en gelukkig met je. Je weet dat een dag met mij er altijd anders uitziet dan je tevoren gepland had en je huis altijd ergens anders komt te staan dan je vooraf gedacht had. Je onvoorwaardelijke steun in dit alles betekent ontzettend veel voor me. Ik kijk uit naar nog veel meer jaren samen met jou, met nog veel meer verrassingen. 